\title{
THE TEACHING OF GEOGRAPHY BRANOM
}




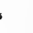




$$
\text { Shy }
$$

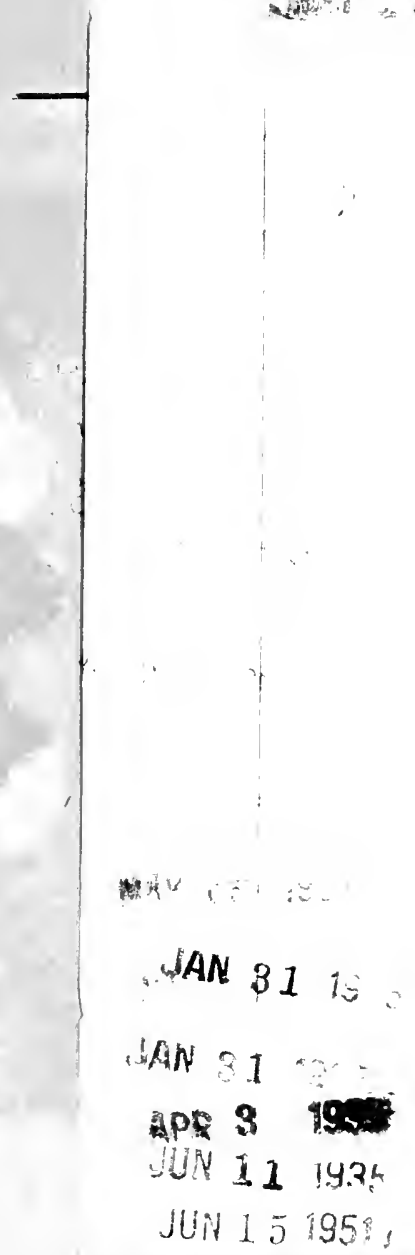





\section{THE TEACHING OF GEOGRAPHY}

\section{EMPHASIZING THE PROJECT, OR ACTIVE, MIETHOD}

$B Y$

MENDEL E. BRANOM

DEPARTMENT OF GEOGRAYHY, HARRIS TEACHERS COLLEGE, ST, LOUIS AUthor OF "THE PROJECT METIIOD IN EDUCATION" ETC.

AN I

FRED K. BRANOM

DEPARTMENT OF GEOGRAPHY, CHICAGO NORMAL COLLEGE, CHICAGO

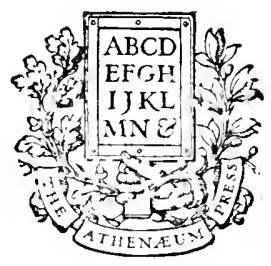

GINN AND COMPANY

BOSTON · NEW YORK + CHICAGO - LONDON

ATLANTA P DALAS COLCMBLS - SAN FRANCISCO 
COPYRIGHT, 1921, BY MENDEL E. BRANOM

AND FRED K. BRANOM

ALL RIGHTS RESERVED

8232

Che Atben $\boldsymbol{x u m ~ D r e s s}$ 
TO

DOUGLAS C. RIDGLEY

PROFESSOR OF GEOGRAPHY, ILLINOIS STATE NORMAL UNIVERSITY WHO INSPIRED BOTH AUTHORS TO TAKE UP

THE STUDY OF GEOGRAPHY 
Digitized by the Internet Archive in 2007 with funding from

Microsoft Corporation 


\section{PREFACE}

This book is the product of several years' experience by the authors in the directing of method courses in normal schools and universities. The "new geography," emphasizing interpretations as well as facts, has been heartily received. The modern spirit, however, has been imparted primarily by the geography departments of the universities, where the emphasis is placed on academic geography and the organization of geographic materials into a coherent body of knowledge. Both the content and method books of geography reflect the influence of the higher schools. The educator is not primarily interested in geography as an academic subject, but as a means of giving the child desirable experiences. He does not hesitate to overstep the boundary lines between subjects if he can give the child more befitting experiences. A practical man does not meet one situation that he calls geography and another situation that he calls history, but in the meeting of a situation he draws on any subject needed, in the proportion needed, to make an adequate interpretation. In his enthusiasm to organize educational content in accordance with the way that the world uses it, the educator has suggested the possibility of blending content subjects in unit situations under the name of social studies.

The authors hold that it is possible to organize the geography course of study in such a way that the dominant viewpoint will be geographic and at the same time will permit of the interpretation of materials about life centers.

Geography is primarily a study of the interacting relations of life forms and nature. It is essentially a study of place 
relations and of the adjustments which man makes to the geographic regions with their varied resources. Since much of the geographic content involves regions far away, considerable care is necessary in providing the child with local experiences and with visualization materials, as pictures and maps, that will enable him to form accurate concepts. The geographers have been rapidly at work socializing the content by analyzing the influence of the geographic environment upon human affairs. The teacher is socializing the content by showing the pupils the significance of their studies in relation to the present, and she is socializing the method by throwing much of the responsibility of class organization in relation to geographic topics upon the class. An attempt is made to relate the work to the child's interests and experiences and to give the child a worth-while motive, so that he will attack the problems whole-heartedly.

Much remains to be done in the devising of adequate tests and scales, but an attempt has been made to indicate the lines of study that seem most promising.

MENDEL E. BRANOM

FRED K. BRANOM 


\section{CONTENTS}

\section{PART ONE. TIIE VIEIVPOINT}

CHAPTER

I. The Practical Nature of Geography . . . . 3

II. The Evolution of Geographic KNowledge emphaSizing the Development of Civilizations . . 22 III. The Relation of Geography to Other Subjects 39 IV. The Evolution of Geography Method . . . . 5 I

V. Aims or Purposes in the Teaching of Geography 62 PART TWO. TIE COURSE OF STUDY Vi. The Organization of a Course of Study . . . 75

PART THREE. TIIE MATERIALS OF GEOGRAPHY VII. Observational Geography . • . . . . • . . 93 Vili. Representative, or Symbolic, Geography . . . 109

PART FOUR. TIIE CLASS

IX. Class Organization . . . . . . . . . . I33

X. Sochalization and Free Activity . . . . . 145

Xi. The Relation of the Stluy Period to the Recitation Period. . . . . . . . . . . . . i 55

PART FIVE. TIE PROJECT, OR ACTIVE, METIOD Xil. Tile motivation of Geography . . . . . . I6j Ail. The Promlen Metion of Teaching Geography . I73 XIV. The Argumentatre Lesson . . . . . . . I93 


\section{viii}

\section{THE TEACHING OF GEOGRAPHY}

CHAPTER

PAGE

Xi. The Topical Outline. . . . . . . . . . 201

XVI. Journey Geography . . . . . . . . . . 211

XVII. Trpe Stldies . . . . . . . . . . . . 224

Xitil. The Story . . . . . . . . . . . . 231

Xix. Dramatization . . . . . . . . . . . 238

XX. The Project . . . . . . . . . . . . 246

PART SIX. TESTS AND SCALES

XXi. Measuring Results . . . . . . . . . 265

INDEX . . . . . . . . . . . . . . . . 289 


\section{THE TEACHING OF GEOGRAPHY}

PART ONE. THE VIEWPOINT 



\section{CHAPTER I}

\section{THE PRACTICAL NATURE OF GEOGRAPHY}

The importance of geography. The World War was helpful in arousing a keen interest in the study of geography. The correct interpretation of many problems affecting the general welfare required a thorough knowledge of geographic relations. The ordinary economic activities and redistribution of surplus commodities were seriously disturbed. In common with the other Allies the people of the United States feverishly engaged in a search for new sources of needed raw materials. Careful surveys to determine the available supplies were made. The transporting system was reorganized in an attempt to secure maximum efficiency. The fundamental dependence of the social structure upon earth resources, as coal, iron, wheat, and cotton, was clearly seen.

The relations of mankind to nature's resources are just as significant in times of peace. Geography is, therefore, as significant in helping to solve the reconstruction problems and the ordinary problems of life as it has been in helping to solve the problems of war.

The activities of man. In the evolution of the social group increasing specialization has occurred. Man no longer depends primarily on the immediate environment for products that he needs and wants. Practically the whole earth contributes to his welfare. He clothes himself with garments made of cotton from the southern 
United States, of wool from Australia or Argentina, or of silk from Japan. His home may contain beautiful furniture made from the hardwood lumber of Kentucky and Tennessee or from the beautiful rosewood and mahogany of tropical forests. In the preparation of his meal he may draw upon the coffee of Brazil or the cocoa of Ecuador or the tea of Japan. The dessert may contain bananas from Central America and pineapples from Cuba. He may sweeten his coffee with sugar from the Hawaiian Islands. In the competitive world-wide economic struggle there is a tendency for each community to specialize in the production of the commodity or commodities which it best can produce. Even in the local community there is a tendency for each person to learn how to do one thing in a superior fashion. In the complex social organization that has resulted no man liveth unto himself alone; each person serves others and in turn depends upon others for service. Irrespective of the type of activity in which an individual engages the geographic viewpoint is vital.

The major activities of man are (I) vocational, (2) recreational, and (3) political.

\section{VOCATIONAL ACTIVITIES}

The leading vocational activities may be classified as follows :

I. Agricultural activities.

2. Pastoral activities.

3. Lumbering activities.

4. Hunting and trapping activities.

5. Fishing activities. 
6. Mining activities.

7. Manufacturing activities.

8. Transporting activities.

9. Professional activities.

I0. Investment activities.

I I. Middleman activities.

\section{Agricultural Activities}

The farmer lives very close to nature. The important factors of crop production, rainfall, temperature, soils, and drainage are not under his absolute control. The amount, kind, and distribution of precipitation are independent of his personal desires. The farmer needs to work with nature. He breaks up the ground, loosening the soil and making the surface more irregular in order to increase the amount of moisture that may be stored in the ground. He keeps the top crust broken so as to break up the capillary movement of water to the surface. He tiles the wet places, digs large ditches for the removal of surplus water, and stores the surplus waters so that they can be diverted over the parched fields when the rain fails.

The farmer is helpless, except in a minor way, in affecting the temperature changes. At considerable expense he can regulate the temperature of greenhouses and of hotbeds. If the temperature over the fruit orchards of Florida and California falls to the danger point, smudge fires will prevent or decrease damage to the orchards, provided the temperature normally would go only slightly below the danger point. Shading is practiced in the production of certain qualities of tobacco and coffee. The farmer must adjust himself, however, to the major temperature 
controls. Shortly after America was discovered explorers who had reached the mainland during the summer season spread reports of a warm climate. Settlers, expecting to find high temperatures favorable for the immediate planting of seeds, came to America in the late fall. They were surprised to find that a cold season was at hand, during which, being unprepared, they suffered miserably. The farmer of Minnesota who orders fruit trees or seeds from Georgia is ignoring the fact that the plants have thriven amidst conditions involving a long growing season. The truck gardener who plants the seeds on the first warm day of spring may be deeply disappointed because of the destruction of the young plants by a heavy frost. In intermediate latitudes the farmer who places his orchard on a southern slope is taking into consideration the importance of heat in the production of fruit, but he is neglecting the fact that in the spring, when winter is entering upon a death struggle with summer, the buds may open under the friendly encouragement of the warm sunshine only to be damaged by a frost, while the trees on the northern slopes may be practically unharmed.

Many people have purchased farms in the flood plain of the Mississippi, to find later that the land was almost valueless because of the overflows and the changing river. In many places, as in certain localities in northern Missouri and in southern Illinois, are large areas of apparently excellent farms, but the underlying hardpan materially decreases the actual value of the land. In the Great Valley of East Tennessee alternating layers of shales, sandstones, and limestones have been tilted on edge. The subsequent disintegration and decomposition 
of the rocks have resulted in different types of soils. The farming land varies so much in quality in short distances that the value of one farm is no criterion for the value of adjoining farms. Near Lexington, Kentucky, a faulting has occurred as a result of which a rich limestone soil is on one side of the fault and a poor shaly soil on the opposite side. A farmer of the Great Valley of East Tennessee knows from experience that the best soil of his region ordinarily is a red soil. If he should move to central Illinois and should prefer a farm with a reddish soil, however, he would make a serious mistake, for the best farms of central Illinois have deep black soils.

The farmer who removes the trees and cultivates a very steep slope may hasten the gullying of the hillside and the deposition of materials in the fertile lowland area. Plowing up and down the slopes forms depressions that encourage erosion. The selection of the lowest part of the farm for pastureland is a response to the greater available moisture content. Agricultural activities on the alluvial plains and pastoral activities in the adjoining hills reflect topographic, soil, and moisture contrasts.

On the basis of experience the time for planting various seeds, the kind and extent of cultivation, and the best time and way to harvest have been determined. In spite of this knowledge, however, a late frost in spring or an early frost in the fall may seriously damage the crops. The hot, dry winds of the summer months may burn the crops, a cold wave may kill the fruit, or the weather may be too wet or too dry. Conditions may favor the multiplication of pests, as the chinch bug, the army worm, and the boll weevil. The farmer seeks to 
adapt his activities to nature's requirements, and the extent to which he is able to do this determines success or failure.

\section{Pastoral Activities}

When the area north of the Ohio River was sparsely populated live stock was relatively of much significance. The cattle transported themselves over the long trails to a market. A few years ago, in the vast, semiarid region of the West, cattle trails, with wide, grassy areas on each side, were laid out. Along these trails numerous herds of cattle were driven to railroad stations. With increasing population suitable areas are given over to crop production, and live-stock raising is related to mixed farming. Grain farming largely dominated for several years, but with diminishing returns from an increasingly impoverished soil the necessity of raising animals, so that the soil may be rested and fertilized, becomes acute. Ordinarily an area that is best adapted to crop production is also best adapted to animal production, since the domesticated animals depend on vegetation for their existence. The typical pastoral activities, however, are found in areas where grass is produced but where climatic conditions are unfavorable for a more intensive use. Conditions are not ideal, but are better adapted to stock raising than to crop production.

A person engaged in pastoral activities should be acquainted with poisonous weeds on which the animals may feed, must take care that the grazing grounds are not overstocked, must know the location of fresh-water pools and the extent to which he can depend on them, 
must anticipate pasturage and water shortage during the dry season, and must provide the necessary shelter against the low temperatures and storms of winter. In many places the scattered grasses cannot profitably be cut and converted into hay, but after the few weeks of precipitation favorable for the growth of grasses may come a period of high temperatures and little rainfall, which cures the grass in situ. The deep snows of winter may cover the grasses so that the cattle cannot reach them. In certain areas the aid of chinook winds, which rapidly melt the snow so that the underlying grasses are available, removes the danger of starvation or the necessity of securing more expensive feed.

\section{Lumbering Activities}

Innumerable uses for lumber have been found. Many farms have been located with reference to the proximity of large forest trees. There are numerous varieties of trees, many of which produce lumber or other products useful to man. The lumberman must be able to identify the different varieties of trees and to calculate their value. All the lumbering operations must be carefully planned so that a maximum coöperation of nature's forces may be secured. The tree must be cut in such a way that it will fall where least damage to younger trees will be done and where the $\operatorname{logs}$ can be most economically handled. In some of the Northern swamps logging operations are carried on in the winter, when the frozen ground gives a solid foundation. Excellent roads of snow and ice may be made along which the logs are dragged or 
hauled on sleds to the water's edge. With the coming of warm weather the ice of the river breaks up and the logs are floated downstream to the sawmill. In the southern Appalachians, where there is a very rugged topography, lumbering operations are carried on during the warmer part of the year, the cold, stormy weather of winter making it very difficult to cut and remove the logs where the area is pronouncedly rugged. In tropical forests the difficulties are all but insurmountable. The dense undergrowth must be cut away, and the logs must be transported over low wet lands during hot, humid weather. In many instances the logs are so heavy - for example, the quebracho logs of Árgentina - that a raft is made of lighter logs to keep the heavie: $\operatorname{logs}$ from sinking. In securing the resources the lumberman is particularly affected by climatic conditions, topograp'iy, location, and the extent and nature of the forest.

\section{Hunting and Trapping Activities}

In sparsely populated regions the wild animal life may. be abundant and varied. As an area becomes densely populated the wild animals gradually diminish. Man determines what animals shall be exterminated and what animals shall be domesticated and permitted to multiply under his direction. Wild animals furnish food for the table and furs and skins for clothing.

\section{Fishing Activities}

The ocean currents are laden with multitudes of microscopic forms which are an appropriate food supply for the larger aquatic animals. The banks or shallower 
parts of the ocean are the best fishing grounds. The Newfoundland Banks have become one of the leading fishing grounds of the world. Half a century ago many fish were caught in the inland waters of the United States. In many places fishing no longer is profitable. Man has emptied the sewage into the streams to such an extent that fish cannot live, or he has fished so recklessly that the fish have been almost exterminated. It has been necessary to establish hatcheries and to enact laws regarding fishing and the pollution of streams. Through such constructive measures it is hoped that the inland waters will again contribute substantially to the nation's food supply.

\section{Mining Activities}

Numerous minerals are eagerly sought. While almost all minerals have a wide distribution, only in restricted places have most of them been concentrated in quantities sufficient for profitable extraction. Inventions and discoveries have aided in the use of low grades of ore. When prices for the products are high many mines can be operated that must be closed when orices are low. Old mines are being exhausted and new mines are being opened. A half century ago Missouri ranked high in the production of iron ore. Large quantities of ore were secured from Iron Mountain, Pilot Knob, and adjoining areas. Caronclelet, now a part of St. Louis, was an active iron and steel center. Missouri has become relatively unimportant not because the iron ores are exhausted but because of the discovery of the superior ores of Minnesota and because of the excellent transportation 
via the Great Lakes to the coke produced in Pennsylvania. Recently the perfecting of a process that will permit the making of a high-grade coke from Illinois coal has suggested the probability that the St. Louis industrial area will again become a great iron and steel center. Illinois coke will be used, and the iron ore of Minnesota will be brought to St. Louis via the Mississippi River. Redistribution of people, changing needs and wants, changing values, and inventions and discoveries are constantly bringing about a readjustment of man to the mineral resources.

\section{Manufacturing Activities}

In the preceding lines of activity the influence of the physical environment was marked. An adjustment of man in order that he might secure as much as possible from nature's storehouses was emphasized. In the manufacture of commodities man is less subject to the changing conditions of nature, as uncontrollable variability is less pronounced. While the environment is very significant, the viewpoint shifts from the influence of nature over man to the influence of man over the raw materials of industry. In the production of wheat the cycle of growth is determined by nature, and man simply attempts to make the environment of the seed and of the plant as favorable as possible. In the manufacture of flour from wheat man determines the various steps resulting in the changed form and nature of the wheat grains. Every manufacturing industry may be studied profitably from the standpoint of (I) machincry used, (2) processes, (3) sources and nature of raw materials, (4) how the 
raw materials are secured and transported, (5) disposition of the finished product, (6) factors under the control of man, and (7) factors subject to forces outside of man's control. In every instance there is a close relationship between the activities involved in securing raw materials and the manufacturing industries. This interdependence should be emphasized.

\section{Transporting Activities}

The resources of the earth are irregularly distributed. Man's needs and wants are becoming more nearly the same everywhere. Only through the redistribution of materials is it possible to meet this broadening demand. Transportation by land, water, and air has been improved to such an extent that it has been possible to produce fruits, vegetables, and various other highly perishable commodities far from the centers of consumption. At one time, before the invention of refrigerators, it was impracticable to ship meats from Argentina across the hot belt to Europe. So dependent is a large city, as New York or Chicago, on transportation facilities that, should the transportation system break down, actual want and suffering would stare the people in the face inside of a week. Nature has exerted a powerful influence, largely topographic, over the transportation lines not only through the invitation extended to use her oceans, lakes, and rivers but through favorable or unfavorable topographic conditions affecting the constructing of railroads.

The explorers, traders, and early settlers of the New World penetrated the interior by means of the waterways. Various trails, developed supplemental to the 
waterways, followed the most favorable topographic lines. The French rapidly occupied large parts of the St. Lawrence and Mississippi basins because of the relative ease with which they could travel from place to place on the numerous navigable streams. When a substantial movement of people from the Atlantic seaboard to the interior began, the Ohio River, with its navigable tributaries, became a great transportation artery. Numerous trails across the Appalachian barrier were established. The famous Wilderness Road, extending through Cumberland Gap to the fertile lands of Kentucky, was used by thousands of pioneers.

In the early construction of railroads the most favorable topographic lines were followed. As the need for more transportation facilities has grown, and as man has learned more and more how to overcome unfavorable topographic barriers, the earlier valley roads in many instances have been shortened and competitive lines, piercing the mountains by means of tunnels and cuts and crossing the valleys by means of trestles and fills, have been built to shorten the distances between important commercial and manufacturing centers.

Owing to the advantages of rail transportation, supplemented in some instances by unfair competition, the waterways of the country fell into relative disuse. As the natural resources have been developed the railroads have been gradually overtaxed, which has led to a revival of interest in the waterways, and numerous steps have been taken looking toward their improvement. The transition from the dominant use of the waterways to the dominant use of railroads, and the present tendency toward a 
maximum use of both railroads and waterways, illustrates how a gradual increase in the mastery of earth resources may bring about a readjustment of transportation routes.

\section{Professional Activities}

In a highly developed society specialization of labor becomes so pronounced that there are many people, as lawyers, doctors, ministers, and teachers, who do not secure their livelihood directly from mother earth, or even by refashioning the raw materials of industry, or by transporting commodities. Indirectly such people depend on earth resources by serving certain needs of members of the social group, who are thus dependent. Such activities are decidedly social, but they should be considered in relation to the basic industries on which they depend. Many of the problems that arise among professional people, moreover, require geographic knowledge for their interpretation.

The lawyer may consult the Weather Bureau records to ascertain the condition of the weather at the time of an accident; the doctor may make a study of different climates with respect to their effects on various diseases; the minister may study the geography of Palestine in order that he may understand the environmental conditions under which the Jewish and Christian religions were evolved; and the teacher may make a study of the air of the schoolroom-its temperature, its humidity, and temperature and humidity variations - with reference to the promotion of the health of the children. 


\section{io. InVestment Activities}

Under modern conditions many individuals accumulate capital. There is always a desire to invest the capital safely, but at the same time to secure a high rate of interest. The more doubtful securities frequently bear the highest rates of interest. Investors frequently are induced by unscrupulous promoters to place their funds in propositions that are almost inevitable failures. If oil stock is before the investor, a knowledge of the conditions under which oil occurs and the areal distribution of probable oil-producing territory is desirable. If swamp lands are to be reclaimed, if an area is to be reforested, if a fruit orchard is to be set out, or if a pecan grove is to be established, in every instance the individual will have a better background for investing intelligently if he knows the physical conditions that must be dealt with in carrying out the project.

\section{i i. Middleman Activities}

A large part of our population is concerned with the bridging of the gap between producer and ultimate consumer. The merchant should purchase goods according to varying seasonal demands. He displays goods according to the particular needs. He must draw on various parts of the earth for his stock. He buys for future or for immediate needs according to his judgment of future prices. He should have an intelligent perspective of his line back to the raw materials and the conditions under which they are produced, and a forward perspective to the consumers and their probable needs. 


\section{RECREATIONAL ACTIVITIES}

As man's mastery of the earth has increased, nature's forces have done much of the work that formerly was done with human energy. The number of hours of vocational work for man has decreased. More time is available for recreational activities. The need for recreational grounds close to nature, where many pleasant strolls amidst beautiful scenes is possible, where there are animals to hunt and fish to catch, and where there is no "maddening crowd," is acute. Some areas are valued because of their low temperatures, because of cool nights, because of the stimulating air of high altitudes, because of the cool, salty breeze, or because of the inviting surf. In other instances the recreational needs are indirectly related to nature. Numerous games, as tennis, baseball, and golf, are played, picture shows and operas are patronized, and social intercourse with friends is welcomed. In either case - whether it is nature beckoning to man or whether it is man refashioning nature - the relationship of man to environing nature is the essential viewpoint.

A grave danger at the present time lies in the fact that people do not know how to use their spare time. This danger is every year increasing as laborers shorten their working hours. The teacher has numerous opportunities to teach the pupils how to employ their leisure time desirably. The geography teacher has a splendid opportunity to implant a love for industry, an interest in one's fellow man, a desire to create, a passion for growing things, a liking for woods and fields and sky, and a craving for travel and travel literature. 


\section{POLITICAL ACTIVITIES}

Every citizen should be actively interested in the political problems and the social policies of our country. An intelligent voter in a recent bond-issue election in St. Louis required considerable geographic knowledge in relation to the proposed improvement of the River des Peres, in relation to the proposed improvement in transportation by the construction of an approach to the Free Bridge, the completion of the Municipal Railway, and the construction of a second municipal pier.

Our legislators must pass many laws bearing on conservation of natural resources, reclamation of arid and swamp lands, the disposition of public lands, the improvement of waterways, and commercial relations with other countries. In the long run the legislators will vote according to public sentiment. It is the function of government to attempt to establish and preserve desirable social relations, but these relations in turn are inextricably interwoven with the economic foundation and the physical environment. A sound public policy cannot be adopted for our natural resources until the voters have an intelligent conception of constructive measures that should be enacted. Consequently a knowledge of geography is a necessary preparation for the exercise of effective political citizenship.

What is geography? Geography is concerned with the discovery and interpretation of the relations between the physical environment and life forms. The physical environment, if geographically considered, includes the 
controls of nature that take place largely apart from the dominating intellectual control of man. The more important controls are location, area, topography, drainage, structure, climate, plant forms, and animal forms: Man's response to the laws of nature, whether he is a mere slave to them or whether he directs the forces of nature along certain channels, is decidedly geographic. The reaction of man on man, when the intellect exercises the dominating control, is less characteristically geographic, although geographic factors are basic even in highly socialized situations.

Place geography the unifying factor. All activities of man are fundamentally geographic, and there is a geographic viewpoint for every subject and for every topic. The subject of geography gives the student the geographic viewpoint of life. If the province of geography was merely to indicate the geographic influences that help to explain other subjects, there would be no general need for geography apart from other subjects, although a person specializing on the geographic side of subjects undoubtedly could aid materially in securing the proper emphasis of geographic factors. The organizing viewpoint for the subject of geography is the relationship of life forms and the physical environment in such a way that the sum total of physical factors is seen functioning as an interacting complex on the life forms, which also are reacting according to their particular tendencies.

The organization of the geographic field is focused about what may be variously termed place, locational, areal, or regional geography - not mere place geography in the sense of location on the earth's surface, but places 
located relationally in such a way that the significant interrelationships are discovered and interpreted. The old sailor geography, therefore, was a natural step pointing in the direction of the relational, interpretative geography of the present.

\section{Suggestions for Further Study:}

1. Make a list of the occupations in which your friends are engaged and indicate the various ways that they serve each other. Show the fundamental relationship of all these occupations to earth resources.

2. Make a list of recreations in which you have engaged and note the physical influences involved in each instance.

3. Make a list of political issues of present importance and suggest any physical or earth influences that may be involved.

4. Make a list of the raw materials that have been used $(a)$ in the construction of the building in which you live, $(b)$ in the manufacture of the clothing that you possess, $(c)$ in the preparations of a meal. Indicate the probable source of origin of each material and suggest the various vocations that were involved in making the material available in its present form.

5. Imagine yourself the manager of some economic enterprise and indicate the various ways that geography may affect your business.

6. A recent educational article appeared entitled "The Reconstruction of the Course of Study on a Social Basis." Would the expression "The Social Reconstruction of the Course of Study on a Physical Basis" more nearly represent the correct viewpoint?

Sclected Refercnces:

I onris, R. E., and Kuncuwey, C. B. The Teaching of Geography, chap. i. pP. I-I 5 .

IRYir, C. R. "What is Geography?" Joumal of Georraphy (1905), Vol. IV, Pp. $34^{\circ}-3$ (ro.

Falkbavks, H. W. "A New Definition of Gengraphy," Joumal of Geografhy (1919). Vol. XV111, pp. 185-1SS. 
Fexpenax, N. M. "The Circumference of Geography," Geographical Reriew (1919), Vol. VII, pp. I68-176. Synopsis in Joumal of Geography (1919), Vol. XVIII, pp. I $48-150$.

Goode, J. Paul. "The Practical Value of Geography," American Schoolmuster (1 920), Vol. LIX, pp. 236-244.

McMurry, Charles. Special Method in Geography, chap. i, pp. I-I 4 .

PACKARD, L. O. "Geography and Reconstruction in Education," Joumal of Geography (1919), Vol. XVIII, pp. 24-28.

PeAtTie, Ronerick. "The New Geography," Educational Review (1919), Vol. LVIII, pp. 420-430.

Sutherland, William. The Teaching of Geography, chap. i, pp. 17-27; chap. vii, pp. 95-109.

Thomas, Henex Goss. "The New Geography," Educational Review (1920), Vol. LIX, pp. 236-244.

Whitbeck, R. H. "The Need of Broad-Gauge Courses in Geography," Sihool Review (I9I8), Vol. XXVI, pp. 199-204. 


\section{CHAPTER II}

\section{THE EVOLUTION OF GEOGRAPHIC KNOWLEDGE EMPHASIZING THE DEVELOPMENT OF CIVILIZATIONS}

The modern world different from the primitive world. Primitive man was largely a creature of his immediate environment. He subsisted on the accidental products of nature and only incidentally affected his environment. If nature was kind he prospered; if nature was cruel he suffered. Today, what a marked contrast! Man has learned how to make the forces of nature serve him, how to increase the production of desirable plants and animals, how to extract minerals from the earth, how to minimize the ravages of disease, and how to refashion and redistribute the resources of the earth according to his varying needs and wants.

Man's relations to his physical cnvironment. The assumption is frequently made that mind plays upon mind and determines man's relations to his physical environment. This emphasis of the influence of mind over nature tends to thrust into the background the overwhelming influence of the physical environment over man not only in stimulating him to think but also in influencing his decisions. Even in the instances that man seemingly has risen superior to his environment, the previous physical environment has been prominent in developing the needed intellectual ability. Not the least fascinating of topics is 
the story of the constant stimulus and control exerted by nature in making possible the wonderful advancement of man.

Beginnings of civilization in favorable regions. It is probable that the human race, while in a low state of development, was widely distributed over the earth's surface. The commission of a crime, the presence of powerful enemies, a curiosity to explore, a famine, the pressure of increasing population, and the confusion of travelers concerning the way are some of the factors that might have induced people to brave the unknown dangers of sea, desert, plateau, and mountain in an endeavor to escape punishment or oppression or to better their status.

Since nature rarely forces man to act, an important civilization would scarcely have developed in every favorable area. In those areas presenting the most favorable environments, however, other conditions being equal, we should expect to find the most rapid development. Among the factors that influenced human evolution are (I) location, (2) protection, (3) area, (4) soil, and (5) the necessity for the working out of group projects.

\section{LOCATION}

In low latitudes, amid the favorable conditions of high temperatures and heavy rainfall, a great variety and abundance of both plant and animal forms are found throughout the year. The climate is enervating, numerous diseases sap the vitality of man, insects are annoying, and nature is so prodigal in supplying the needs of man that the necessity of taking thought for the morrow-or at 
least the stimulus for such thought, and particularly for an extended period of time - is all but eliminated. Where man's fundamental needs were cared for readily and continuously, and where the control of prodigal nature was extraordinarily difficult, there was little stimulus to great mental activity. In the higher latitudes, on the other hand, the low temperatures and meager rainfall are unfavorable for the existence, in the same variety and abundance, of life forms so common in equatorial regions. Nature is almost parsimonious in her gifts to man. Because of this inhospitable environment and the difficulties of improving it, the energies of man are consumed in providing for a bare existence. In neither equatorial nor polar latitudes, therefore, are conditions very favorable.

In dry desert regions, with an inadequate water supply, not only are the problems involved too great to be solved by man emerging from a primitive state, but even today these fields remain largely unconquered by man.

If a region existed in which the climate for a part of the year was favorable for an abundance of life forms, followed by a period of drought due to lack of rainfall or proper temperatures not too long or severe, the necessity during the period of plenty of laying by supplies for the period of want would have stimulated man to exercise forethought. The beginnings of civilization, therefore, might be expected in intermediate latitudes (where the growing period alternates with the winter season) or in an area (as in parts of the trade-wind deserts) where for a part of the year rainfall is sufficient or irrigation is possible. Since the land mass of the Southern Hemisphere in intermediate latitudes is very limited, while in the 
Northern Hemisphere it extends over large areas, the chances were in favor of more centers of civilization developing in the Northern Hemisphere.

\section{PROTECTION}

A group of people surrounded by other groups, with no natural physical protection, may be forced to devote too much of its energy to protective purposes. Adequate physical protection leaves the group free to devote all its energies to internal development. The sea, the desert, and large plateaus have been the three very formidable barriers.

\section{AREA}

The area should be large enough to permit an important group development, but not so large that the energies are scattered.

\section{SOIL}

Excellent soil which will encourage agricultural rather than pastoral activities is necessary.

\section{GROUP PROJECTS}

If there is occasion for working out group projects not too clificult, as irrigating systems, the social development may be greatly stimulated.

The valley civilizations. The Nile valley met the conditions necessary to encourage a beginning. The valleya long, narrow depression five to ten miles in width - was large enough to support many people, although it was not. 
so large but that a community of interests was readily established. The valley at one time was much deeper, but conditions had changed so that a large quantity of fine material, giving rise to an excellent soil, was deposited. One of the major sources of the Nile is in the lake region near the equator, where heavy rains are characteristic of the whole year. The flow of the Nile, therefore, is constant. Another large tributary, the Blue Nile, originates in the plateau of Abyssinia, where the rainfall is heavy but seasonal. At the time of year that the greatly increased volume is added to the White Nile, the lower Nile overflows its banks, depositing a fine mantle of rich soil on the flood plain and providing the water necessary for crop production. The valley is depressed with reference to the barrier desert lands on the east and the west, which results in a sharp transition from verdure to barrenness. On the south not only did desert conditions prevail, but the ruggedness of the country and dangerous rapids in the river prevented ready contact with people to the south. On the north lay the Mediterranean Sea, a formidable barrier to man just beginning to emerge from very primitive conditions. The temperature was warm throughout the year, but the rainfall was negligible. Dependent on the annual flood of the Nile, the people found it necessary to exercise forethought in storing up foods for the period of the year when agriculture was at a minimum.

In the Tigris-Euphrates valleys similar conditions existed, but in a varying degree. There were numerous small areas separated from other parts of the valley by swamps, too wet for roads but too dry for boats. With increasing need for land the swamps were gradually 
drained, and with the barriers removed the smaller communities were cemented into a larger group. While a winter precipitation was dominant, the melting snows of the higher tributaries favorably affected the summer flow. Unlike the Nile, the valleys were not depressed much below the adjoining areas, which facilitated irrigation. Neither were the adjoining desert conditions quite so pronounced, but a sparse pastoral population adjoined the valley population and formed a slender thread of contact with other peoples. The people, therefore, were not isolated to the same extent as the people of Egypt, and foreign influences were correspondingly greater. In times of relative scarcity elsewhere the rich valleys were always a tempting prize.

The Assyrians, living in an area with very restricted opportunities, naturally looked longingly on the betterfavored parts of the valley, and, spurred on by physical necessity and later by a desire to secure those things which nature had taught them were valuable, engaged in a policy of conquest until much of southwestern Asia was under their control. Their conquests, however, were effected and maintained by force, and as soon as opportunity offered, the centralized government was overthrown.

Contact between people of the Nile and people of Mesopotamia seems to have been established through the accidental meeting of parties seeking for copper or other valuable materials in the intervening desert. The exchange of materials and ideas resulting was a mutual benefit in stimulating still further development. Between the two civilizations ways determined largely 
by topographic and desert conditions were discovered. The narrowest part of the desert lay between Egypt and the coastal plain of Palestine. The people of Palestineparticularly those of the coast and of Samaria and Lower Galilee living along the most important of the waysnaturally were stimulated by contact with the caravans.

The Mediterranean civilization. It can hardly be a coincidence that the Phœnicians began the commercial conquest of the Mediterranean from its eastern end. The stimulating influence of the fluvial civilizations, with their moderate utilization of rivers as transportation carriers, may have been significant. The coast of the Phœnicians was irregular, offering numerous landing places for small vessels, the adjoining mountains had meager resources, while the sea beckoned. The numerous islands of the eastern Mediterranean were stepping-stones, and the cautious mariners crept from place to place along the coasts. Gradually the Phœnicians became acquainted with the various parts of the Mediterranean, and a considerable commerce was developed. As the Mediterranean became better known and as other groups of people became organized and advanced, the center of Mediterranean influence tended to shift to the central part-first to Greece and later to Rome. Further acquaintance with the sea and improvements in the art of navigation enabled the seamen to disregard the coasts and to sail directly across the sea from one part to another.

Not only were the Romans, in part because of their central location and relatively large body of compact, desirable land, able to control the Mediterranean, but through their extensive construction of good roads they 
were able to exert a unifying influence on large land areas. It was the individual initiative and ability of the Macedonian, Philip the Great, that enabled him to conquer much of the known world, but it was the general ability of the Romans that enabled them for a long time to control the Mediterranean and, in addition, to extend their operations northward through the Rhone gateway until all of western Europe even unto England was under their control.

As the geographic factors began to function differently, the Roman Empire gradually declined. The eastern part of the Mediterranean, by reason of distance from the ocean, earlier civilization, numerous islands, and relations to Asia, was different from the western section. Western Europe was broken up into numerous groups mainly determined by topographic conditions. From the large plains of Eurasia to the northeast restless hordes threatened the Empire. Necessity for defense had influenced the martial ability of the Romans; with the enemies far removed to the northeast the Romans lost much of this ability. With the breaking up of the Empire, naturally the strongest capital was established at Constantinople nearer the danger points.

The Romans had exerted a powerful influence on numerous units of people, each of which had been distinctively civilized. With the removal of the strong, centralized government western and southern Europe contained numerous groups which, struggling among themselves, moved in the direction of relative stability. The varied physical features gave rise to varied adjustments which tended to develop and maintain distinct groups of 
people, but at the same time the various groups, through interchange of ideas, learned from each other.

The closing of the route to the Orient. In the meantime a wild, courageous, cruel, aggressive people-the product of their environment in the semiarid steppes of Asia-overswept southwestern Asia and intercepted the profitable commerce that had been carried on between Europe and Asia. To these people the Mohammedan religion, advocating religious conquest by the sword, made a strong appeal. Under their fanatical activities southwestern Asia was rapidly conquered, and a spur extended eastward to India and, creeping along the southern shore of the Mediterranean, they even occupied the southern part of Spain.

The ordinary routes to Asia were so firmly held that the commercial cities of Italy, whose greatness had been due to the commerce with Asia carried on by way of the Red Sea, Mesopotamia, or the Caspian Sea, declined, and all Europe was affected. Naturally the question persistently arose, Is there no other practicable route to the Indies? To the south was the great land mass of Africa, which popular superstition had bounded on the south by a great river. Perhaps it would be possible to sail around this land mass and thus reach the Indies. From time to time various thinkers had expressed their belief in the sphericity of the earth. If this were true, the mysterious Atlantic to the west of Europe also might offer another route to the Orient. There had been no adequate testing of these theories because (I) man had not advanced sufficiently to deal with the more difficult problems involved, and (2) in 
the course of human evolution the Mediterranean, western Europe, and eastward relations with the Orient had absorbed most of the energies. At the time that the hordes were pouring out of central Asia, however, not only was there a need of finding some other way to the Orient, but the advancement that had been made was sufficient to stimulate explorations.

It was not a coincidence that the two countries of the Iberian Peninsula made the most earnest attempts to find these new ways. On one side of this peninsula was the Mediterranean Sea, which was well known; on another side was the Atlantic, with its more difficult problems. The people of the peninsula came under the influence of both bodies of water, and the experiences with the one were used in the conquest of the other. The Portuguese, pushing southward and encouraged by the gold, ivory, and slaves secured from Africa, finally rounded the continent and began a profitable trade with the Orient.

The New World. The discovery of the New World and the Cape of Good Hope route to India nerved men for still greater accomplishments, and Magellan conclusively established the unity of the oceans. The Portuguese route to the Orient alone was practicable. The Spaniards, finding the route to the Indies too long, eagerly explored the New World for gold and silver. Taking advantage of the northeast trarles, they discovered and occupied islands of the West Indies, from which bases the mainland was explored. Expeditions penetrated far into the interior of North America without discovering valuable products. Southward the Spaniards were more 
successful. In the tropical highlands of Mexico and South America the natives, stimulated by a favorable environment, had developed a high type of Indian civilization. Precious metals had been concentrated in these mountainous regions, and the Indians had accumulated large quantities.

The Spaniards, with their superior control of energy, were able quickly to conquer the Indians. The Andes Mountains became a center of operations because the climate was more favorable than in the hot, humid lowlands adjoining, and because the precious metals were in the mountainous sections. Gradually the Spaniards came to exercise a dominant control over the whole of South America with the exception of Brazil. The Portuguese had sailed east, the Spaniards west, and the Pope in separating the east from the west had drawn the line in such a way that Brazil belonged to Portugal. Latin America, relatively, has progressed slowly, in part as a result of unfavorable physical conditions-particularly climate and dependent factors. In those small areas with climatic conditions similar to those of the United States the greatest progress has been made.

Progress in Eurasia. The other countries of western Europe became interested in the use of the Atlantic. The hinterland of the Portuguese was limited, and spices had to be distributed from other ports. The Rhine offered a passage into the heart of Europe. Holland and Belgium commanded its mouth. The Dutch, encouraged by numerous islands and shallow seas, engaged in the fishing inclustry. Far from the seat of Roman Catholic influence, the Dutch also quickly had become Protestants. 
The Spaniards with their gold had purchased materials and engaged men. Columbus was an Italian; Magellan was a Portuguese. The Dutch, to a greater extent, used their own energy and soon had secured much of the trade that the Portuguese had initiated. Holland was too small, however, to withstand the competition of larger countries with similar advantages.

Paris, strategically located with respect to the waterways of France and at the narrowing of the Seine where the Norsemen were repelled, became the influential center of France. The policies of France were swayed in part by the invitation to expand eastward, in part by the influence of the sea. This division of interest, while leading to the downfall of the sea power of Holland, so weakened France that she was unable to compete successfully for ocean power against Britain, whose insular location made her interest in the sea supreme. Diversity of physical features gave rise to different groups, but the insular unit finally prevailed, and Britain gained the ocean control.

In the meantime agricultural communities were established in the forests of Russia, and gradually, with an effective political organization, they were able to overrun the adjoining steppes. Russia had aspirations to secure better seaports, which has brought her into difficulties with other countries, as Sweden, Japan, England, and Turkey.

Modern Germany has a central location and diversified features. It has constantly been affected by different groups pressing in on various sides. Through a strong, centralized government Germany has effected an enormous 
saving of energy, the diversion of which to war purposes has resulted in the present downfall of Germany and her allies.

Europe, influenced by its diversity of physical features and irregular outline, had several important population centers. These groups of people, without the improved transportation facilities which permitted the coherent development of the United States, and without the large simple natural units, developed in relative isolation. Different groups developed varying ideals, customs, and languages. In the course of time, through the fortunes of war, migrations, assimilations, and marriages, the political units came to differ widely from the ethnographic units. Poland, for example, against the wishes of the Poles, was arbitrarily divided among the countries of Russia, Austria-Hungary, and Germany. In spite of the political changes the different groups of people tended to preserve their identities and to hope for a restoration of their political powers.

With the outbreak of the war political and racial antagonisms were intensified. With the completion of the war an attempt was made to rearrange the boundary lines of the countries and to establish new countries, primarily along ethnic and physical lines. Each of the groups of people occupied some distinctive natural region, although in the absence, in many instances, of pronounced topographic barriers the groups had intermingled on the margins in such a way as to make the determination of the most desirable boundary lines extraordinarily difficult.

The Poles and the Magyars occupy river basins; the Austrians, the Czechoslovaks, and the Jugoslavs occupy 
mountainous areas. Under modern conditions natural boundary lines are of minor significance. Temporarily the national spirit of the various groups has been greatly intensified, and numerous disputes have arisen. Each group needs to recognize the natural region basis for its political independence and to develop its unit in an efficient manner. Instead of coveting its neighbor's territory, each group needs to arrange for an exchange of commodities and ideas that will be mutually beneficial. Unless the various groups can arrange an economic and social balance among themselves, further dissensions and conflicts are almost inevitable unless some superior organization can restrain them. The problems of Europe suggest that the social and political groups of the world are not yet in equilibrium either with respect to the economic resources of the world or with respect to each other.

Chinese civilization was cradled in the Wei valley of the Hwang. It gradually spread down the valley to the great Hwang and, helped by the uniformity of physical conditions and opportunities, overspread a large area, giving rise to similar adaptations everywhere. In India, subject to wave after wave of people coming by sea from the East Indies and by land through the passes of the northwest, there are many physical units, and many local governments have been formed, capable of being united only by some outside power, as Great Britain.

The United States dependent upon natural resources and upon other countries. Varying types of civilization have developed in different parts of the world. In each case earth influences have been marked, although with increasing development these influences have factored both 
directly and indirectly, giving rise to very complex situations difficult to interpret. The wonderful progress of the United States has been possible, in part because of the successive racial experiences in Egypt, Babylonia, Palestine, the Mediterranean Sea region, and western Europe; in part by reason of the large topographic provinces, the varied and abundant resources, and the favorable climate. Favored by nature as much as northwest Europe, America, profiting from experience, has had less economic and social machinery to scrap and, taking advantage of latest inventions, has forged ahead. America owes much to nature and to other people. Is it not a part of the divine plan that in the evolution of the human race America, in turn, with a perfected experience, shall help other countries to develop and shall lead the world through a perfecting of parts, through an exchange of commodities and ideas, and through a sympathetic understanding to a higher level?

The wonderful future. Gradually the earth has come to be related as one organic whole through the discoveries and inventions that have been made. "It may be said that in its widest sense on its material side history is the story of man's increasing ability to control energy." While remarkable advances have been made, the geographic conquest has just begun. There are large areas of the earth that man uses but little; for example, the great tropical forests, the cold deserts, and the hot deserts. If man can control or mitigate the effects of adverse factors in such regions as the Amazon and Kongo basins, there may in time be a readjustment of populations, since

${ }^{1}$ James Fairgrieve, Geography and World Power, pp. 3-4. 
plant and animal life, the food of man, are found in great abundance. Large populations may be concentrated in now barren desert wastes if an economical way can be found of utilizing and storing the sun's energy. It seems probable that the human race is on one of the steepest slopes of evolution, and the mind is awed with wonder at the potential discoveries and inventions of the future, which may make man more nearly "lord of creation."

\section{Suggestions for Further Study:}

1. Imagine yourself a person with your present physical body but with no more intelligence than is possessed by some animal with which you are acquainted. Indicate the hardships that you might experience in protecting yourself and in supplying your needs.

2. On an outline map of Eurasia indicate the routes connecting the Mediterranean countries of Europe with the Orient before the discovery of the Portuguese route.

3. On an outline map of the world indicate the Portuguese route by way of South Africa, and the Spanish route by way of the Strait of Magellan. Imagine yourself with Vasco da Gama on his voyage from Portugal to India or with Magellan on his trip around the world and describe probable incidents of the journey.

4. Is the realignment of the political boundary lines of Europe a retrogressive or a progressive step in relation to civilization?

5. In the light of the development of civilizations and inequalities in the distribution of earth resources, what should be the attitude of every civilized being toward the establishment of a world-wide understanding that will result in political stability?

6. Has the economic brotherhood of man already been established? What relation may the long-desired social brotherhood of man bear to the economic brotherhood?

7. Beginning with the present relationships of man to earth resources, indicate the possible changes, through inventions and discoveries, during the next thousand years. 
Selected References:

Fairgrieve, James. Geography and World Power.

Gorgas, William Crawford. Sanitation in Panama (I9I 8), p. 298.

Holtz, Frederick L. Principles and Methods of Teaching Geography, pp. 290-308.

Huntington, Ellsworth. World Power and Evolution, p. 287. Levine, IsAaC Don. The Resurrected Nations, p. 309.

Renway, Jacques W. The New Basis of Geography, pp. I-I 5.

Smith, J. Russell. The World's Food Resources. Stoddard, Lothrop, and Frank, Glenn. Stakes of the War, p. 377 . 


\section{CHAPTER III}

\section{THE RELATION OF GEOGRAPHY TO OTHER SUBJECTS}

Geography a part of the world-whole of knowledge. The people of each generation, through social inheritance, have the accumulated knowledge of the past on which they can draw for assistance. This knowledge, whether accidentally or purposefully discovered, in so far as it has functioned usefully, has been considered with reference to life situations. In an attempt to pass on the social inheritance so that there will be no loss, and so that the knowledge may be put to maximum use, it has been customary to establish organizing centers about which material representing a similar viewpoint may be clustered.

Numerous subjects, such as geography, history, and mathematics, have been thus recognized. Geography has been further subdivided into many parts, as mathematical, economic, political, regional, and locational geography, each of which represents a particular viewpoint within the field of this subject. Each special phase again is divided and subclivided unto the last minor detail. Any topic, consequently, is related to a larger topic and to corresponding larger topics, in the last analysis forming a part of a major organizing center, which gives rise to a subject-geography - and which in turn has definite, unavoidable relations with all other major organizing centers or subjects. 
It should not be forgotten that the various subjects included in the curriculum are recognized for convenience in desirably transmitting the more fundamental aspects of the social inheritance. The teacher, consequently, is interested not only in the development of the geographical concept through a logical, well-graded arrangement of geographical material, but also in the proper relating of geography to other subjects in such a way that the subject will not be thought of in isolation, but as a coördinate part, in common with other subjects, of the world-whole of knowledge and a coördinate part of the knowledge of the individual.

The "mutual assistance" of subjects. The university student of geography, stirred with a strong desire to interpret a topic geographically, may spend much time in clarifying and elaborating this field of knowledge. He may be interested in the study of geography in relative isolation from other subjects in order that he may bring out clearly the significance of this vicwpoint. The teacher is not interested in making any subject as a subject stand out prominently in the child's mind, but she wishes the pupil, through the various subjects, to establish a rational, comprehensive contact with his social and physical environment. With this aim in mind she avails herself of every desirable opportunity to draw on other subjects to illuminate some geography topic, and she likewise is glad to have other subjects reënforced through a liberal use of geographical data.

The same topic a part of several subjects. Subjects can be made of mutual assistance to each other without necessarily losing their identity. The same topic 
may be discussed in connection with several different subjects. Japan may be discussed in history with reference to its development, culminating in the present. Japan may be discussed in geography with reference to the effects of the physical background in influencing the present adjustments. A series of arithmetic problems dealing with Japan may be solved by the arithmetic class. The subject to which a given topic belongs is dependent upon the particular or dominant viewpoint taken in the discussion of the topic. In the handling of topics in the classroom the geography teacher will draw liberally on other subjects as needed, in order that the pupil may secure a well-rounded view of the topic; but the geographical material must dominate and the material of other subjects must merely "assist" in the development of the topic or the teacher has ceased, temporarily at least, to be a geography teacher.

Relation of tool and content subjects. Geography (place) and history (time), comprehensively considered, involve the total of human experience. While these subjects are all-inclusive, many subjects have been conveniently recognized for the purpose of realizing the aims of education.

Subjects have their raison d'être in relation to time (history) and place (geography). The basic content subjects of the school curriculum, therefore, are geography and history. Other content subjects, however, have been recognized for the purpose of accomplishing specific aims; and, in addition, certain subjects, as writing, reading, spelling, and arithmetic, have been organized for the purpose of securing definite habits and skills. 
History and geography offer the opportunity for the securing of situations out of which the need for a mastery of the formal subjects may arise. It is evident, then, that while other subjects will react on geography and history in a helpful way, the motive for interpreting geography may be found in the situations of these subjects, while the significant motive for the mastery of the tool subjects is to be found in the need of mastering certain drills and skills in order that the product may be more efficiently and quickly used in the interpretation of content situations. Geography and history may be used in an important way in assisting the teacher to make the drill subjects worth while and purposeful. In a minor way the drill subjects may arouse an interest in the content subjects. One does not naturally interpret a life situation, however, in order that one may learn how to read, write, and calculate, but one engages in drills in order that the situations of life may be met more readily and effectively.

Geography and real life situations. The suggested relation between tool and content subjects is based on the assumption that the topics selected for detailed study in the content subjects represent natural situations. If geography is taught as an academic subject, the need for the subject, in turn, arises out of life situations. If life situations with a lominantly geographical basis are selected for the geography course, and if the content of other subjects is incidentally drawn on to illuminate the situation, the need for the subject is found in the topics themselves. To the extent that geography emphasizes only the physical background at the relative expense of correlative social relations, the justification of the subject is found 
in the study of the geography topic as a part of the complete unit of work. Under these conditions it is not the drill subjects but the more comprehensive real life situation that will furnish the relational interpretation that makes academic geography meaningful. The present tendency, as indicated elsewhere, is to select topics with a strong geographical element and to study them as complete units rather than to select topics for a one-sided geographical interpretation.

Geography and the tool subjects. ( I) Reading. The teacher understands the importance of incorporating into the reading lesson ideas that are related to the child's interests and experiences. She draws on literature, history, civics, and geography. Since the child has become acquainted on the functional side with the wants and needs of man, - food, clothing, shelter, fuel, light, luxuries, and transportation, - reading material based on these experiences is utilized. The child has a keen interest in children and their activities. Many of the selections, therefore, are based on activities not only characteristic of our own children but also of children of other lands. The teacher of geography, while incidentally interested in any geographical ideas aroused in connection with reading, is fundamentally interested in the pupil's reading skill as a basis for the unlocking of the great storehouse of geographical material found in books, newspapers, and magazines. The extensive reading involved in the study of geography is invaluable in enlarging the child's reading vocabulary.

(2) Spelling. The teacher, if her spelling period is to yield the best returns, will attempt to secure words that 
are used in other subjects. The geography course offers a special opportunity to secure numerous words both of a special and general nature. The geography teacher is interested in correct spelling in connection with the child's written expression of ideas. To the extent that the pupil is unable to spell words needed in geography, the teacher assists by placing the words on the board. The list of words gradually secured in this way is sometimes used for drill work during the spelling period.

(3) Writing. The teacher of writing, in securing words, expressions, and sentences in which the child has an interest, may draw on geographical experience. The geography teacher may assist the writing teacher by insisting that pupils shall write neatly and legibly. Unless a pupil is held to a high standard of written self-expression in other subjects he will tend to discount the value of either spelling or writing. The geography teacher is keenly interested in the ability of the child to express himself in a clear, legible hand.

(4) English. In every subject correct written or oral English should be stressed. The geography teacher should be interested both in the content and in language as a medium of expression. The geography content, however, rather than the English form, will receive the major emphasis. Too much attention to the form may retard freerlom of expression. It may be desirable, therefore, to note some of the more common mistakes, to which special attention may be given in the English lesson. After the mistakes have been analyzed, the teacher of other subjects should assist in breaking up the undesirable habits. Geography material may be used by the 
Engiish teacher as a means of enlarging the vocabulary, improving the organization, and correcting wrong habits. Any geography contribution of the English teacher, however, is incidental; language improvement as a basis for expression is fundamental.

(5) Arithmetic. The arithmetic teacher no longer believes that a well-graded series of problems is sufficient. He recognizes the desirability of organizing his problems about life situations. The pupil's work is more highly motivated because he thinks of arithmetic not merely as a drill subject but as a means of developing an arithmetical point of view in relation to life situations. Arithmetic, functioning as a subject in relation to human problems, tends to become more assuredly a part of the usable knowledge of the student. Geography, concerned with the adjustments of man to natural resources, offers unusual opportunities, hitherto but little recognized, for the selection and grouping of such problems about geography centers.

The Wentworth-Smith School Arithmetics (Ginn and Company) illustrate admirably the combination of careful grading and worth-while problems drawn from life situations. Geographical problems, illustrating the close relations of arithmetic and geography, have been included.

In the chapter entitled "Introduction to Percentage" ("School Arithmetic, Advanced Book," p. r39) is a page of "Problems about Geography," including such problems as the following:

The area of Illinois is $56,600 \mathrm{sq}$. mi. approximately. Of this ${ }_{3} \%$ is underlain with coal beds. How many square miles of coal lands are there in the state? 
The area of the United States is 3,600,000 sq. mi. approximately, and of this about $7 \frac{1}{2} \%$ is in Texas and about $3.4 \%$ is in New Mexico. Find the approximate number of square miles in each of these states.

It will be noted that these problems not only teach percentage but convey correct geographical impressions. Thus the first problem emphasizes the abundant coal supply of Illinois, which contributes so much to the industrial development of the state, and the second compares the relative sizes of Texas and New Mexico both by per cents and by areas.

In teaching graphs we find such problems as the following (p. 382):

The population of the earth by continents in millions is approximately as follows: Africa, I43; North America, I40; South America, 56; Asia, 873; Australasia, I6; Europe, 465. Draw a graph representing these facts.

By the time the student has completed the graph called for in the problem he will have an effective conception of the distribution of population.

In other parts of the same book the products of certain sections of the country are emphasized. Thus in a group of problems on "Shipping Fruit" (p. I77) we have the following:

The standard Florida orange box for shipping is 12 in. by I 2 in. by $26 \%$ in. How many cubic inches does it contain?

In shipping Georgia peaches a crate 8 in. by $12 \frac{1}{2} \mathrm{in}$. by 22 in. is used. This contains how much more than I bu.?

The geography teacher is eager that the child shall have the ability to express himself in an arithmetical way. 
The development of arithmetical skill in relation to geographical material enables the pupil, with a minimum of effort, to apply his skill in the interpretation of geographical situations. The geography and arithmetic teachers are mutually helpful. If the arithmetic pupil needs a geographical background, the arithmetic teacher gives him the slight amount required, the dominant viewpoint being arithmetical. If the pupil has already secured the necessary geographical background, the arithmetic teacher eagerly relates his work to the geographical material. In the first instance the pupil's initial grasp of geography may be given by the arithmetic teacher; in the second instance the value of the geography work is incidentally impressed on the individual because of the use to which it is put in arithmetic.

Content subjects. (I) History. As long as history was largely a mere chronological account of the significant happenings, geography was not drawn upon in an important way. With a shift in emphasis to the interpretation of historic events, geography has been levied upon heavily. The inequalities in the distribution of nature's resources -differences in climate, in topography, and in soils-have influenced groups of people differently. The opposed attitude of the North and the South toward slavery was largely a reflection of a contrast in climatic conditions, the resultant products of which made slavery profitable in the South but unprofitable in the North. The preclominance of manufacturing in New England has caused this section to favor a high protective tariff. The presence of gold in California hastened the settlement of the Pacific coast. The presence of the Appalachian barrier 
kept the colonies concentrated along the Atlantic seaboard until their strength was sufficient for larger conquests. The streams, forests, and prairies influenced the development of America. Every military campaign or battle becomes meaningful if interpreted in terms of topography, climate, and resources.

In a corresponding way the geography teacher makes use of history. An interpretation of a geographical situation is often inadequately presented unless, in addition to the influence of the physical environment, the past events bearing on the situation are also considered. A geographical discussion of the development of a modern city, as New York, may be interpreted in a strictly geographical way, but the topic is grasped more effectively if the historical perspective of development is included. Among other topics similarly in need of history may be noted ( I) transportation by river, canal, and rail, and (2) economic production, as orange growing in California and the raising of Egyptian cotton in the Imperial Valley. The discussion of the geography of a country, as Mexico, is one-sided from a unit standpoint unless the historical explanation of the present unsatisfactory development is included. A consideration of numerous topics of the new Europe-for example, the poverty of present Austria, the dying of Vienna, and the aspirations of the Polesrequires a historical perspective. As long as history is regarded as a sturly of the relations of peoples and their progress, and geography is regarded as a study of the interacting relations of man and the physical environment, the two subjects will be fundamentally helpful to each other, but neither will be absorbed by the other. 
(2) Literature. Literature becomes tinged with a deeper meaning if the geographical background is properly developed. If the selection is a true account or has a basis in fact, geography may aid literature much as it assists history. Even though the selection is a construction of the imagination, an understanding of the physical factors involved - whether some aspect of nature, products, or places - will add to the appreciation. In reënforcing the geographical discussions the geography teacher may select pieces of literature in which the geographical factors are intimately involved. Geography, however, has much more to contribute to literature than literature has to contribute to geography.

Maintaining the geographical viewpoint. Each subject represents an outlook over the great field of human knowledge. An attempt is made to develop the arithmetical outlook, the geographical outlook, and the historical outlook. The geography teacher has a definite responsibility in developing the geographical outlook, but, as has been noted, this outlook can be adequately developed only by relating the geography work to other subjects. If the teacher permits the assisting subject to become predominant, however worthy the material under discussion may be, she is lost. It is the business of the geography teacher to find in the field of geography worth-while material for discussion. She is interested in developing the individual through the subject of geography, the other subjects incidentally contributing. Through the appropriate use of geographical material the teacher may hope to arouse the pupil's interests in geography in relation to the development of corresponding interests in other subjects. 


\section{Suggestions for Further Study:}

1. (a) List some topic in geography and indicate how an adequate discussion of the topic may requize the assistance of other subjects, and $(b)$ list topics in other subjects that may be illuminated through the use of the geography learned in the discussion of the topic.

2. Which of the school subjects can be most helpfully related to geography? Give reasons for your selection.

3. List a geographical topic and show how, through a discussion, the class may gradually digress until the discussion has become a part of another subject. Suggest how the teacher, if digression is threatened, may keep the class in the field of geography.

4. Select a topic and show that it may be considered from $(a)$ a geographical viewpoint, $(b)$ a historical viewpoint, $(c)$ an arithmetical viewpoint, and $(d)$ a language viewpoint.

\section{Selected References:}

Anmstrosic, T. H. "Relation of Geography to the Other Studies in the Elementary Course of Study," Education (1903), Vol. Xxili, pp. 331-336.

Chamberlaix, Jamfs F. "Literary Selections as an Aid in Teaching Cieography," Joumal of Geograthly (Ig16), Vol. XV, pp. $9-16$.

CockBrkx. Sh Jom:. "Geography as a Correlating Center," Fiducational Foundations (1904), p. 193.

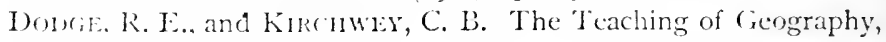
chap. vii. pp. $98-111$.

Entrsox. 1'mulp. "I'rimary Gengraphy and Reading," Joumal

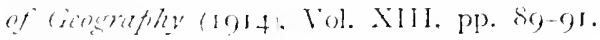

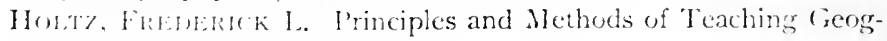
raphy, chap. xxi. pp. $273-289$.

Makivifr, II. J. "Irevelopment of Geography out of Nature

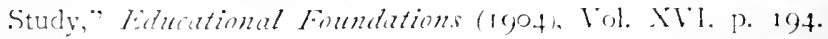

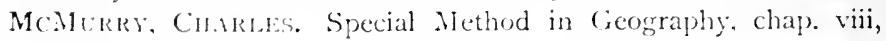
Pp. $117-12 \%$.

Sutherlakn, Whimu J. The Teaching of (ieography, chap. iv, pp. 52-6/3: chap. v, pp. 63-8o. 


\section{CHAPTER IV}

\section{THE EVOLUTION OF GEOGRAPHY METHOD}

Status of geography method before the World War. For some years before the outbreak of the World War lecturers had frequently spoken of the "new geography." The leaders of geographical thought had already noted the shortcomings of descriptive geography, of fact geography, and of place geography. The emphasis had been shifted to relational and interpretative geography. Mere description of the location, area, topography, soils, and climate of a region was insufficient. The "new geography" involved an interpretation of the relations that man sustained with his environment. The facts of geography were still necessary, and a good memory remained a valuable human asset, but information was related to interpretation.

The "old geography" had been organized according to a standard outline: (1) location, (2) area, (3) topography, (4) climate, (5) life forms, and (6) human activities. Any area under discussion was ordinarily developed with the aid of this outline or some similar outline. With the shifting of emphasis from informational to interpretative geography, as represented by the "new geography," the standard outline was retained, and an endeavor was made to ascertain the influence of each physical factor upon human activities. The retention of the standard-outline organization of physical factors is readily understood 
when it is remembered that geography in this country has secured its impetus in large part from teachers of natural sciences, particularly geologists. At the outbreak of the World War the old topical outline of place and description had been vitalized by relating these topics in a meaningful way to mankind.

Status of geography method during the World War. With the outbreak of the World War the people of the United States became much interested in the European situation. As the United States was gradually drawn into the struggle this interest was intensified. The entire resources of our country were marshaled in an endeavor to preserve American ideals. Every institution of society was called upon to do its appropriate work. In the great battle of nations the schools proved their sterling worth. The children were called upon to sell liberty bonds, to buy thrift stamps, to collect waste materials, to knit clothing, and to arrange patriotic programs. In every instance they responded whole-heartedly.

The war not only appealed to social instincts and interests, but it directly affected practically every member of the social group. Interrupted production and the diversion of large quantities of materials for war purposes helped to increase prices. In many instances an actual shortage of products for home consumption, as sugar and coal, brought the war very close to the firesides of the American people; consequently the war profoundly affected both the social and the individual lives of men, women, and children. The school problems growing out of the war were closely related to the social organization, on the one hand, and to the lives of the children on 
the other hand. Why was the work of the children done so quickly and so effectively? Because the children had an opportunity to do something that would really count. Their activities were directed by the dominating purpose of realizing an aim that to them seemed worth while. They were finding worth-while situations in the world's activities. Because of the spontaneous response of the children, the World War brought vividly before the teachers the increased efficiency that can be secured if the school work is related closely to the child's interests and experiences. In other words, the World War strikingly illustrated the value of motivated work.

The readjustment of the local economic field resulting in the curtailment of certain industries, as brickmaking, and resulting in the enlargement of certain industries whose products contributed directly toward the winning of the war called the attention of the residents to the nature of the home industries and brought into prominence the raw materials upon which these industries depended. The intense interest in local affairs aroused a further interest in the related national and international affairs. Home geography was emphasized more than ever because of the social situation which demanded it. The teachers, recognizing the value of local materials intrinsically and as a basis for the interpretation of the far-away, inspected local topographic features and industries and discussel local problems. As a result of the World War, therefore, local geography was amplified and, in the discussion of world problems, illustrations were drawn from the home field whenever this was possible. More carefully than ever before, the teacher related the experiences 
of the child, secured from his immediate environment, to the problems of the distant regions.

The numerous problems that came up in connection with the war were studied in their natural setting. The war arose out of a difference of ideals among the social groups. The attention of the world, therefore, was drawn first of all to social groups, the various peoples at war, the armies and navies. It was soon seen that the social structure was fundamentally based upon a physical background, particularly the plant, animal, and mineral resources and the transportation facilities. The economic resources of the earth loomed into fateful significance. It was realized as never before that the resources of the earth are unequally distributed and that the increasing needs and wants of man were being supplied only through the wonderful transportation system that had been developed, reaching to all parts of the world. The distribution and nature of the earth resources, the means of increasing production, the redistribution of resources so as to serve the Allies in the most effective fashion, were some of the big subjects that came up for discussion. While the physical background was brought into prominence, it will be noted that the approach to the physical background came from the social side. The problems that arose during the World War, therefore, expressed the needs of the social group, and all physical factors that had a bearing on the problem entered into the discussions. With the thorough motivation of problems, the approach was from the social rather than from the physical viewpoint.

The use of maps and globes had long been recommended for geography classes. In many schools, however, 
these symbols were more or less indifferently used. During the war the interest of people in various parts of the world caused them to make a liberal use of maps and globes in locating places and in discovering the conditions of climate, relief, and drainage that affected activities. This demand was noticeable in the homes as well as in the schools. More map equipment was purchased for the schools, and dust-covered atlases were resurrected from their obscure places. Real, vital problems, which could best be answered with the aid of maps, stimulated both teacher and pupils to use them frequently. As a result, geography teaching was improved through the use of more effective tools in the consideration of problems.

Before the war the tendency had been to consider any well-defined geographical influences, whether these influences were of slight or of fundamental significance. In the life-and-death struggle of a nation the more important problems naturally will become prominent, while incidental problems will scarcely be given passing notice. The problems that were discussed by the social group, in general, were very vital. When Constantinople was being attacked, it was not a peculiar custom of the Mohammedans that was being discussed, but the difficulties involved in capturing the city and the significance of this city, if captured, to the Allies. In the consideration of various regions, therefore, the more significant problems were brought out in detail, while the less significant physical influences were ignored.

Status of geography method after the World War. With the termination of the war the demands of other institutions upon the schools rapidly diminished, although 
the worth of the schools in helping to solve the social problems had been conclusively demonstrated. At the time that the need of other institutions for direct assistance of the schools was acute, the ready response of the pupils proved that the schools also needed the assistance of out-of-school forces. It remains yet to be proved that the problems of peace may be made just as appealing as the problems of war. Teachers have been taught a lesson, and they are eagerly scanning the newspapers for vital, appealing current events and are making an important use of local industries and topographic forms and processes.

Teachers are no longer insisting that a standardized outline should be used in the teaching of the various countries. They are seeking earnestly for the more significant problems of each area and are leaving the unimportant details for more advanced study. The trained geographer can help the teachers by making a special study of the content of geography for every part of the world and by selecting the more important problems for an elaborate development without reference to an encyclopedic inclusion of all facts that have been included to satisfy the demands of the standardized outline. The teacher will make a special study of the geographic problems that the geographer considers of primary importance and will make a special study of the interests and experiences of children with the purpose of causing the problems to arise out of natural situations of the child's life. It is the duty of the geographer to indicate the geographic problems that are of greatest worth to society, and it is the business of the teacher to find some means of getting 
the child to adopt these problems as his own personal problems, to be solved through his initiative.

Evolution of geographic method. In the preceding discussion it has been indicated (I) that until about the close of the last century the subject of geography consisted largely of description and location; (2) that the various countries were studied according to a standardized outline; (3) that this standardized outline approached the study of an area from the physical standpoint; (4) that when informational geography was supplemented with interpretative geography the same standardized outline was retained. The process of pedagogical evolution was hastened by the advent of the World War, so that ( $\mathrm{r}$ ) more attention was given to the effective motivation of problems; (2) the more significant problems of each region were selected for careful study; (3) the problems were approached from the social rather than from the physical standpoint; (4) the special symbols of geography, the map and the globe, were effectively used; and (5) local geography received much emphasis. With the termination of the war the teachers have attempted to retain the advantages that the war has unquestionably brought. Many of these advantages, it is believed, can be retained through the use of the problem method.

The problem. The areal unit under consideration may be Poland. The significance of motivation may be indicated in the various types of assignments that may be made. Poland may be studied systematically according to a standardized outline, by topics, or each topic may be stated in the form of an interpretative problem. 
The status of Poland in the world affairs of today may be roted, and the chief problems of immediate concern to the world may be studied. A problem of considerable interest is "Is it probable that Poland will become a great European power?" The technic of the teacher enters into the assignment in an important way: ( 1 ) she may simply assign the problem for study; (2) she may discuss the partition of Poland, the aspirations of the Poles, and the factors leading to the recognition of Poland, and thus seek to arouse an interest in Poland. This discussion may precede or succeed the statement of the problem. Preferably the introductory material should precede the statement of the problem, which should arise out of the interests and experiences of the child appealed to in the introductory discussion.

After the problem is raised and concisely stated, the degree of enthusiasm with which it will be attacked will depend upon the feeling of worth-whileness of the problem that has been aroused in the initial discussion and upon the more or less urgent appeal of other problems that the pupil may have. When the problem has been properly aroused in the minds of the children, the next step involves the securing of material that has a probable bearing on the problem. This material is carefully studied in relation to the problem. In a discussion of the Polish problem such topics as the following will be discusserl: the effects of location, with reference to the sea, to friendly or unfriendly nations, to the chief land routes of Europe; the possibilities of friction with adljoining nations due to boundary lines not physically well defined, economic jealousies, political ambitions, and vaguely 
defined ethnographic boundaries; the resources of the country-(I) minerals, particularly coal and iron, (2) agricultural products and conditioning factors, such as temperature, precipitation, soils, and drainage, (3) pastoral products, with respect to their significance in rugged regions, and the place of live stock in diversified agriculture, (4) products of the forests, (5) the development of transportation facilities as affected by topography and economic needs, (6) the surplus resources and their disposition, (7) needed products which must be imported, (8) the importance of the manufacturing industries, and (9) the possibilities of developing latent resources and of increasing the value of manufactured products; the physical and economic factors encouraging or discouraging political stability; stimulus of the physical environment, particularly climate, directly upon the people; and the character of the people as developed historically under the influence of the physical environment.

In the handling of topics over which the public is thoroughly aroused, considerable skill is required on the part of the teacher. In the school of yesterday modern problems of a really vital nature were scarcely discussed because it was recognized that such problems were full of social gunpowder. We are coming to believe that vital problems should be discussed. and we are coming to jurlge a teacher, in part. by the skill she shows in developing all parts of a problem, in securing a free and easy discussion on the part of the children, in getting them, although perhaps disagreeing, to respect the opinions of each other, and in teaching them how to discuss conscientiously problems over which there may be serious 
disagreement and yet to continue to dwell together in brotherly love and in harmony.

After the problem has been thoroughly discussed, conclusions should be reached or the material summarized. If adults are divided over the proper solution of the problem, it is better to encourage each child to come to his : own personal conclusion, but he should be required to summarize the material in such a way as to indicate that reason as well as feeling enters into the result.

\section{Suggestions for Further Study:}

1. Select some country and contrast the treatment that was given it some years ago with the best possible presentation according to the light of modern pedagogy.

2. Is the author justified in taking the World War as a pivot for the discussion of geographic progress?

3. Is it probable that substantial progress in the teaching of geography would have been made if the World War had not occurred?

4. What relation may be established between the evolution of geographic knowledge and the evolution of geographic method?

5. Along what lines should investigators work with the view of improving further the teaching of geography?

Selected References:

AtwoOn, Wallace W. "Geography in America," Geographical liericu (1919). Vol. VII, pp. 36-43.

Bruninan, A. I'. "Geography and the War," Joumal of Geografhy (1920), Vol. XIX, pp. 89-102.

BRow, Robert M. "Ceography in Practice and in Theory," Eduational lieriere, Vol. IV, p. 30.

Goond, J. PACl. "What the War should do for our Methods in Geography," Sichool and Society (1919), Vol. IX, pp. 459-462. 


\section{EVOLUTION OF GEOGRAPHY METHOD 6r}

Miller, Grorge J. "National Council of Geography Teachers," Journal of Geography (1920), Vol. XIX, pp. 69-76.

Phillips, C. A. "Development of Methods of Teaching Modern Geography," Elementary School Teacher, Vol. X, pp. 427-515. Potter, JefFerson R. "History of the Methods of Instruction in Geography," Pedagogical Seminary" (I 89I), Vol. I, pp. +1 5-424. Rooper, T. G. "Methods of Teaching Geography," Joumal of Geography (1902), Vol. I, pp. 70-76.

Thomas, Olive J. "Development and Present Organization of Elementary School Geography in the United States," Journal of Geography (I9I 7), Vol. XV, pp. 21 3-221.

Wisship, A. E. "From Absurd to Beautiful Books," Journal of Eduction (1909), Vol. LXIX, pp. 674-676. 


\section{CHAPTER V}

\section{AIMS OR PURPOSES IN THE TEACHING OF GEOGRAPHY}

Agreement with the general aims of education. Since geography is one of the subjects through the teaching of which the desirable development of the child is effected, geographical aims must be in harmony with the general aims of education. Through education the individual learns how to adjust himself to his physical and social environment for the common welfare. Through the many processes of adjustment and readjustment he secures the finest kind of training in citizenship. The importance of training the pupil not only to adjust himself to existing conditions, but also to interpret existing conditions with the view of improving them, is keenly recognized in our progressive schools. If the general aims of education are adequately realized, geography, taught from the modern viewpoint, inevitably is strongly emphasized.

\section{VIEWS OF EDUCATORS CONCERNING THE AIMS OF GEOGRAPHY TEACHING}

Usable geographical knowledge. The desirability of acquainting the child with usable geographical knowledge is suggested in the following statement of R. E. Dodge and C. B. Kirchwey: ${ }^{1}$

${ }^{1}$ The Teaching of Geography, p. 8. 
The decision as to what should be included in a school course in geography, then, depends on our understanding of what we would like a pupil to gain from his elementary-school study of geography. The desired result may be considered under two heads: first, knowledge of geographic facts and principles; and second, power to use that knowledge in daily life both during the school years and afterwards.

Enlightened outlook on the world. Geography should give the student a comprehensive view of man's relations to the earth.

The purpose of geographical teaching may be defined as the acquisition by the pupil of a familiarity with the working of geographical principles in concrete cases, and the creation of a more enlightened outlook on other peoples and on certain classes of public events. ${ }^{1}$

Practical and cultural aims. Professor F. L. Holtz ${ }^{2}$ classifies the aims as practical and cultural. Under practical values he states that ( $\mathbf{r}$ ) geography teaches place relations that may be used in daily life; (2) the commercial and manufacturing world depends upon geographical information; (3) geography teaches us about our own country and also about foreign countries, which are but complements of home geography; (4) national and international sympathies are broadened; (5) geographical allusions in current reading material may be more readily understood and appreciated; and (6) ability to use geographical material in after-school days is given. Under cultural aims he states that ( $\mathrm{r}$ ) geogiaphy contributes to the enjoyment of the natural elements and forces, the

1 Archer, Lewis, and Chapman, The Teaching of Geography, p. 7.

2 Principles and Methods of Teaching Geography, pp. I-5. 
beauty of scenery, and the ways of life of the people, both in our local walks and in more extended travels; (2) the subject is intrinsically very interesting; (3) geography as a discipline tends to establish certain habits of thinking, a geographical method of looking at the relations of the earth and man.

Gcographical adjustment. Professor Sutherland has stated $^{1}$ that (I) geography should assist in adjusting the pupil to his physiographic, economic, social, and political environment; (2) geography has much practical value; (3) geography should be studied as "the only true basis for the study of natural science"; (4) the cultural value of geography is very evident. "Many students of geography assert that there is no subject that has done more to broaden their intellectual outlook and to deepen their appreciation of nature and life generally than has the study of geography."

Knowledge of peoples and countries with adequate interpretations. A broad acquaintanceship with numerous groups of people will be helpful in maintaining desirable social relations.

Let us grant that many a man is earning a living and is getting a good deal of satisfaction out of life, and doing both on a very limited knowledge of geography. Men have become millionaires and presidents who did not know whether St. Rociue is a cape or a river, and the man who invented the roller process of making flour may not have known the "leading five wheat-growing states of the Union." Yet this and a great deal more may be granted without altering the general truth that geographical knowledge is a good thing and a useful

${ }^{1}$ William J. Sutherland, The Teaching of Gcography, pp. 80-93. 
thing; that it makes our reading more satisfying, our conversation more intelligent, our minds more broad, our sympathies more cosmopolitan, and our citizenship more enlightened. . . .

If taught with much field work, geography trains the powers of observation; if taught with much map drawing, it trains the eye and hand; if taught as it was in my country-school days, it trains the memory. All of these are legitimate, all deserve some degree of emphasis, yet the study of geography is not a device or an invention for accomplishing even these worthy ends of training the observation, the eye, the hand, or the memory.

Without intending in the least to minimize the importance of training the powers of observation or imagination or the powers of eye and hand and memory, I am still convinced that geography has it own mission in the school. That mission is to give the broadest possible knowledge of peoples and countries, their cities, their industries, their achievements, and all that goes to make them strong or weak, leaders or followers among the nations of the earth; and the principal reasons why these things are as they are. ${ }^{1}$

Mcthod aims versus content aims. The teacher may stress the various ways in which results are secured, or she may stress the content with slight reference to method.

Teachers of one group believe that the object of the study of gcography is the acquisition of a certain mass of definite, organized material, useful in its application in later student life. Teachers of the other, realizing the impossibility of the pupils' acquiring in a few years an encyclopedic mass of material which shall always be equal to the demand upon it, hold that the purpose of geography teaching is to arouse in the pupil a desire to follow out each geographic lead to its logical

'R. H. Whitbeck, "Ideals and Aims in Elementary Geography," Journal of Geography (1915), Vol. Xil, pp. 69-70. 
end, to teach him where to seek geographic information and how to use it, and to create in him an interest in all things geographic,- to give him, in short, a working knowledge of geography. ${ }^{1}$

Training and cultural values. Geography should impart an ability to adjust one's life to the opportunities presented.

To sum up: Through the study of geography we may direct the student to current periodicals and newspapers of a good class, we may stimulate them to read books of travel and description and arouse a desire to travel, and at the same time we may train them into library habits. We may lead them to respect labor, to appreciate beauty in nature, and to an ethical point of view in the social phase of the study of the great commercial products. ${ }^{2}$

Brotherhood of man. The dependence of men, in common, upon the resources of the earth should form the basis for a universal brotherhood.

The fact that other people believe themselves the "chosen ones of God," and act upon this belief, in no way atones for our $\sin$ in this direction. We should be held responsible for our acts, and unless the belief in the brotherhood of man becomes a conviction instead of a platitude, race war is inevitable. Race prejudice must be eliminated in order to avoid this awful calamity. In perplexity we turn to the school for help. Here we find that the geography teacher more than any other has the opportunity of erasing race prejudices. This is because geography is the only subject that brings one into

${ }^{1}$ Jane Perry Cook, "Primary Aims in Geography Teaching in the Grammar Grades," Journal of Geography (IqI), Vol. IX, p. 203.

2 Bertha Henderson, "The Cultural and the Training Value of Geography," Journal of Geography, Vol. XIV, pp. 100-IOI. 
contact with all the living peoples of the world. . . In order that the student may learn to emphasize the best natural qualities of others as readily as he is wont to emphasize those of his own people, care must be taken to stress the greatest achievements and best characteristics of all foreign peoples studied. ${ }^{1}$

The following quotation from a paper by J. Russell Smith" suggests that an inadequate emphasis upon the "brotherhood of man" in the teaching of geography may have been a factor that caused the Germans recklessly to plunge the world into a terrible struggle:

Germany is self-centered. The courses in history begin and end with Germany and give very little attention to any other country. The method of instruction seems to savor strongly of the imperial idea, with militant Germany as a unified and central figure. History is a tool to excite patriotism, and geography, by its great emphasis on Germany, is in some measure her sister. One result is a surprising ignorance of foreign countries, and America is no exception.

Esthetic cnjoyment. The study of geography should lead to a deep appreciation of the beauties of nature.

Every land has its beauties of form, impressive, appealing and beyond human understanding or complete appreciation. If they be analyzed into their parts from a purely artistic standpoint, like the curves of ancient architecture, they have an artistic force that is striking. If they be viewed as wholes and behind the forms there be seen in suggestion the long life history that each form may reveal in a fragmentary way

'Zonia Baber, "Lost Opportunities in the Teaching of Geography," Journal of Geography (1916), Vol. XIV, p. 207.

" "Geography in Germany," Journal of Geography (IgI2), Vol. I, p. 430 . 
to the sympathetic and understanding inquirer, they offer a source of pleasure, joy, and profit to all.

To know one's landscape, to feel in sympathy with it, is often to be at peace with life. When all the world seems wrong and the burdens overwhelming, he who can look out on the familiar fields and hills or get among them and give way to their beauties of form and color has a resource within himself that will be an ever-present power of recuperation. ${ }^{1}$

Aims noted in the St. Louis School Survey. ${ }^{2}$ The subcommittee on the course of study in geography agreed that the following results should be secured in the teaching of geography in the elementary schools:

I. Vocational understanding. They express the judgment that geography is of direct and immediate technical vocational service for only a few occupations, but that it is of immeasurable service for developing that general occupational intelligence necessary on the part of all within a democracy for the purpose of general supervision, through public opinion, of the various constituent social groups: manufacturing, commercial, mining, agricultural, and other industrial groups. They also refer to the value of geography to those who consume the products of the multitude of occupational groups.

2. Social and civic understanding. The subject has, further, the all-important task of developing an understanding and appreciation of the interdependencies existing among individuals and social groups of every type. "The teaching," they say. "should cultivate sympathy with others whose needs, resources, efforts, and feelings are like our own. Prejurlices grow out of ignorance and are best removed by understanding."

${ }^{1}$ R. E. Dondee, "An Fsthetic Side of Geography," Journul of Geography (1015), Vol. XiIl, p. 305.

"Survey of the St. Lrouis Public Schorls, Board of Education of St. Louis (19I7), pp. 91-92. 
3. They refer to the enrichment of consciousness through giving one a vision of the geographical environment that is as wide as the world itself. It is to give him intellectually, socially, and otherwise a world that is bounded not by the narrow visible horizon of the region where he dwells, but which is bounded by a world horizon. Familiar thus with multitudes of things and relations, his consciousness is not only liberalized, but he is given the very practical power of adaptability to conditions wherever he may find himself.

4. The committee also refers to conventional values-knowledge of gcographical facts that people are supposed to know just because the schools have been in the habit of teaching them. The positive program of the committee naturally negatives this criterion. They show their negative attitude toward it particularly as they draw up the program of work. The minima of place geography are relatively brief and include practically nothing beyond what people need to know in that general geographical orientation indicated by the committce in the three purposes above enumerated. The list of minimum essentials omits hundreds of place names that for most people have no value beyond the conventional one.

5. The committee refers to certain other general types of results of the subjective "mental discipline" character. It is not possible to judge the extent to which these subjective aims influenced the committee in its choice of geographical subject matter. The first three of the aims just mentioned are the ones that are most fruitful and appear to be the ones at least chiefly in the minds of the committee in their work.

The teaching of geography should impart the more important facts of conventional or practical value, should secure on the part of the pupil ability to interpret properly the geographical factors that enter into problems of timely moment, and should develop an appreciation of 
the importance of the United States intrinsically and in its relational aspects to the world as a whole. The realization of these aims requires not only that the teacher shall relate the child to the necessary geography content but that she shall present this material in approved ways. The teacher who would succeed in the teaching of geography, therefore, must have an adequate mastery of both content and method.

Immediate aims. In order that the general aims shall be realized, it is necessary that a teacher shall set up specific aims that she wishes to realize through each geographical unit of work. The immediate aims should be definite. These aims may involve (I) certain facts, (2) the interpretation of facts, (3) the ability to use knowledge in a new situation, and (4) the establishment of ideals. Many of the weaknesses in the teaching of geography can be traced to the lack of definiteness in teaching a unit of work. The teacher agrees with the general aims, but does not sufficiently analyze her work to insure that she has certain immediate objectives leading in the direction of the generalized aims.

Suggestions for Further Study:

1. Select the aim that you consider of greatest significance and give reasons for your selection.

2. What relation should exist between cultural and practical aims? Are the two groups of aims incompatible in the same situation?

3. Select a geographical topic and indicate the immediate aims that you would hope to realize, and note the relation of these immeciate aims to the seneral aims in teaching gcography. 
4. Indicate how you would expect to realize the aims noted in exercise 3 .

5. What is the value of well-defined aims?

6. Indicate how the aim of the teacher and the aim of the pupil in relation to the same unit of work may be different.

\section{Selected References:}

Aldex, Nellie B. "Power versus Knowledge as the Aim in the Teaching of Geography," Journal of Education (I919), Vol. LXXX1., pp. 233-234.

BAbER, ZoNiA. "Lost Opportunities in Teaching Geography," Joumal of Gogmphy (1916), Vol. XIV, pp. 295-298.

Brigitam, A. P. "Present-Day Need for Geography," American Schoolmaster (I920), Vol. XIII, pp. 6I-63.

Cook, J. P. "Primary Aims in Geography Teaching in the Grammar Grades," Joumal of Geography (I9I I), Vol. IX, pp. 203-208. Donge, R. E. "The Asthetic Side of Geography, - Beauty in Landscape Forms," Journal of Geography (1915), Vol. XIII, pp. 302-305.

Greiory, W. M. "Symposium on what is most needed in the Teaching of Elementary Geography," Joumal of Geography, Vol. X, pp. 244-262.

Hendersox, Bertha. "Cultural and Training Value of Geography," Joumal of Geography (1915), Vol. XIV, pp. 97-10I. HoLTz, F. L. Principles and Methods of Teaching Geography, chap. i, pp. I-5.

Sutuerland, William. The Teaching of Geography, chap. vi, pp. So-95.

Wirtbeck, R. H. "Ideals and Aims in Elementary Geography," Journal of Geography (1915), Vol. XIV, pp. 65-70. 


$$
\text { , }
$$


PART TWO. THE COURSE OF STUDY 


\section{CHAPTER VI}

\section{THE ORGANIZATION OF A COURSE OF STUDY}

Requirements. A course of study in geography should be graded in such a way (I) that it is adapted to the child's interests and experiences, (2) that the work of the earlier grades is a preparation for the work of the later grades, (3) that the work of the earlier grades may be reviewed in a new view in the interpretation of uppergrade topics, and (4) that a child leaving school in any grade will have a fund of usable knowledge. There are four viewpoints that should be held in mind in the organization of a course of study: (I) local geography, (2) journey geography, (3) regional geography, and (4) world geography. Home geography emphasizes the environment immediately within reach of the child. Journey geography involves actual and imaginary journeys leading to a conception of the earth as a whole. Regional geography is an intensive study of the geography of a definitely defined region. World geography is a consideration of topics from a world-wide standpoint. These divisions of geography will be taken up in the grades in the order named.

Testing a course of study. A course of study should be theoretically sound. During the present period of experimentation emphasis is being placed on actual results secured under ordinary schoolroom conditions. It does 
not follow that all topics which "work" should be included in the geography curriculum. All topics selected, on the other hand, should "work" or be eliminated. A good teacher may succeed with a poorly selected topic, while a poor teacher may fail with a well-adapted topic. Empirical experiences need to be carefully evaluated and checked in the light of a sound theoretical organization. In the last analysis the theoretical and the practical course of study, the one reënforcing the other, should be harmonized.

\section{THE INFORMAL GEOGRAPHY WORK OF THE PRIMARY GRADES}

The meaning of pre-geography work. The study of geography as a distinct subject in the school curriculum is begun in the first grade in a few schools. In most instances, however, formal geography work is begun in the third or the fourth grade. The child, therefore, has had six to ten years of experience with a physical and social environment before taking up the study of geography as a subject. No need for the concept denoted by the word "geography" arises until the materials dealing with the study of the earth in relation to man are differentiated from the other phases of school work. The term "pregeography" includes those aspects of the child's experiences, whether accidentally or purposefully acquired, which constitute a foundational preparation for the study of formal geography.

The recognition of pre-geography work. It would be a tedious and difficult beginning for both teacher and 
pupil if the child, at the beginning of his formal geography work, had no conception of geographical materials. The teacher who does not systematically recognize this foundational work runs the risk of lingering over familiar material or of presenting material for the assimilation of which the child has had inadequate preparation. The teacher who carefully considers the pre-geography work of the child and who intelligently questions him to make sure that the assumed conceptions are present, and in order to recall the old as a basis of departure for the new, is establishing an ideal situation for substantial progress. It is constantly urged that the teacher should relate her work to the child's experiences. The danger of retarding development by repetition, by keeping the child on work with which he is thoroughly familiar, is just as acute. A proper understanding of the relation of the old to the new eliminates both dangers.

The acquisition of pre-geography knowledge. The child has secured his pre-geography knowledge in the home, at play, at school, and on various trips in the home community or elsewhere. On the basis of need he has modified his environment or adjusted himself to it. From the adult standpoint his knowledge is limited and simple. His problems, however, have been real, and perhaps for him just as difficult of solution as the more complex problems of the adult. He has never concerned himself with the systematic logical organization of his experiences nor with the purposeful acquisition of knowledge because it may be needed by and by. He worries little about the morrow, but meets each situation that arises in the way that seems best to him. 
Very seldom, if ever, is it the case that the pre-school life of the child is planned so that a series of successive, graded, relational situations will train toward a definite objective. During the earliest school life of the child no abrupt change in the accustomed way of learning is made. The child informally comes into contact with situations similar to those in his out-of-school life. There is this difference, however. Consciously on the part of the teacher, but unconsciously on the part of the child, the situations are systematically arranged in order of difficulty so as to bring about a continuous and persistent growth and development. In addition a simple organization of experiences is accomplished. No formal mention of the word "geography" has been made, although if the child knows the word "geography" he has not committed an unpardonable sin.

Formal geography an outgrowth of pre-geography. The pre-geography work has been accomplished, undifferentiated from other subjects, in relation to the child's needs. The materials are classified into subjects for convenience and for real or fancied economy of time in teaching. We take the child from an unorganized environment into the school life, where he is given intensive training. The transition is gradually effected from the informal to the formal teaching of geography.

\section{FIRST VIEWPOINT OF GEOGRAPHY}

Importance of the local environment. Should the pupil proceed from the study of the world as a whole to its parts or from a study of parts proceed synthetically to build up 
a concept of the world as a whole? The answer lies in an understanding of the law of apperception. Since the child is dependent on his immediate environment for an arousal of consciousness and increasing intensity of consciousness, the nature of his actual environment is very important. The early organized work of the geography teacher should deal particularly with the geographical material with which the child has become acquainted or with which he may be brought into first-hand contact. The teacher is concerned with the organization of the child's experiences from a geographical viewpoint and with the enriching and enlarging of these environmental experiences. Since many of the things with which the child is acquainted - as bananas, chocolate, and silk - have been secured from a distance and specially treated by man, the interest aroused in relation to environing things may be the means of introducing the child in an elementary way to the producing areas. A teacher should not select promiscuously from the child's past or present environment. There are many elements of an environment, even of an adult, that make no strong appeal. As is characteristic of the adult, the child is greatly stimulated by those factors of his environment that have some definite relation to his own life. Of particular concern to the child is the way his physical needs and wants are met. The geography work in the lower grades, consequently, is concerned primarily with the requirements of the home for food, clothing, shelter, light, fuel, and luxuries, and with the means taken to meet these requirements.

Interest in the child life of forcign lands. Not only are children interested in their own activities and relations, 
but they are also interested, through contrasts and comparisons, in the experiences of people, especially children, of other lands. The lower grades, therefore, should provide for a consideration of types of people in different environments. The human types that have been emphasized have been selected because of some dominant physical factor in the environment. In some instances several outstanding influences are related to the same group, as may be seen in the following classification:

Latitude

I. High : Eskimo, Laplander.

2. Intermediate: local type, as the St. Louis, Chicago, or Boston type.

3. Low: Negro, Amazon Indian, Filipino.

Altitude

I. Lowlands: Dutch.

2. Highlands: Swiss.

Rainfall

I. Desert: Arab

2. Hot, rainy lowlands: Negro, Amazon Indian.

Land mass

I. Coastal: English, Norwegians.

2. Interior: Russians.

Deserts

I. Hot: Arab.

2. Cold : Eskimo.

Contrasted cirilization

1. Occirlental: local type.

2. Oriental: Chinese, Japanese.

Historical contrasts

r. Present: local type.

2. l'ast: Indian. 
Each type is developed as a unit. In story form the children follow and live through the activities of the Eskimo child. Not only do they contrast Eskimo life with their own, but as the successive types are considered each type is also contrasted with the various types previously studied.

During the early period that the organizing centers for geography are found in the child's environment the teacher gives the child much practice in the direct observation of materials. The class makes an elementary study of available land forms and visits industrial plants where the processes and materials are sufficiently simple. Care is taken to avoid a complex environment which is too difficult or too far removed from the child's interests.

Diversity of materials emphasizcd. The first view of organized geography emphasizes the organization of and additional contact with the materials of the immediate environment and lightly touches on the producing areas. The local life is the big organizing center. The teacher depends largely on visualization material. Using the cotton garments of the children as a point of departure, the teacher may appeal to their curiosity to learn how the cotton garment came to be. The children are shown a cotton boll, the cotton is separated by them from the seeds, and the threads are woven into cloth. The child is not merely told the relation between raw cotton and wearing apparel, but actual materials are given him to handle. In tine absence of actual material the teacher depends on the picture, which is the symbolic material most nearly representing the cotton boll. The child has no adequate foundation for a detailed exhaustive study of any topic, 
but is securing, through the points of contact with a diversity of materials, numerous initial concepts that, through enrichment in the successive grades, will constitute a valuable nucleus for further development.

\section{SECOND VIEWPOINT OF GEOGRAPHY}

Building up a concept of the earth as a whole. The distant regions are now considered in relation to their dominant or outstanding characteristics. Cotton, which was considered in relation to clothing, is now considered in relation to a cotton plantation. The rather vague idea aroused concerning cotton production is now elaborated through a detailed type study. Similar detailed type studies are made of a tea plantation, a coffee plantation, a wheat farm, a stock farm, a diamond mine, a fruit farm, etc. Through the detailed study of widely distributed areas in relation to the production, manufacture, or handling of some article with which the child is acquainted, various parts of the earth gradually become meaningful to the child. An attempt is made to build up a general concept of the earth as a whole. The local area is the radiating nucleus for a consideration of remote areas.

Journey geography and type studies. The various areas shoulcl be definitely related to the home area as to direction, distance in miles and time, and land and water routes connecting the two areas. This will help the child to think of the area as a real area in which people are living and making desirable adjustments to the resources. The area will be thought of as a part of the earth as a whole, of which the home unit is another part. The child's interest in the remote area is aroused not only because of 
the products with which he is acquainted that originate therein but also through this relating of the far-away lands to his home region. Those who would emphasize this gradual upbuilding of a conception of the world as a whole, through relating the areas studied to the home region and to each other, have spoken of this work as "journey geography." Those who consider that the really significant thing is the detailed study of an important unit of work in widely distributed areas, and that the relating of the region studied is primarily a motivating step, through the realistic areal relations established, have spoken of this work as "type studies," or as studies of organizing centers. Whether one thinks of journey geography leading to type studies or of type studies approached through journey geography, the completed unit of work is essentially the same.

\section{THIRD VIEWPOINT OF GEOGRAPHY}

Regional geography. The next viewpoint of geography involves a systematic study of the regions of the earth. The children first consider their needs and wants, then they consider characteristic conditions under which the products to meet these needs and wants are produced. Their elementary acquaintance with different parts of the earth has prepared them for the advanced step of studying regional units. In the first viewpoint the emphasis was the immediate environment; in the second viewpoint the emphasis was a consideration of how the remote areas serve the local community, and an interest was aroused in widely distributed areas. The second viewpoint represents an easy transition from emphasis on the local 
environment to emphasis on the local environments of other groups of people, widely distributed.

Political units. For purposes of administration the land areas have been divided into unequal parts called political units. The boundaries, dependent in part on the unequal pressure exerted by contiguous groups of people, are in numerous instances artificial, dividing areas that geographically are one. For working purposes the political unit, whether city, county, state, or nation, is a coherent unit. Statistical data, collected by the governments, are ordinarily based on the political unit. In the preparation of geographic data, consequently, authors have found that the political unit can be more conveniently handled. The material presented, moreover, is organized in relation to a group with common political aspirations, and therefore a group whose interests, theoretically, are in common. The geographic units and parts of geographic units within the political unit are given special consideration. Frequently the parts of a geographic unit are not related adequately to the larger geographic unit, although this is a shortcoming that can readily be eliminated. This type of regional geography approaches the study of the region from the standpoint of the social organization in control and uses the activities of the people as a means of interpreting the physical background.

Natural regions or geographic provinces. It has been suggested that the earth should be divided into natural regions, or geographic provinces, as a basis for geographic study. In each region with a similar physical environment the people react characteristically. A political boundary line running athwart the region will not, in the 
long run, essentially modify the activities of the people on either side of the line. Whether the natural unit, therefore, is included in a country, or whether it is a part of several countries, because of the similarities in adjustments throughout the region it is argued that an economy in time is effected, that a more nearly accurate conception of life relations is given, that the material can be more desirably organized for presentation, and that the problem method of attack can be more readily used. Political boundaries may be sweepingly changed as a result of the vagaries of war; physical boundaries change very slowly.

The political units would not be neglected. The pupil would learn of their positions in relation to the physical background. Noting the regions and parts of natural regions included in the country, and having a conception of the characteristic adjustments in each province, the pupil is in a position to appreciate not only the resources of a particular country but also the extent to which these resources, through a division of provinces, are shared with adjacent countries. The study of geographic units does not bar the teacher from approaching or motivating the unit through a political area. The suggestion for the study of a natural region may come through the consideration of a country in which the region is contained or in which the region is characteristically represented.

Order in which to study regions. The order in which regions should be studied will depend, in part, on the location of the school. If the school is located in a great commercial and industrial center,-St. Louis, for example,a systematic study of the factors contributing to its location and development may be made. A general view of 
the United States suggests the location of this city toward the center of the great interior depression, to the east of which is the great eastern section and to the west of which is the great western section of the United States. The great interior depression will be divided into appropriate provinces for study, and through the close economic and social relations between this area and the eastern and western sections will be found approaches for a similar detailed study of the rest of the United States. The concepts developed in connection with the regional study of the United States form a basis for a rapid interpretation of geographic provinces elsewhere. The geography of the United States, in fact, becomes a measuring rod by means of which other regional units are quickly mastered. Perhaps the study of Europe is next approached through the historic, economic, social, political, and blood ties that relate the two areas. Since Europe has been the great modern colonizer, the other areas-Latin America, Asia, Africa, and Australia-are considered not only in relation to the United States but also in relation to Europe. Many teachers prefer to study South America immediately after the study of North America (I) because South America is a part of the New World and through the Monroe Doctrine has special relations with the United States, (2) because South America extends far enough southward from the equator so that the two continents together give all ranges of climates in both hemispheres and therefore a marked contrast of products, (3) because South America is in a relatively early state of development, and (4) because South America consists of large, simple geographical units. 


\section{FOURTH VIEWPOINT OF GEOGRAPHY}

An international breadth of view desirable. Through improved transportation facilities, and the consequent opportunity of moving commodities readily, the worldwide production of important articles tends to determine prices. Materials are redistributed in accordance with world-wide demands. The local community, moreover, is dependent on remote areas for many products, while the surplus of the local area may be transported to remote areas to satisfy a corresponding demand. As a climax to his geography course it is desirable, therefore, that the pupil shall secure a world-wide view of the more fundamental products, problems, and principles affecting man.

The world-wide production and consumption of each significant product-as wheat, corn, potatoes, sugar, coffee, cotton, cattle, hogs, sheep, coal, and iron-should be considered. Among other topics may be mentioned land and water distributions, climatic diversity, distribution of population, the trunk land and water routes, and the distribution and relative importance of political units, including colonial possessions. Mathematical geography -involving the planetary relations of the earth to the sun and the consequences of the earth's form, size, rotation, and revolution - should be emphasized.

Logical and psychological order of development in harmony. The suggestive organization of a course of study as presented in this chapter not only unfolds the subject in a logical, systematic fashion, but is also carefully related to the developing interests and increasing 
experiences of the pupil. The pupil is led by easy steps from a consideration of his local environment to a consideration of the environment of other people; an intensive study of the various types of environment is made through regional geography; and finally, after an intensive study of parts is made, the child notes the world-wide relations of parts as they definitely affect man. The course takes the child in the local environment in which he happens to be placed, and expands it into a worldwide environment.

\section{Suggestions for Further Study:}

1. Why should every teacher be interested in the whole course of study in geography even though she may teach the work of only one grade?

2. Compare the course of study with which you are acquainted with the course of study outlined in this chapter.

3. Should a definite geography course be outlined for the primary grades?

4. Select a textbook in geography and compare it with the suggested course of study.

5. How might a detailed course of study be worked out effectively by the geography teachers of a school system or a group of teachers from different rural schools?

6. What should an ideal course of study in geography contain?

Sclected Refercnecs:

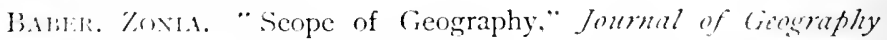
(I0)5\% Vol. IV, pp. 386-396.

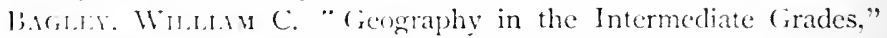

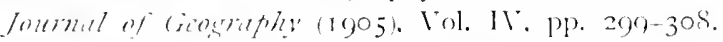

B.ARxis, I3. A. "Cectraphy in the I) troit Elementary Schools," foumal of (jeograthy (1916). Vol. XlY. pp. It+-150. 
Brighan, A. P. "Report of Committee on Geography," American Education (1920), Vol. XXIII, pp. 300-307.

ChHus, BrETa W. "Study in Home Geography," Joumal of (ieggrathy' (1920), Vol. XIX, pp. 15t-158.

CALKINS, R. D. "Commercial Geography from the Regional Point of View," Joumal of Gegraplyy (1918), Vol. XVII, pp. I8-25.

Dickersox, R. E. "Improvement of Geography Teaching," Journal of Geography (I915), Vol. Xill. pp. 297-301.

DODGE, R. E. "Course of Study in Geography," Joumal of Geografhy (Igo8), Vol. VII, pp. 7-14.

DRYER, C. R. "Regional Geography;" Joumal of Geografhy' (1912),

Vol. XI, pp. 73-76.

Fatrisaks, H. W. "Organization of an Ideal Course in Geography," Joumal of Geography (1919). Vol. XVI, pp. 233-237. FreElAN, FrANk N. The Psychology of the Common Branches, chap. viii, pp. $161-178$.

Kincruws, C. B. "Goography in the Junior High School - Its Relation to Elementary School and to Senior I Iigh School Geography," foumal of Geosmophy (19I6). Vol. X1V, pp. 29I-294. Mcllukr, Cinardes. Course of Study in the Eight Grades, pp. $123-139$.

Suthirdand, W. F. "Course of Study in Geography," Joumal of Giegraflin (1912), Vol. XI. pp. 126-129.

Tuomas, Inewex Goss. "How shall we teach reography" Jourmal of Giosuthy, (1920). Vol. XIX, pp. 250-254.

"Geography in the St. Louis Schools," Joumal of Giosmathy" (1918), Vol. XVII, pp. 122-127.

"Regional Geography in a Course of Instruction for the Serenth Grade, Massachusetts Manual," Joumal of Geosmophy (1919), Vol. XVIII, pp. $6 z-75$. 



\section{PART THREE. THE MATERIALS OF GEOGRAPHY}





\section{CHAPTER VII}

\section{OBSERVATIONAL GEOGRAPHY}

Nature of observational geography. Through direct contact with the social and physical environment many fundamental impressions are secured. All direct experiences with geographical materials are phases of observational geography. The small child observes that people wear raincoats and rubbers as a protection against a storm. He also may desire similar protection. A heavy rainfall or snowfall may make the roads almost impassable. The wind may cause considerable damage to buildings. The warm, sunshiny days may stimulate the gardens to grow rapidly. Whether the person is actively concerned or whether he is a mere spectator, he is securing geographical sense impressions of observational geography. The direct interpretation of the physical environment is significant to everyone irrespective of age.

Relation to local and home gcography. There is a tendency to regard the terms "observational geography," "local geography," and "home geography" as more or less interchangeable. Local geography refers to the geography of the immediate region of the home, irrespective of whether the person can observe the materials; home geography refers to the ways in which the needs and wants of the homes of the pupils are met, and therefore relates the homes, in part at least, to the rest of the world; 
observational geography refers to the direct experiences of the child, whether in the home, in his local community, or in other parts of the worid.

Observations by children and adults. Observation by a child is different in degree from observation by an adult. The child has had limited experiences, and therefore has a limited number of concepts, most of which are but poorly developed. He is only beginning to make his acquaintanceship with the phenomena of the world and reacts simply to the successive situations. The observations of an adult may be no more nearly accurate in so far as the actual elements of the situation are concerned, but his grasp, because of the wealth of material he can bring to bear on the situation, may be much more comprehensive. The child observes and seeks to understand; the adult observes and seeks to interpret.

Emphasizing observational geography. In the early part of the school course observation should be strongly emphasized. These observations should be interesting, accurate, and as comprehensive as the state of development of the child will permit. These basic, concrete impressions form the material for the concepts by means of which he will interpret the world-whole. If the observational experiences are inaccurate or but hazily understood, the pupil's knowledge of the world-whole will correspondingly suffer. The success of the teacher of geography in the upper grades is conditioned by the type of observational geography taught in the lower grades.

Observational geography should be taught throughout the grades. An intelligent adjustment to the environment and a sympathetic understanding are desirable if one is to 
live most effectively and most happily. The reinterpretation of observational material, with the aid of the increased and enriched concepts of the older pupil, is as necessary for adult success as the simple observations of the lower grades.

Nature of observations. The practical utilization of observational material in school involves ( $\mathbf{r}$ ) the use of materials and processes which are a part of the ordinary environment of the child, (2) the bringing of materials to the school, and (3) excursion work, by means of which the child is taken to the materials.

In so far as it is practicable, materials and processes should be observed in their natural or industrial environment. Since opportunities of this kind are very limited at the school, the need of excursion work with the children is evident. Excursion work in geography is primarily concerned (I) with a study of physical forms and processes, commonly included under the term "physical geography," and (2) with plant, animal, and mineral products and industries, commonly included under the term "commercial and industrial geography."

\section{EXCURSION WORK}

Value of ficld work. Field work (I) relates the school work to out-of-school problems, (2) adds interest, (3) gives concreteness and realism to the work, (4) affords a basis for the schoolroom work, (5) helps the pupil to fit himself into the world of relationships, (6) teaches interdependence, (7) arouses sympathy for people of all vocations, (8) stimulates an appreciation of the beautiful and useful, (9) indicates, through the products and 
processes, the wonderful power behind the world of affairs that conditions man's activities and thus brings the pupil into closer touch with the Infinite, and (Io) shows that nature, including man, is eternally changing and promotes mobility of adjustment on the part of the pupil. Field work does not have a monopoly on the advantages above noted, but a line of work that combines so many possibilities should not be neglected.

Reasons for insufficient ficld work. If the value of field work is recognized, why is this phase of geography not systematically organized and incorporated as a part of the course of study? Why is much of the field work almost valueless? To what extent is the teacher to blame? Is it practicable to introduce more field work into our schools? How should more field work be introduced? Should the course of study definitely state what should be done in each grade? Should field work be required or should it be optional with the teacher? What are the difficulties that a teacher and superintendent meet in attempting to emphasize field work, and how may these difinculties be overcome?

Among the reasons for the placing of insufficient emphasis upon field work may be noted the following:

I. The teacher was not taught with the assistance of field trips and has had no experiences as a pupil that help her to appreciate the neel. She was taught largely through books and through discussions about things. She has marle her own arljustment to her home, the route to school, and the routine formal school work. Even thoug't she may now and then feel that the school work is not sufficiently related to real things and life situations, 
because of her lack of knowledge of field work and its revelations she feels that nothing but failure would attend her efforts; or, perhaps, comfortably adjusted to a minimum of activity and of varied experiences, she selfishly prefers to substitute the shadow of knowledge for the substance.

2. The pupils may become unruly. They may even become unruly in the schoolroom. How much more likely are they to lose all respect for discipline in God's great out-of-doors, where many things are beckoning hither and thither. In many cases the apparent order of a schoolroom may be a surly or resigned submission to the inevitable, and underlying the surface appearance there may be insubordination in every child, awaiting a favorable opportunity. The teacher who has this type of order in the schoolroom should wisely shun field work, for the opportunities offered to evade her iron discipline will be used to worry her into an early grave. There is some hope that if such a teacher should take a few field trips she might begin to see that there is such a thing as securing liscipline through the interests of the children in the materials of the world. If she takes a few field trips she may cither "make or break" herself as a teacher, for unless she reforms her disciplinary methods in the schoolroom the pupils once given a taste of real knowledge will tend to disrespect her schoolroom tactics more than ever. If teacher and pupils are working together in a companionable way in unfolding the wonders of the earth, the arlvantages of field work are such that teacher and pupils will be brought even closer together. Little external discipline is necessary when the pupils feel that they, 
with the teacher, are doing something worth while. The teacher, therefore, who is afraid that her children will cause her too much trouble by being unruly should searchingly analyze her schoolroom work and methods.

3. The attention of the pupils will wander. There is a tendency for each pupil to follow his own personal inclinations in making observations. The child tends to establish relations with those things which please him most. No teacher should attempt a field trip without a prearranged plan, but she should be quick to sense the immediate interests of the children and to build on these. Sometimes it is just as desirable to follow the lead of a pupil as to follow the lead of a teacher. It is well to encourage the pupils to make personal observations and to follow these with suggestions or questions. The wandering attention of the pupils can be seized upon by the wide-awake teacher as a means of emphasizing the opportunities offered by the trip.

4. The pupils do not learn anything new in field trips. If this statement is true the reason is not far to seek. Can the blind lead the blind with any certainty of definite progress? It is desirable that a teacher with this view should accustom herself to an analytical study of field trips. She should have training in observing, in classifying and in organizing her observations, and in considering the value of school work properly related to field work.

5. The public will disapprove. The patrons of the school were not taught through field trips. They think that a teacher's place is in the schoolroom. They confuse field trips and picnics. Such a situation must be 
handled as diplomatically and as patiently as possible. Parents should be taken into our confidence, and we should tell them what we are doing and why, in an attempt to get them to sympathize with our aims. Written permission of the parents may be secured, and those who are unfortunate in not being permitted to go along can be benefited by the lively discussions relating to the field trips. Public opposition to field trips can be readily overcome through a proper enlightenment of parents.

6. Some of the children may be injured. There is probably no situation whether in school or out that is absolutely devoid of danger. The wise teacher will avoid very dangerous places. It is better to play safe by taking every possible precaution to prevent accidents.

7. Many trips involve transportation charges, which prevent some from going. To deprive any child of the privilege of going on a field trip, especially in view of the fact that field work fundamentally is important, is decidedly undemocratic and deplorable. The school board should provide for the transportation cost of field trips out of the school fund as general equipment is paid for, or at least those unable to secure the needed money from home should be provided for. In the meantime it is better that those who can go shall be taken on field trips.

8. Classes are too large to be handled in the field. Some classes are too large for schoolroom work. Such classes will also be too large for effective field work. The large class does not excuse the teacher from doing her best in the schoolroom, although she is laboring under a serious handicap; neither does it excuse her from doing her best with the large group in a field trip. Field trips 
that will permit the class to work in large groups may be selected. Some of the mothers of the pupils may be giad to assist, the field work being greatly facilitated through their help. The principal may find it possible to assist the teacher.

9. The teacher may be in charge of a class that is reciting and of a class that is studying at the same time. In such instances it is not practicable to go at that particular time, unless arrangements can be made for someone to take charge of the room temporarily or unless both groups of pupils can be taken.

Io. The time involved in a field trip is longer than a period. If possible, arrangements should be made to have a longer period for the field work, or, if necessary, arrangements can be made so that a part or all of the trips can be taken after school or on Saturday.

I I. The superintendent is not in sympathy with field trips, not because he believes the field trips are valueless but because they interfere with the routinized efficiency of the school plant. This is a serious situation, but the enthusiastic, self-sacrificing teacher, inspired with a vision of her opportunity, will engage in field work with the pupils in out-of-school hours. Gradually, as the significance of this work becomes more and more evident, the school periorls will be made sufficiently elastic so that the real field work can be done on the same level as other school work.

$A$ brief survey of the leading difficulties arising in connection with field work indicates that while there are diffculties, there are none that are insurmountable. All lines 
of activity, in school and out, have their special problems. If field work is recognized as having a marked value which no other type of activity can meet, the problem of those responsible for the education of the children is not to ignore or slight this work on the grounds of convenience or inherent difficulties, but manfully to attack the problems so that field work will be done-done intelligently, consistently, and persistently.

$M y$ resolve. I believe in observational geography. I believe in field work in physical and industrial geography. In order that I may make my work more effective, I resolve that $\mathrm{I}$ will engage in field work, whenever and wherever the opportunity is offered of raising the standard of geography work. In order that I may plan my field trips intelligently, I furthermore resolve that I will forthwith proceed to acquaint myself with the physical forms and processes of my community, working up type studies of these, that I will visit the various industrial establishments of my locality if possible, and, if this is not possible, that I will secure detailed information concerning them. So help me, Mr. Superintendent, and keep me steadfast and true.

Nature of physical-geography field trips. The nature of the field work in physical geography is determined by the types of physical forms and processes that are available. In a volcanic region, in a glaciated region, or along the seacoast the field work will differ somewhat from the field work in a region where rivers, with their helping agencies, have largely determined the forms and processes. In preparing herself for field work the teacher may 
approach the subject in the following way: a general survey of the principal forms and processes; the general distribution of these forms and processes, with particular reference to the United States; the prevailing forms in the physiographic region in which she lives; a specific consideration of the particular forms and processes that are available for first-hand consideration. If a teacher is living in a region where the work of running water, with helping agencies, primarily has been concerned, she will be interested in noting the divides and valleys; how the valleys are being widened, deepened, and lengthened; the rapidity with which these changes are going on; rapids, falls, meanders, currents ; materials being transported and deposited; the nature of the materials ; the relation of tributary valleys to main valleys; the effects of topography on human relations; and floods. Her problem primarily involves the making of accurate, searching observations and the interpretation of the facts noted.

Nature of commercial-geography ficld trips. The problem with respect to products and industries is somewhat similar. What are the principal products and industries, how are they distributed, what raw materials are secured in your neighborhood, and what disposition is made of surplus products? What materials are brought into the neighborhood and what use is made of them? What industries are carried on, what raw materials are used, what products are obtained, and what disposition is made of them? What is the significance of the inclustries of the neighborhood to the people? Observe industries and materials carefully and seek to interpret correctly the facts ascertained. 
Preparation of the teacher. Not until the teacher has a detailed knowledge of local physical forms and industries is she qualified to become an expert teacher of geography. Even then she is not qualified unless she also understands methods in relation to child growth. The teacher who lacks knowledge or who lacks correct methods is to be pitied; the teacher who lacks both knowledge and correct methods should not be tolerated.

Some teachers may feel that the requirements suggested are so high that they never can become good teachers. An unattainable ideal has not been pictured; an ideal has been set forth that few teachers have reached. Unless one has met these requirements, is it wise to engage in field work? Field work fundamentally is important for both teacher and pupils. A group of boys and girls stimulated by a common situation learn much from each other. It may be practicable to take a field trip with children even though the teacher does not know much more about the materials than the children. Teacher and pupils can learn together. The pupils may not derive so much benefit from such a trip, but the teaching will be much more efficient as a whole than if field work is omitted altogether. Gradually the teacher will broaden her experiences and become more and more proficient in directing pupils. The poor pupils on whom she practices will suffer. They will not suffer nearly so much as they would if field work were altogether avoided.

A teacher should carefully consider the various factors involved in a field trip. She should not let her enthusiasm run away with her good judgment. A single accident will seriously retard the possibilities of further developing 
field geography. Some industrial establishments are unsafe for any classes of elementary-school pupils. Short trips near the school at noontime, at recess, or after school may be taken with pupils who are interested. A teacher will find these simple trips so appealing, so helpful, and so comparatively easy that by degrees she will come to feel that she can tackle the longer trips. Splendid geographic material is usually close at hand, often no farther away than a stone's throw from the school building.

IIeasuring the success of ficld work. Children should be encouraged to make supplementary observations and reports. Pupils who take temporary trips to other regions should be encouraged to make observations and to report their experiences to the class. Observational geography should never be finished in so far as the pupils are concerned. The field work of the school should be regarded merely as a point of departure for continued growth along this line. A teacher can measure the success of her work in part by the extent to which she has realized her content aim, in part by the interest and enthusiasm in field work that has been aroused.

Bringing matcrials and activities to the child. The ideal situation is to take the pupils to the places where the actual work, whether of man or nature, is being accomplished under normal conditions. In one's own community, however, there are factories which for some reason, perhaps because of dlanger or because of the policy of the company, are not available for first-hand study. Such industries should not be ignored. It may be possible to secure samples of materials or to set up simple experiments or demonstrations that wiil help the 
children to understand such industries. Special investigations may be made by members of the class who are able individually to secure permission to inspect the factory. If the children cannot be taken to the factory, as much of the factory as possible should be brought to the children. Some industrial units-as a cotton, coffee, or tea plantation - may be unavailable for first-hand study because of remoteness. If industries must be discussed in the schoolroom, it is good pedagogy to have as much observational material as possible on hand to make the presentation as concrete and realistic as possible.

Collections by individuals should be encouraged. The opportunities of children to secure materials are varied. Collections of local products are particularly relevant. One child may make a collection pertaining to the corn plant and its products or to the wheat plant and its products. Another child may be able to secure through correspondence or through some older person samples of products from a distance, as gold ore from Alaska, copper ore from Montana, or crude oil from Oklahoma. The interest of the child in his own collection is personal and intense.

Materials cannot always be secured by the children at the time that they are needed. There arises, therefore, the need of accumulating materials that will be available at any time. Out of the needs of the pupils and teachers has arisen the educational museum. Pupils and teachers may gradually accumulate materials. Such a museum is of great value to all children who have been concerned in its formation, but it also has more of the personal element in it for future classes than formal museum material that is purchased ready-made. It is not always 
possible to secure through the pupils the materials needed. In response to this need for material not readily secured, companies have been formed for the purpose of collecting and arranging materials. The teachers thus may be relieved of the task of securing materials on the basis of need, and are not disappointed because of inability to secure materials as needed. Such museum cabinets unfortunately tend to remove the personal element. 'The museum material tends to become a part of the formal, mechanical equipment of the school, much superior to the former abstract teaching, but pedagogically inferior to the personal collections.

Is it possible to combine the advantages of the personal collections and the formal museum material, and at the same time reduce to a minimum their respective disadvantages? Pupils should be encouraged to make individual collections. The teacher should cast the weight of her influence in this direction by showing her appreciation of all attempts of pupils in this direction. She should make them feel that she values much more highly their collections than the formal museum material. The discussion, when practicable, should center about the informal material to the neglect of the regular museum material. The museum material can be used as a check upon the materials of the children. Materials of the museum should be correlated or associated with the materials of the children. If the children cannot secure the needed material, then, and only then, as the next best plan, is it advisable to place considerable emphasis on the museum material. Since much of the material of value can be secured only through the formal educational museum, every school 
system should have a liberal appropriation for the upbuilding of a museum. Many materials, however, as ores, seeds, nuts, etc., can be secured in quantities, as laboratory material in general is secured, and the pupils, with the help of the teacher, can classify and arrange the materials to much greater advantage than through the mere observation of material that has been already systematically arranged and classified.

Results. If the needed emphasis is placed on observational geography, the child will become widely acquainted with his own environment and will have the ability and desire to keep himself acquainted with changes; he will appreciate the interdependencies in his own community and the relations of his community to the world-whole as it actually exists; he will have a measuring rod by means of which extra-community geography can be understood; he will believe more thoroughly in school work, because it actually is dealing with things worth while.

\section{Suggestions for Further Study:}

1. Make a list of topographic forms and processes that may be observed in your community. Make a supplementary list indicating the forms and processes that cannot be observed in your community.

2. Make a list of industrial establishments that are in your neighborhood and indicate $(a)$ those to which access cannot be secured, (b) those to which it would not be wise to take children, although the teacher might profitably observe, and (c) those that are available for visits with children.

3. Select a definite industry in each class as indicated in exercise 2 and indicate in detail the use that might be made of each industry educationally.

4. Make a list of products that might profitably be brought into the schoolroom and suggest desirable ways of using them. 
5. Make an individual collection of products that are available in your community.

6. Compare the relative value of exhibit materials secured and organized by the children with those organized by commercial firms for school use.

\section{Selected References:}

Baber, Zoxia. "Field Work in the Elementary School," Joumal of Geography, Vol. IV. pp. 18-22.

CARNEY, FrANk. "Observational Work for Children," Joumal of Geography. Vol. IV. pp. 12-17.

Davis. W. H. "Home Geography," Joumal of Geosraphy, Vol. IT, pp. 1-5.

Dodie. R. E., and Kirchwer. C. B. Teaching of Geography, chap. xi, pp. 135-153; chap. xvii, pp. 217-244; chap. xiii. pp. $16+-18 \mathrm{I}$.

Hixe, L. W. "Function of the School Excursion," Joumal of Geografhy, Vol. IV, pp. 446-450.

Holt\%, F. L. Principles and Methods of Teaching Cography, chap. iii. pp. 13-19: chap. v, pp. 30-40: chap. vi. pp. 44-59. Howe, Ellzalietr. "Can the Collecting Instinct be Itilized in Teaching?" Elementary Sikool Teacher. Vol. VI. p. fo6.

Jiffersox. M. "Out-of-door Work in Geography," Joumal of (ieesrafhy. Vol. IV, pp. 49-57.

Mr.Mlrkr, Cunkes. Special Method in Geography, chap. vii, PP. $101-117$.

P.kKк. A. E. "Teaching the Geography of a Small Area." foumal of Geografley (1920), Tol. NIX. pp. 130-1.

REnwa, JAcues. The New basis of Geography, chap. xi. Pр. $135-153$.

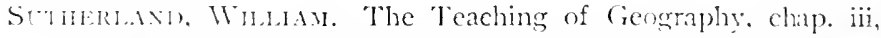
pp. 3t 52: (hap) xviii. pp. 202-217: chap. xix. pp. $217-235$. Wumtrk. 1. 1). "The leginnings of (itography." foumal of Gentrifle (1917) Vol. XVI, pp. 21-25.

" (iongraphy at council bluffs, lowa," Joumal of Genersphy, (i). II. Pp. $56-92$. 


\section{CHAPTER VIII}

\section{REPRESENTATIVE, OR SYMBOLIC, GEOGRAPHY}

Value of symbols. Since the child will have an opportunity of observing a very small proportion of the geographic material that he will study, effective devices must be employed to assist him in picturing vividly and accurately situations far away. Symbols must be substituted. During the period that observational work was being stressed the child needed symbols as a means of expressing and recording his observations. On the basis of need symbols were adopted, in accordance with his own ideas or at the suggestion of the teacher, to represent certain concepts.

When the teacher is ready to enter into a detailed study of the geography of the world-whole, the pupils have a mastery of symbols by means of which they can intelligently interpret conditions elsewhere. If they have learned to express themselves in terms of symbols that are generally employed, they will be able readily to interpret the symbols of others. Representative geography, therefore, involves the adoption and use of symbols for the expression of thought, and the interpretation of the thoughts of others through the use of symbols. Without a common language of symbols it would be practically impossible for man to profit through social inheritance; it would be practically impossible for a child ever to pass 
beyond his actual experiences in securing a knowledge of the world or in the interpretation of remote areas.

The leading symbols used by the child in the expression of thought and the interpretation of the world-whole are pictures, drawings, models, illustrations through graphs and diagrams, maps, globes, and language.

\section{PICTURES}

Increasing emphasis of pictures. In the early American textbooks of geography, pictures were almost lacking. Shortly before the Revolutionary War, Jedediah Morse's American geographies appeared in two volumes without pictures. Jacob Willetts explained the absence of numerous pictures in his geography (1826) in the following words: "It has not been deemed expedient to sprinkle the book with pictures, from a conviction that they serve to divert the attention of the pupil rather than to inform his mind or improve his taste."

As increasing emphasis has been placed on visual education the number of pictures in the textbooks has increased. Many pictures, however, have been selected with insuffcient care, the teacher has not trained the pupils in the interpretation of pictures, and the emphasis placed on the reading material in contrast to picture study has brought about a general neglect of pictures in spite of the fact that their value theoretically is recognized. It is gratifying to note that the recent textbooks contain numerous pictures each of which has been selected with a definite purpose in mind, that meaningful statements directly relating to the pictures are made, and that in some instances questions intended to stimulate the pupil to interpret the 
picture are included. With the definite recognition of pictures as an essential part of the textbook organization, picture study undoubtedly will be more generally practiced.

Visualizing scenes through pictures. Only a small part of geography can be studied through direct observation. The child's knowledge of world geography, necessarily, is secured primarily through the use of symbols. The picture, which is the least arbitrary of symbols, closely reproduces scenes beyond the child's vision in such a way that the child can economically and accurately secure the appropriate mental images.

When a picture of the Niagara Falls is presented, this great scenic feature immediately assumes an element of reality. Now, by virtue of the interest aroused through what the vision reports, the great sheet of water is seen to fall. Its thunder as it strikes the rocks one hundred and sixty feet below is heard. The descent to the Cave of the Winds can actually be made, and, through skillful teaching, the children will almost gasp for breath as they are drenched by the falling spray. Now, in some measure at least, the pupils can make the connection between this falling water and the power that propels the street cars in Buffalo and illuminates the streets and buildings of the city. ${ }^{1}$

Comparison of photograph with the original. A school camera, used during field trips, may be helpful in training pupils correctly to observe and interpret pictures. The pupils will observe carefully the scene photographed, and when the print is made they will attempt to explain

${ }^{1}$ James F. Chamberlain, "The Use of Pictures in Geography Teaching," Journal of Education (May 7, 1914), Vol. LXXIX, p. 523. 
appropriate parts of the trip in relation to the picture. During a field trip an area may also be discussed in connection with photographs previously taken. The pupil, through such analysis, will come to appreciate the value of pictures in representing, and he will learn to look for the important things. Pupils who have learned to observe nature and man's adjustments to nature will desire to use their cameras not only in taking pictures of their friends but also in recording geographic observations.

In comparing the picture with the area photographed, teacher and pupils will ask themselves many questions. Does the picture typically represent the area studied? Does it show more or less of the area than is necessary for recalling the field discussion? Does the picture bring out the important things in a clear way? Are there any seemingly irrelevant things represented in the picture? Are things represented in the picture that were not observed in the field? Does the picture help in imaging more vividly the field work? Is there anything in the picture to indicate the relative sizes of things represented? The camera records an area comparable to the area that comes under the observation of the individual from one viewpoint.

Oorroming weaknesses in picture study. A geographic picture should have some distinguishing characteristic. Panoramic views of cities are frequently almost worthless because of the confused jumble of roofs and trees, which might represent almost any large city. The important part of the picture should stand out in prominent relief. When a person is making a special study in the field other objects of greater prominence may scarcely be noticed, 
but the photograph will bring these less important objects into sharp relief. Pictures are subject to misinterpretations, and particularly is this true of the ordinary photograph, which does not indicate the true colors of the original. Since the picture is static, there may be difficulty in getting the child to construct a mental picture of the situation represented. His mental imagery may stop with the picture. The picture does not indicate the change that is in progress, but merely indicates the situation at a particular moment. If a picture of a silo being filled is taken, the men, horses, wagons, silage, forks, etc. are shown in one position only. The picture of a silo being filled should be used as an organizing center for an appreciation of these changes. A picture does not give a pupil a real appreciation of a situation unless he has had similar experiences. A pupil may note a diver preparing to dive for sponges, but unless he has had similar experience he will not secure a real appreciation of the situation. An analysis of a picture of a hay-pitcher may indicate that there is a stack of hay, a man with a pitchfork, a partially loaded hay-frame to which two horses are hitched, while a jug of water is placed in the shade. The pupil may easily get the "know" of the situation, but it is desirable that he also shall get the "feel" of the situation. He will need to know about the work of the water-boy, the heat of the sun's rays, the thirst of the pitcher for cool water, the fatigue involved in lifting the hay, the cliversion offered by snakes, rabbits, and field mice, the pleasant thoughts aroused over the excellent meals that are served. An appropriate feeling concerning the scene represented, in relation to changes and in 
relation to the situation itself, can best be secured, in the absence of actual similar experiences, through the use of clear, vivid, descriptive, and interpretative statements, which will stimulate the imagination of the child to picture the scene in its naiural setting.

Value of pictures. Picture study is invaluable in geography teaching. A picture, if wisely selected, ( I) enables a pupil to take in at a glance a complex relationship economically and accurately, (2) recalls a concrete, specific situation, (3) gives, through its reproduction of the original, an appearance of reality, (4) is easily understood, and (5) arouses questions which will lead the pupil far beyond the immediate purpose of the picture.

Collecting and using pictures. The modern textbooks have many excellent pictures. There are numerous supplementary sources, including newspapers, magazines, post cards, and advertising materials. The National Geographic Magazine, Asia, the Pan-American Union, and the rotogravure section of the Sunday newspapers are valuable sources. Every school should have a collection of pictures to illustrate the various topics of geography. This is particularly true of the lower grades, where the child is building up his initial geographic concepts. Pupils should be encouraged to make individual collections and to organize these collections under appropriate headings.

The supplementary pictures of the school may be classified and filed in envelopes with the general topic and the particular pictures indicated on the backs of the envelopes. The pictures, when needed, may be withdrawn from the files and clasped to cardboards. If it seems 
preferable, each picture may be mounted on a cardboard, and the mounted pictures may be carefully classified and filed away.

The pictures may be placed on a table in any order, and the pupils may be asked to arrange them in logical order so as to show causes and effects or successive changes in sequence. Pictures dealing with a topic under discussion may be mixed with irrelevant pictures, and pupils may be asked to select the pertinent pictures. The individual contributions may be compared with the school collection to determine what additional contributions have been made. The teacher may depend on the individual contributions and use only as much of the school collection as is necessary to illustrate the various phases of the discussion. The pupils may indicate the phases of the discussion that should be illustrated, and they may attempt to find appropriate illustrations. Pupils may study questions bearing on a set of pictures, the discussion following during the class period. Pupils may be asked to make a list of appropriate questions dealing with each picture. The ability of students to interpret pictures and to use them as organizing centers may be tested ( $\mathrm{r}$ ) by presenting them with a picture and appropriate questions, (2) by distributing pictures, each with a number, the pupils to write opposite the same numbers on a sheet the important thing represented, (3) by giving pupils the names of the pictures and asking them to place beside each the appropriate number as indicated on the picture. In journey-geography work pupils can "think through" the details of the trip more successfully if they have pictures illustrating the appealing scenes along the 
route. The pupil may describe the journey in relation to the pictures. The details may vary, but the teacher will attempt to use the pictures in such a way that she secures a maximum of worth-while mental activity from each member of the class.

The suggestion of pictures. A picture is of value because of what it actually teaches and because of what it suggests. Some questions can be definitely answered from a study of a picture; some questions can be answered inferentially; while other questions may be suggested by the picture study, but other materials may be required for satisfactory answers. In the verification of inferences other sources may be consulted. If the pupil, for example, is looking at a picture of a truck garden, he may be able to identify certainly the sprinkling system, he may infer that the growing vegetation consists of radishes, lettuce, and onions, but he may find it necessary to consult the descriptive material to verify this inference. He may want to know the location of the gardener's market, and it may be necessary for him to consult the context and to locate the city on a map. With the picture of a part of a truck garden as a point of departure he may answer questions directly related to the picture, and widening his viewpoint he may use the picture as an organizing center for a large body of related knowledge. It is better to make a careful study of a few pictures than to dazzle the pupil with a large number of pictures which are flashed before him in rapid succession. Pictures should become meaningful centers for large borlies of knowledge, and exceeding care should therefore be exercised in their selection. 
Classes of pictures needed. Among pictures that it may be desirable to collect for geographic use may be mentioned ( I ) those showing climatic and topographic conditions, (2) those showing plant and animal distributions, (3) those showing the various ways in which man has utilized the resources of the earth and the ways in which these resources, through transportation facilities, have been distributed, and (4) those pictures which present the scenic attractions of nature. A picture collection should be frequently revised through the elimination of the less desirable pictures and the addition of superior ones.

Picture study related to study of other materials. If the interpretation of pictures in connection with observational geography has been emphasized, the child has a very important mastery of a symbol that will help him to image conditions far away. If a picture cannot be certainly interpreted it is useless to spend much time discussing it, but good pictures of scenes far away should be carefully studied. Pictures should be used to reënforce other means of teaching geography; the other materials of geography may be used in helping the pupil to answer questions raised, but not satisfactorily answered, through the picture.

Stcrcoscopes. The stereoscope increases the vividness of the picture by the apparent depth given. Excellent pictures are available for practically every geographic topic. The stereograph has all the advantages that have been attributed to the ordinary picture, and in addition there is the advantage of increased vividness. The picture may be reënforced by descriptive material on the back. If only a few stereoscopes are available the 
stereographs and stereoscopes may be placed on a table, and the pupils may be permitted to study a set of pictures as a part of their assignment. It may be desirable occasionally, when a stereograph will throw light on a discussion, to pass the stereoscope and picture from one student to another, the class discussion in the meantime being continued. If enough stereoscopes are available each child may be supplied with a stereoscope and picture. The pupils will study their pictures for a given time, and when the teacher says "pass" the pupils will pass their pictures. If there are twenty pupils in the class and one minute is allowed for each picture, every pupil will have the opportunity of seeing all the pictures in twenty minutes. If the pupil also reads the explanation on the back, a longer period of time will be necessary. After the pupils have seen all the pictures, each pupil may be asked to make a special study of the stereograph that he happens to have. The class may then hold an appreciation exercise. Each pupil may describe his picture, and the rest of the class may attempt to recall the picture. Each pupil may be assigned a picture, and an oral report of each picture relating to a central topic may constitute the basis for the class discussion. Each pupil, standing before the class with stereoscope and picture before him, may describe what he sees, and the other pupils later may have an opportunity to look at the pictures described, if they desire. The stereoscope is of particular value in arousing an interest in worth-while topics.

The lantern. The lantern offers the particular advantage of enabling the whole class readily to observe the same picture at the same time. A discussion with the 
picture before the class enables each pupil to make the appropriate associations. In connection with the study of a topic a lantern-slide lesson may be desirable. Occasionally the teacher may give an illustrated talk. In harmony with the idea that actual participation of students will involve maximum activity, however, it is frequently desirable to assign a slide to each pupil. The pupil makes a special study of his slide. The slides may be thrown on the screen in a given order, but if the mastery of the subject under discussion is not affected, it may be desirable to put the slides in the lantern in any order, with a challenge to the pupil to recognize his slide when it is shown. If a slide lesson is introductory to a study of a topic, the teacher may need to supplement the pictures with pertinent descriptive material. The pupils should be encouraged to describe the pictures also. If a slide lesson succeeds the discussion of a topic, the pupils should be able to interpret the slides out of their experiences. Unless a slide makes a definite contribution to the topic it should be omitted. The slide lesson tests the ability of the pupil to discuss a topic in a clear, vivid way.

The motion picture. The crowning achievement in the reproduction of that which is good to see is the motion picture. The moving picture overcomes the primary disadvantage of an ordinary picture. It not only reproduces the original but also gives the appearance of action. The picture through the changing scenes becomes dynamic. The changing relationships help the child to get the "feel" as well as the "know" of the pictures. The moving picture is the nearest approach to a first-hand observation. Many situations which would involve a 
long time for direct observation, or which can be observed only with great danger or difficulty, can be observed at a nominal expense in a comfortable environment.

It is impossible to overrate the power and influence upon our national life which is being exercised by motion pictures today. They are a part of the life of the people. The rich and the poor, the educated and the illiterate, of all ages and all classes, no matter what language they speak or understand, find amusement and recreation in them. The motion picture speaks to the mind in a universal language. A picture can be absolutely absorbed merely by seeing it. It is probably the easiest way to receive impressions that the world has yet discovered. Mr. Oberhoetzer, Secretary of the State Board of Censorship of Pennsylvania, says: "One can read and get an impression if he is industrious enough to do so, but when he views a motion picture he gets an impression in spite of himself. The influence of a motion picture is obviously much greater than the influence of a book. It is more graphic and is an influence which fixes the mind of a person who does not read or who cannot read and he absorbs it anyhow." 1

In the Detroit schools ${ }^{2}$ a recent experiment was conducted to test the value of the picture film. The film told about oranges. The children were able to talk about fumigating the trees, watering the trees, packing the oranges, etc. in a clear, accurate manner. An attempt was made to teach a group with similar ability the story of oranges through oral presentation. The twenty-four pupils averaged 78 per cent for the seventeen and one-half

"Estella L. Moulton, "Our School Children and the Movies," I'isual Education (June, 1020), Vol. I, p. 24.

2 J. H. Wilson, "Visual Education in Detroit Schools," Visual Educacation (June, I920), Vol. I, pp. 9-10. 
minutes involved in looking at the film, and the other group of twenty-four children averaged only 70.8 per cent in an oral presentation of the same topic lasting thirty minutes. The time saved by the visual method was nearly 50 per cent, while the children showed an increased score of 7.2 per cent.

There are many difficulties involved in the use of films for educational purposes. The film companies have been catering to the demands of the people, who, to the number of over six million daily, attend moving-picture theaters in the United States. The school-teachers have been very conservative in their attitude toward the picture film as an educational agency. The strong appeal of the moving picture to people of all ages and the vivid mental impressions thereby secured suggest the desirability of making a special study of the wonderful educational possibilities of the motion picture.

\section{MAPS AND GLOBES}

In connection with the observational work of the early grades locational or place geography inevitably receives emphasis. Where did we go and how did we go? Can we draw a plan of our schoolroom, or of the block on which the school is located, so that someone else can look at our plan and understand the location of places? Can we convey a clearer idea of where we went by indicating on paper the direction and the location of the object of our field trip? At first, without much attention to accurate scale, but only with a rough sense of proportion, crude maps can be made, by means of which the child can 
describe his trip more vividly. If the child wishes to illustrate a difference in elevation of two adjoining areas, he can resort to two colors. If green stands for the lower part and brown for the higher part, he can indicate this in the legend, and then another person can isll from the map which is higher and which is lower. During the period that observational work is emphasized the map work will be largely local and will be developed in connection with the observational work on the basis of need. A symbol that, unlike the picture, has no necessary relation to the scene will come to be so associated with the thing represented that the child can readily understand the thing.

Through the expression of ideas in relation to observational geography the child becomes acquainted with the use of maps. As he studies the world-whole he will have occasion to use maps many, many times. The maps made by others, depicting conditions removed from his locality, will be intelligible because of this preliminary work.

There is greater danger of an abuse of maps than there is of pictures. The pictures can readily be associated with a concrete scene. While the child starts with a map that represents a small, well-known area, he soon passes to areas not well known. Since the symbols are purely arbitrary, unless extraordinary care is taken the child will come to think of the map as the thing itself. This tendency could probably be avoided in part if largescale maps were used to represent local areas in the region under discussion. Many false impressions concerning the location of our leading cities would never have been 
formed had the pupils, when first introduced to these cities by means of a map, been given a large-scale map of the city. The tendency to stop with the symbol is most pronounced with maps that represent areas that are much larger than those to which the child in his experience is accustomed. Europe, for example, does not become a real region, populated with real people engaged in real activities, but Europe is in the room hanging on the wall. Many a child has wondered if the Europe across the Atlantic had any real relation to the map of Europe in the schoolroom, and many a child, talking glibly as if he realized the relation, in reality had no feeling of a close relationship.

Work in geography which stops with the symbols is in large part a failure. Symbols are of value only as they will enable the child to image the real thing more vividly. One of the crying needs is that teachers shall constantly check the pupils so as to avoid the "horrible practice of not reading beyond the map." Much of this difficulty can be overcome by having pupils consider the location of the area with respect to themselves - the distance, how long it will take to get there, how one may go, materials that are sent there, and products that come from the region.

Maps are valuable because (I) they bring together in an intelligible way large areas that could not otherwise be grasped, (2) they present the essentials and omit the nonessentials, and (3), while the symbols may be arbitrary, they represent a definite thing. 


\section{DIAGRAMS AND CHARTS}

It is sometimes desirable to make use of diagrams and charts. The child has observed something which he can illustrate by means of a diagram. To aid in explaining he constructs the diagram. He may wish to illustrate a cross section of a valley, the relation of divides and valleys, the gradient of a stream, the formation of natural levees, the use of a derrick in lifting stone out of a quarry. In each case he simply, and perhaps crudely, seeks to increase the vividness of his description or explanation through illustrations or diagrams. He may wish to visualize the varying production of some crop from year to year. Geographers are coming more and more to use diagrams to aid the pupil in visualization. The teacher should devote more time in helping the child to express his thoughts diagrammatically, so that he will appreciate the value of this method of transmitting thought.

A diagram constructed by the pupil to aid in explaining a problem to the class may be defective, but the pupil, while speaking, may be able to amplify the diagram in such a way that the defects are minimized. The questions of the class may be helpful in pointing out weaknesses. Pupils should be encouraged to construct diagrams carefully and to explain them fully.

\section{LANGUAGE}

In observational geography an excellent opportunity is offered of training the pupil in oral and written expression. New irleas are being secured. The pupil tallis about what he has seen. Perhaps field notes are taken. On its return 
from the field trip the class engages in an oral discussion of the trip. Probably a written account of the trip or some aspect of it is required. Some of the accounts may be typewritten, and students may read several accounts concerning the trip. Accounts in books, directly related to the field work, may be found. In connection with the field work the need of words to represent ideas is keen. In connection with the observation, involving an account of industries far away, in which museum material is used, the need of representative material becomes acute.

The teacher, in language adapted to the children, tells them many things of interest. IWritten articles adapted to the state of development of the children are placed in their hands. There is a gradual shifting in emphasis from observational to representative material. The geography textbook is placed in the hands of the child at an early age, and it consequently becomes important not only in conveying ideas but also in helping the child to enlarge his reading vocabulary.

Considerable practice should be given the pupils in the vivid visualizing of ideas that have been conveyed to them through language. There is danger that both the teacher and the pupils will mistake knowledge of words for knowledge of ideas. Pupils may memorize words in relation and recite glibly. This danger may be guarded against by having pupils attempt to reproduce the ideas in different words, or in a different set of symbols, or by enriching the material presented on the printed page. With advancing years the pupil will, to an increasing extent, be dependent on the printed page for geographic information. 
Sources of representative material. The principal sources of representative material are textbooks; supplementary readers; newspapers; magazines; government publications of the United States, of the states, and of various foreign governments; publications of an advertising nature, as railroad folders, reports of manufacturing companies, and reports of chambers of commerce; maps and globes; atlases; gazetteers ; encylopedias ; dictionaries; stereoscopic and stereographic material; and pictures. These materials are used with varying emphasis in the several grades.

Textbooks. In the textbooks will be found reading material, maps of various kinds, diagrams, pictures, a pronouncing vocabulary-practically everything it is possible to show in a book in the way of representative material that will assist in geography teaching. Necessarily, because of the large field covered, the material in most instances is insufficiently amplified and requires the use of supplementary materials. The textbook is valuable in directing the teacher and pupil, in giving pertinent and authentic material in well-organized form, but it is, in too many instances, a skeletonized presentation.

Maps. Wall, library, and outline maps are valuable supplements of the textbook. The wall map offers the children an opportunity to work concertedly and presents the material from a somewhat different viewpoint. The outline map reduces the work of the children to a minimum, gives them correct outlines through which their impressions of form are secured, and permits them to engage in self-expression by filling in the information desired. 
Supplementary reading. Detailed articles from supplementary readers, magazines, etc. are significant in enriching and making meaningful the condensed statements of the textbook. They may be used in arousing interest in the textbook material, or, as questions arise in connection with the study of the textbook, pupils may use the supplementary material to answer their questions. Pupils should be encouraged to note geographic materials and to make reports concerning them.

Rcsults. The teacher has the responsibility of seeing to it that each pupil shall become acquainted with the various types of geographic materials, that he shall understand how to use them, and that he shall have a desire to use them. One fundamental aim of the teacher in connection with geography should be to give the child the ability to find quickly and satisfactorily any item of geography concerning which he may wish to inform himself in after life.

In connection with observational geography the child, on the basis of need, becomes acquainted with the various ways of conveying ideas, through the use of symbols, to others. Some of the symbols are in general use in all subjects, and some, as maps, are particularly pertinent in geography work. The child, through his acquaintance with symbols as a means of self-expression, is prepared to interpret them. Through the numerous means of conveying ideas the pupil makes an intensive study of the world as a whole and its various parts. An increasing grasp of subject matter is accompanied by an increasing ability to recognize and interpret the symbols of geography. 


\section{Suggestions for Further Study:}

1. What is the relation between observational and symbolic geography?

2. Select five pictures that are valuable geographically and five that are almost valueless geographically. Explain your basis for selection.

3. Select a geographic topic and suggest a series of pictures that would assist materially in the study.

4. Attend a "movie performance" and indicate the extent to which geography was desirably depicted.

5. Read a daily newspaper with respect to $(a)$ the important place names mentioned and $(b)$ the current events with a strong geographic viewpoint.

6. What are the essential characteristics of a desirable geography textbook?

\section{Sclected Rejerences:}

Expression Work:

Dow)iE, R. E., and Kirchwey, C. B. The Teaching of Geography, chap. viii, pp. I 10-120.

IJAsinx, L. A. "Simple and Rapid Method for Making Relief Models from Contour Maps," Joumal of (ieguruphy (1917), Vol. XiI. pp. 97-100.

Lonisck, A. K. "lilock Diagrams," Joumal of (iiostuphy (1920),

Vil. XIX, pp. 24-33.

MalR. I. W. "Theme Writing in Geography," Journul of Geogrmflh. Vol. X. p). 130-131.

VAN CHEF, L. "Language of Geography," Joumal of Geografily, Vol. XI, pp. $235-238$.

Globrs:

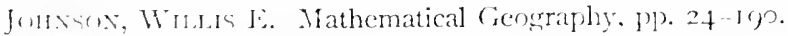

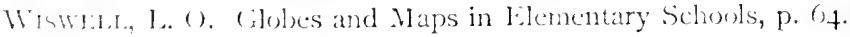
Maps:

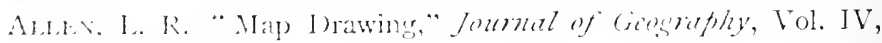
I) $33^{\circ}-33^{\prime}$. 


\section{REPRESENTATIVE GEOGRAPHY}

Andrews, A. A. "Maps in the Teaching of Geography," Journal of Geography, Vol. I, pp. 97-102.

Browv, R. M. "Map Reading, South America," Journal of Geography, Vol. IV, pp. 273-288.

Dodge, R. E., and Kirchwey, C. B. Teaching of Geography, chap. $x$, pp. $126-135$.

Gulliver, F. P. "Orientation of Maps," Journal of Geography, Vol. VII, pp. 55-58.

Holtz, F. L. Principles and Methods of Teaching Geography, chap. xiv, pp. I62-174; chap. xv, pp. 175-204.

Keltov, M. E. "Experiment in Fourth-Grade Geography," Journal of Geography, Vol. XIV, pp. 245-25 I.

RevwaY, JaCQues. New Basis of Geography, chap. ix, pp. 156-172. Sutherland, Willian. The Teaching of Geography, chap. xx, pp. 235-26r.

\section{Pictures:}

Averill, L. A. "Educational Possibilities of the Motion Picture," Eiducational Rerierw, Vol. L, pp. 392-398.

Сhamierlain, J. F. "Use of J'ictures in Geography Teaching," Joumal of Education (1914), Vol. LXXIX, pp. 523-524.

Gardner, L. M. "Picture Study," Joumal of Geography, Vol. XIII, pp. 85-89.

Hine, L. W. "The School Camera," Elementary School Teacher, Vol. VI, pp. 3+3-3+7.

HoLtz, F. L. I'rinciples and Methods of Teaching Geography, chap. vii, pp. 60-71, 83-95.

Suther laxd, Williail. The Teaching of Geography, pp. 193-202.

\section{Textbooks:}

CAlkivs, R. D. "The Text, the Course of Study, and the Teacher," Jourmal of Geography, Vol. IV, pp. 164-167.

DonciE. R. E., and KuRchwer, C. B. Teaching of Geography, chap. ix, pp. 120-126.

Hall-(2)est, Alfikid. The Textbook (1918), p. 247.

HoLtz, F. L. I'rinciples and Methods of Teaching Geography, chap. iv, pp. 20-29; chap. xxiv, pp. 321-334. 
Kexrox, W. J. "Consideration of Geography Texts," Elementary School Teacher, Vol. VI, pp. 97-107.

Sutherlani, William. The Teaching of Geography, chap. xv, pp. $172-18_{3}$.

Supplementary reading :

DODGE, R. E., and KIRCHwey, C. B. Teaching of Geography, chap. xiv, pp. $181-193$.

Grose, H. D. "Making Library Work, Field Work, and Laboratory Work Mutually Supplemental," Joumal of Geography, Vol. XIV, pp. 253-256.

Holtz, F. L. Principles and Methods of Teaching Geography, chap. xiii, pp. $156-181$.

Sutherland, William. The Teaching of Geography, chap. xvi, pp. $183-193$. 


\section{PART FOUR. THE CLASS}





\section{CHAPTER IX}

\section{CLASS ORGANIZATION}

Threefold conception of class organization. For working purposes the class may be organized ( $\mathbf{r}$ ) as a unit, (2) in subgroups (group work), or (3) on an individual basis. The three organizations indicated are not sharply separated. A class of thirty may be given the same assignment and divided into groups, each group being held responsible for a certain part of the assignment, or each member of the class may be assigned a different topic.

The class as a unit. The whole class may work on the problem "Account for the dominating significance of manufacturing in the New England States." During the study period each member bends his efforts toward attempting to solve the problem. Each individual is responsible for the interpretation of the problem. There is no phase of the problem that he can conscientiously neglect. His ability to meet the situation on his own initiative is challenged. His success depends in part upon his ability to interpret maps and books.

During the recitation period the class discusses the material that has been secured. The statements of each member are received and evaluated by the other members. Every student has studied each phase of the problem and is prepared either to discuss or to criticize the statements of other students. The whole discussion is appreciatively 
followed to the extent that the student has mastered the assignment. The recitation period is a clearing house for the exchange and modification of ideas. This type of organization has the advantage of placing on each pupil a maximum responsibility of meeting the whole situation individually. Depending on himself, he is stimulated to "see a problem through." The desirability of checking one's conclusions with those of other people is noted through the class discussions. Individualism, checked by social evaluation, is emphasized.

Group work. In an attempt to secure a greater socialization of the course of study, teachers have placed increasing emphasis on group work. The class may be divided into any desired number of subgroups. The problem "Account for the dominating significance of manufacturing in the New England States" may be subdivided into a sufficient number of minor problems so that each group will have a subproblem. The teacher may indicate the subtopics, or preferably the class as a whole may suggest the topics that should be studied in an attempt to solve the problem.

The class, with the help of the teacher, should plan the details of the work. The class may be divided into a variable number of groups accordirg to the number of minor problems. It is not necessary that all the groups shall contain the same number of pupils. If the minor problems vary in importance or in available material, the number in each group may vary accordingly. Inasmuch as the pupils are grappling with a new situation, the suggestions of the teacher will be helpful in securing a reasonably satisfactory distribution of topics and of groups. 
Ordinarily it seems better to select a leader for each group. The leader may be selected by the class, occasionally by the teacher, or each subgroup may select its own leader. If the leaders are selected, each leader may select in turn students for his group. This method, however, emphasizes the group organization apart from any special interest of the pupil in a minor problem. The pupil must adjust himself to the problem which his group happens to have. The volunteer system may be employed, and each student may select the minor problem that he prefers to study. This method emphasizes individual adjustment on the basis of strong interest already existing in the subject matter, and an appropriate distribution of pupils in relation to the various topics may not be secured.

In many instances it may seem wise to steer a medium course. The topics, with the suggested number of pupils needed, may be listed on the board. Pupils may be asked to volunteer for each topic, and then those topics for which there is least demand may first be assigned. If only five pupils are wanted for the first topic, and ten volunteer, the teacher may temporarily pass by this topic and all similarly popular topics. If five are wanted for a topic, and only three respond, the teacher may call for more volunteers. Frequently enough pupils, stimulated by a desire to coöperate and pleased with the thought that they are yielding their preferences for the general welfare of the group, or because their original preferences were not very strong, will volunteer. If the less popular topics are disposed of first, the more popular topics are automatically disposed of. If the coöperative class spirit is inadequately developed, it may be necessary for the 
teacher arbitrarily to make selections. Pupils should have the opportunity both to follow up their preferences and to adjust themselves to problems in which they have no particular interest.

Care should be taken not to build up fixed groups. Pupils, prompted by friendship, may clique together not because of a special interest in the same topic but because they like to work together. Such combinations, once effected, may tend to become self-perpetuating. Pupils rearranged in different groups have a broader experience in learning how to work with other people.

If each group selects its own leader, there will be a tendency to select the one who has shown marked qualities of leadership. Unguided, the subgroups may select the same leaders repeatedly. According to our democratic conception of education each pupil should have the opportunity to work under a leader of a group and also the opportunity of exercising the functions of leadership. Pupils tend to clique together, to select the same topic, and to appoint the same captain repeatedly because they have not learned to analyze such situations. The real teacher will not arbitrarily break up these tendencies. She will analyze these situations with the children, and she will attempt to get their intelligent coöperation in realizing the maximum possibilities of group work.

Report of subgroup to the class as a wholc. The individuals of the group must coöperate; the groups also must coöperate in order that the larger problems may be solved. Theoretically the major and minor problems should make such an appeal that each pupil in preparing the work, in explaining to the group, and in listening to 
the explanations of others is enthusiastically interested. Practically, because of failure to realize ideal conditions, various devices may be helpful. The group leading the discussion, stimulated by the responsibility of carrying forward the program and the desire to win the approbation of the class, in addition to the stimulation secured from the problem itself, ordinarily is mentally very active.

Since the pupils are immature, they may need assistance in discovering the attributes of a well-presented report. The pupils should be encouraged to criticize constructively their own work and the work of other members of the class. They should analyze the responsibilities of the "giver" and the "receiver." The group reciting, with an absolute mastery of its subject matter, should present its materials in a clear, convincing, enthusiastic manner. New words should be written on the board, and place names should be located on the map. The pupil, anxious to please, may attempt to memorize the pertinent parts of an article. His mind may be diverted from the thought to the form. He may copy the words from a book and read these "notes" to the class in such a way as to indicate that he is not thinking. The pupil may be astred to talk without his notes, or, if he apparently has memorized a form, an interruption through a few well-directed questions may break up the memory chain. The teacher should constantly attempt to lead the pupils from the plane of mere transmission of the thoughts of another to the plane of giving ideas which the child thoroughly understands.

Rarely will it be possible for pupils to give a finisind presentation. They are not masters of the art. The 
teacher, with her knowledge of the interests and experiences of the class, with her broader grasp of subject matter, should be able to select, organize, and present subject matier in a more appealing way. The teacher's talk may make a stronger appeal because of the care with which the details have been selected and may be more profitable to the listeners. Pupils should be trained, however, not only to receive knowledge but to present their views effectively. However conscientiously the group may attempt to present its topic, it may fall short of an ideal presentation with reference to the rest of the class.

The listeners. Since group presentation is rarely ideal, the attention of the rest of the class is not always held, even though the topic itself may be very appealing. In spite of a well-selected topic and an excellent preseistation, certain students, unchecked, may yield to some more appealing interest. Numerous devices may be used to retain class attention. Pupils not only need to learn the art of presenting, they need to learn the art of listening. As a matter of politeness and tolerance of other viewpoints pupils should learn to control themselves irrespective of the topic that is presented.

The group in charge has a responsibility that it cannot shift without detection. The listeners, unless presented with ideas that they can use or for which they will be held responsible, may secure little benefit, even though outwarlly they are attentive. The presentation may be followed by a quiz, the questions being asked by the group, by the teacher, or by various members of the class. The group presenting the material may be questioned. The class may be asked to write on one or more questions, 
which will permit individual checking of results. Pupis may be asked to engage in systematic note-taking, to list appropriate questions as the discussion proceeds, and to summarize the discussion. The class may occasionally be asked to criticize the presentation of the group, and this may make it alert, although in this instance the emphasis is shifted from subject matter to the means of presentation.

Idcal group work. The discussion thus far has proceeded with the assumption that the work is imperfectly motivated and that the means of transmitting ideas, because of immaturity, is faulty. As perfect motivation is more nearly attained the need for devices correspondingly decreases. The teacher's ambition is to secure perfect motivation; to the extent that she fails she must resort to devices or lose control of the situation.

The teacher will attempt to get some objective before the class which the class feels is decidedly worth while. She will analyze with them the materials that ought to be examined. If their interpretation will involve too much work for each individual, the need for group work, involving a subdivision of the unit of work, arises. Each group feels its responsibility because its contribution is necessary in reaching the goal. The class is interested in the contribution of each group because coëperative endeavor will enable them to reach the goal more guickly and economically. Each student is interested in every contribution as a means to a desiner end. No problem of discipline arises, and there is no neet of securing devices to hold the nttention of the punil, for his interest is centered on the possible value of the material in hejoing nim to reach the goal. The eagerness of the pupils to give and to 
receive more than counterbalances the effects of imperfect giving and receiving. The teacher will attempt to realize this ideal situation; in proportion as she fails she must resort to devices and arbitrary control.

Questioning. The pupil, in reporting, may succeed in presenting his report more effectively if he occasionally will ask questions and give the class an opportunity to make inferences. A subgroup need not always give a formal report. It may stand ready to answer any questions of the class dealing with its topic. The questions challenge the ability of the group to use its findings in response to class needs and tend to break up any mere memory organization of the report.

Advantages of group work. There are several striking advantages that may come from group work. (I) A teacher may have found it diificuit to secure responses from certain members of the class. If such a person becomes a member of a small group, social pressure of other members of the group will be brought to bear on him. The pupils are quick to discover and shame the slacker into action, and they are correspondingly successful in levying on the abilities of the timid persons. (2) The student who has been attempting to monopolize the recitation learns to check himself and finds an outlet for a part of his energy in assisting the weak members of his group to participate. (3) Training in leadership is given. (4) Not only is coöperation in a group secured but also the coöperation of the various groups because of the common objective. (5) Much of the responsibility is shifter from the teacher to the pupils, where it belongs. (6) Initiative is readily developed. (7) Economy of time in the 
consideration of the problem is effected because of the division of the work. (8) More ground can be covered in a given time because of the team work.

Difficulties of group work. There are certain difficulties that may arise in connection with group work. Teachers may become enthusiastic over group work because of the ease with which they can shift the responsibility for the work to the pupils. The teacher, lulled into minimum activity, may permit the assignment to degenerate into purposeless, topical assignments to each group, each group helping the class to beat time through the recitation period. If the class period is divided into the needed parts so that each group can recite, each group may learn from experience about how much time it will be given, and it may prepare merely for the length of time required to "take up" its part of the time. The pupils may not develop the independent spirit that comes from incividual work. The leaders may tend to do most of the work. The teacher will need to guard against (I) undue exercise of leadership by a few, (2) the monopoly of work by a few, (3) the mere transmission of ideas by memorizing articles, (4) careless, inaccurate, or irrelevant statements, ( 5 ) poor presentation, (6) willful inattention, and ( 7 ) purposeless work.

Individual work. Incliviclual work may consist of individual assignments of minor problems, each bearing on a major problem; individual assignment of articles, each bearing on the same topic; an individual assignment to sectre further light on a topic under discussion or to be discussed; or an individual assignment to satisfy some problem in which an individual expresses particular interest. 
Perhaps the most common individual assignment involves a preparation of a report for the class. Following a discussion of the lumber industry, the teacher may assign each pupil a different slide or picture to be studied and later interpreted before the class. In a discussion of the resources along the Trans-Siberian railroad the whole class may express an interest in the difficulties involved in its construction, and some individual may be asked to read a given article or to attempt to find the desired information. He will later make a detailed report to the class. In a study of China an individual, but not the class as a whole, may express a desire to learn more about the significance of the Great Wall in Chinese history. The individual concerned may make a detailed study, but, because the class is not generally interested, a report, if made to the class, will be very brief. The individual report may be made with the aim of acquainting students with certain books or magazines. Each pupil may be assigned a bound volume of the National Geographic Magazine, the Geographic Review, the Journal of Geograpily, Asia, or the Pan-American Union, or the current numbers of other magazines, and he may be asked to select an article and prepare it in the form of a written report for presentation to the class. It is not the business of the school to prescribe maximum essentials, but minimum essentials. Individual reports permit the teacher to stimulate each pupil to accomplish as much more than the minimum essentials as seems desirable.

An individual assignment is of particular value in developing and testing the ability of the individual to work alone. In the reading and reporting of an article 
some pupils will insist on reporting from notes or from memory almost the exact statements of the author. Inexperienced pupils will not readily discriminate between important and incidental statements. There will be a tendency for a pupil to pass on to a class statements that he himself does not understand. Pupils should be encouraged not to be mere transmitters of knowledge but to raise the special report to a problem level. They should select, evaluate, and reorganize the material. The final report should indicate a thorough mastery of the article.

In the foregoing discussion an attempt has been made to indicate the value of class, group, and individual work. Group work is being emphasized in many schools, and in her enthusiasm the teacher may feel that all geography work should be organized on this basis. The thoughtful teacher, however, will make frequent use of all three class organizations suggested. It should be noted that the three organizations shade into each other. The individual report has many of the characteristics of the group reports, and the class as a whole is one large group. In any case the pupils do not exist for the purpose of exemplifying these class organizations, but the organizations are analyzed and skillfully utilized in the development of the pupils.

\section{Suggestions for Further Study:}

1. In the last analysis should group and class work be measured through the accomplishment of the class as a whole or through the accomplishment of each individual?

2. Which of the three kinds of organization suggested should be emphasized the most? 
3. Does it, after all, make much difference how the class is organized if the pupils are mastering the content of geography, or are there special habits, attitudes, and ideals that the pupils should secure through the study of geography?

4. What are the functions of the teacher when the class is doing group work? May she become absolutely unnecessary?

\section{Selected References:}

Bigelow, Lria E. "The Individual Assignment in Geography," Elementary School Teacher, Vol. IX, pp. 250-256.

KilPATRick, VAx E. "Emancipating the Individual Pupil," Education, Vol. XXX, pp. 375-3S6.

Mafberry, L. W. "Individualizing Problems for Pupils," Elementary Sihool Teacher, Vol. XVIII. pp. 133-137.

Morkis, Wilsox C. "The Individual and our Educational System," School and Socicty (1915). V'ol. II, pp. 55t-557.

Scott, Cons A. Self-Organized Groups, Kindergarten and First Grade, Vol. II, pp. 3I6-320.

Siaw. C. B. "Some Experiments in Group Work," Elementary" Sihool Teacher, Vol. VII, pp. 329-334. 


\section{CHAPTER $\mathrm{X}$}

\section{SOCIALIZATION AND FREE ACTIVITY}

Socializing the school. The school has been established primarily with the aim of preparing for social efficiency. The school has always been a relatively socialized institution, but society is dynamic, and it has been difficult to adjust the school curriculum in accordance with the changes so as to keep the content thoroughly socialized. The increased complexity of social organization has added to the difficulties of determining the fundamentals of a socialized school. The influence of the Greek ideal of culture apart from utility has still further retarded a thorough socialization of the school plant. Since the school not only should help the child to adjust himself to the present social organization but also should give him the ability to readjust himself to the changing conditions of society, it is desirable that a broad view shall be taken in the socialization of content.

Those who daily come in contact almost exclusively with children can hardly be expected to have their ring of social interest widened beyond the confines of the school playground or the second back alley. . . Not infrequently teachers so lose touch with the needs of the social order that this in its progress washes past them altogether, leaving them stranded himh and dry like fossils on the deserted shore line of an ancient sea. As for taking any active part in civic and political affairs, 
some teachers meet perfectly a recent characterization of college students - "as innocuous as a flock of sheep." 1

Socialization resolves itself into two parts- ( I) socialization of the content and (2) socialization of the method. The socialization of content involves the selection of subject matter that has a well-defined relation to presentday activities. The socialization of method involves the organization of subject matter in relation to the class in such a way that, through the mastery of content, the pupils secure positive training in social relations.

Geography as a socialized study. Geography, dealing with man's relations with his physical environment, is ideally adapted to socialized work. The pupil, through the study of geography, sees man in his socialized relations making a living directly or indirectly from mother earth. He sees people coöperating and groups of people coöperating. The subject itself, therefore, suggests both to teacher and to pupil the value of socialized work.

Socializing the work of geography classes. If socialized work is desirable, as indicated through the study of geography, in the out-of-school activities, it is a reasonable assumption that the school, an institutional organization of society, can also profit through socialized work. What are some of the characteristics of socialized work?

r. Socialization demands that the pupils shall do their proportionate share of the work in accordance with ability. The teacher may be regarderl as a pupil who, presumably as to methods and knowledge, is a little

${ }^{1}$ D. D. Johnson, "Socializiner Education," School and Society (December is, i915), Vol. II, pp. 808-809. 
farther along than the rest of the pupils. She is a member of the social group that meets with specific aims in view.

2. Socialization demands that pupils shall enter into the discussion in a democratic manner. No pupil will be permitted to monopolize the recitation period. Pupils who do not contribute will be made to feel that they are passive members of the group. Their own self-respect will demand that they participate. Pupils inclined to talk too much, on the other hand, will resolutely give way to the more timid members. The active will encourage the passive; the passive will arouse themselves so that they will have a voice in the proceedings.

3. Socialization demands that pupils not only shall answer questions but also shall ask them. In the formal recitation work it has been the custom to regard the teacher as the one who should ask questions and the pupils as the ones who should answer them. Pupils, through their own questions, can more nearly meet their real needs than a teacher, who is unacquainted with the special difficulties that the child has encountered. It requires skill to ask as well as to answer questions. The teacher, in common with the other pupils, has a right to ask questions and also has an opportunity to answer questions, but her assistance in either case is given only so far as it is necessary in order to enable the children to utilize the time and material in the most effective fashion.

4. Socialization suggests that pupils may originate problems or topics for discussion. With respect to any topic thus advanced, the class may consider whether the topic is pertinent and worth while. The guidance of the teacher may be necessary in assisting the pupils to form 
a judgment. Frequently, if teacher and pupils are living on the same intellectual level, one topic leads to another in such a way that pupils can make the proper suggestions and thus adopt topics which the democratic situation demands.

5. Socialization suggests that sameness of preparation on the part of pupils does not necessarily bring the best results. It is desirable that a variety of material bearing on the topic shall be available as a part of the school equipment. Pupils should be encouraged to depend on a variety of sources. They should be made to feel that their success, in large part, depends upon their ability to make actual contributions to the classroom discussions. The classroom becomes a clearing house for the ideas of the pupils. False icleas are corrected and concepts are enriched and increased. The democratic exchange of ideas, involving a maximum of mental activity, promotes rapid development.

Socializing industrial studies. In a discussion of the silk industry some pupil may visit a silk factory, a silk wholesale house, or a silk retail house. Some child may be able to secure silkworms. Various children may secure mulberry leaves, different articles made from silk, stories relating to the inclustry, etc. It may be practicable to assign different topics to different members of the class. The class may hold each member responsible for a specific contribution: or each member may be held responsible for a specific contribution, and all may be assignerl certain topics: or each member may be held responsible for the same topic, but a spirit of rivalry may be reveloped in the securing of really valuable material. In general, it 
is better to have a definite nucleus of material to illustrate the study, in part as an organizing center for the individual contributions, in part to take the place of materials that the children cannot at the moment secure from independent sources.

On a field trip the teacher may ask the children to be observant of any details that may come to their attention. The teacher may ask questions; the pupils may ask questions. Everyone feels the responsibility of making a contribution either by directing the attention of the class to a particular thing or by helping to answer the questions that may be raised. The teacher indirectly retains her leadership of the party, and her attitude is unobtrusive.

A test of socialization. A test of successful socialization is made when a teacher is called out of the room or when she is unable to aitend the class exercise. This is particularly significant in the upper grades, since with the increasing development of the pupils, if socialization is successful, the direct influence of the teacher should be less and less needful. If the pupils are able to continue the exercise and to discuss it along desirable lines, the teacher can flatter herself that she is working in the right direction. In a room where the personality of the teacher is dominant a class may dissipate its energies when the teacher is absent. The teacher, as a leader, presumably knows how to conduct herself as a member of the social group. Her aim as a director of children is to give them this same knowledge and desire.

Function of the teacher. The responsibility of the teacher is just as great in socialized work as in an 
arbitrarily directed exercise. In the lower grades the teacher consciously directs the work of the class with definite objectives in mind. With increasing maturity both teacher and pupils are guided more and more by the subject matter, and as the pupils come nearer and nearer to the general intellectual level of the teacher, the teacher's direct and indirect leadership becomes less important. Even though some of the pupils should reach the same intellectual level as the teacher, since the pupils have learned the value of coöperative work, all can continue to advance through helpful group study.

Free activity. In its extreme form a pupil engaging in "free activity" is permitted to do just as he pleases. The pupil, during a free period, may not care to study the particular part of geography that the class is studying, or he may prefer to study some topic wholly foreign to geography, or he may not care to study at all. A pupil left wholly to his own desires may engage in activities that are harmful to himself or inimical to the best interests of society. The free-activity period permits the teacher to make a special study of the child's genuine attitudes and special interest.s and gives her an opportunity to note his shortcomings and his strong points.

No indivirlual can engage in absolutely free activity. Nature conditions man's activities, and the social relations of the indiviclual frequently limit his activities. Consequently; when the expression "iree activity" is used, free activity whin limits or limited free activity is meant. There is a considerable diference in the extent to which a person may be permitted to ensage in free activity. In the arlult group there are all gradations of 
free activity, from the activity of the man who always coniorms to the laws because of desirable habits and attitudes, and therefore never is compelled by society to do right, to the activity of the man who frequently breaks the laws in his attempts to engage in antisocial free activity, and therefore finds himself restrained by the stern hand of the law. The problem of the school is to secure right habits and attitudes, so that the pupil, when given relative freedom in determining his actions, will always enter into desirable social relations.

Desirable free activity cannot always be secured by arbitrary control. The pupil needs to have experiences in initiating activity. The socialized recitation permits the child to propose plans of action, while at the same time his plans are approved or modified by the other members of the group. Through active participation the pupil secures training in social relations, the pleasant or unpleasant effects of which tend to establish habits and attitudes of a desirable nature.

Gcography and free activity. It has been shown that the discussions in geography can be readily socialized. In the geography classes, therefore, the pupils can be given that training which will tend to cause the free activity of the individual to conform to social needs. Not only may this social free activity be secured through the coöperative efforts involved in the various forms of class organization, but the subject matter itself may be used so as to permit considerable freedom of action.

Examples of limited free activity: a country. The pupils of a geography class were told that they might read anything about Japan that appealed to them. They 
were to make a brief report at the next recitation period. As each pupil recited the other pupils took notes. The pupils were asked to organize the notes and to classify them. The pupils then secured supplementary contributions. Each pupil attempteci to organize the material presented. As a result of the miscellaneous contributions the individual outlines on Japan were secured, and from the individual outlines the class comparatively agreed upon a single outline. The class proceeded from a wealth of disorganized details to a systematic organization. Absolute freedom of selection of material bearing on Japan was at first permitted, but, as the contributions were made, the restricted new material and not the teacher gradually limited the range of choice. Finally an outline organization of material was effected to which the pupils adjusted themselves in their further studies. The pupils were not forced to conform to an outline organization imposed on them by the teacher, but they gradually evolved and used an outline organization because they had discovered its value.

Study of a continent and free activity. The pupils were told to glance over the articles in their textbooks concerning the different countries of South America. They were told to select the country that they preferred for cletailed study. Each pupil was held to the material of the textbook concerning each country. The periods during which each country would be discussed were indicated. The pupils who har marle a special study of a country contributed their additional information at the time that the class was studying about that country. 
Supplementary reading. During the time that the class was studying Asia pupils were given a reference list of supplementary material dealing with that continent. They were told that the list was given them merely for their convenience and that they might make a selection of any other materials bearing on Asia. This work was not required, but the pupils were made to feel that their supplementary work was worth while through the class contributions they were encouraged to make and through the list of voluntarily read books and articles submitted to the teacher.

Socialization and free activity in harmony. Unanalyzed, "socialization" and "free activity" seem to be contrasted terms. The two phases of development are in reality different viewpoints of the same educational endeavor. The individual is a unit of society. The establishment of desirable relations among the different members of a group by appropriate use of the subject matter is socialization; the unhampered initiation of activity, based on the desires and judgment of an individual, constitutes free activity. The teacher, with the assistance of content subjects, - particularly geography and history, - attempts to develop the individual in such a way that his actions, as determined by himself, will harmonize with the common group welfare.

Suggestions for Further Study:

1. Note the characteristics of a thoroughly socialized recitation.

2 . Is it possible for a person to engage in free activity and at the same time be thoroughly socialized? 
3. Should the greater emphasis be placed on the socialization of content or the socialization of method?

4. Is geography superior to most subjects in the possibilities that it affords for highly socialized work?

\section{Selected References:}

Barbour, C. W. "Free Period as an Educational Factor," Kindergarten and First Grade (1918). Vol. III, pp. 133-139.

Blgelow, LixA E. "The Social Life in Geography," Elementary Sihool Tiacher, Vol. IX, p. 113.

Curmiss. Robert A. "A Completely Socialized School," School and Society (1919). Vol. X, pp. 685-692.

Fox, Florexce C. "Socialized Recitations," Sithool and Socicty" (191S), Vol. Vill, pp. 650-651.

Johnsox. D. D. "Socializing Education," Sihool and Society (I9IS), Vol. VII, pp. $86_{5}-873$.

Miles, D. "Socializing Outside Reading," English foumal (I9I 7), Vol. VI, pp. 330-333.

Pexdletos. C. S. "Socialized Recitation," American Education (1920), Vol. XXIll, pp. 307-312.

Pierce, B. L. "Socialized Recitation," Historical Outlook (1920), Vol. XL, pp. 307-317. 


\section{CHAPTER XI}

THE RELATION OF THE STUDY PERIOD TO THE RECITATION PERIOD

\section{SUPERVISED AND INDEPENDENT STUDY}

Former conception of the recitation period. When the recitation period was regarded as a "hearing" period for lessons learned from books, emphasis was placed on repetition of form as well as repetition of fact. The teacher, with open book, followed the words as the pupil recited. The more nearly the pupil could recite in the language of the book the better his recitation. The study period, dealing with a particular topic, necessarily came before the recitation period.

Since children were "little grown-ups," the same order of preparation and recitation and the same method of memorizing and reciting was followed in the lower and the upper grades. The principal work of the teacher was to assign in terms of pages and to hear recitations so as to test the faithfulness with which the pupils had memorized the lesson.

Present conception of the recitation period. The recitation period has come to assume a much more important place than the mere assigning and testing of the book material. Sheer memory work of assigned material in gcography has been reduced to a relatively insignificant 
position. The recitation period is a meeting period for the discussion of problems and for the opening up of new lines of thought. The recitation period may provide material for the study period; the study period may provide material for the recitation period. These periods react upon each other. The pupil secures motives in class for studying certain topics; in the studying of the topics the pupil may have other motives aroused which he will communicate to the rest of the class during the recitation period.

A motivated assignment. In the discussion of the assignment during the recitation period a class may raise questions which cannot be answered without further study. All inadequately answered questions may be listed as a basis for the work of the study period. Since these questions have arisen in relation to needs, conditions are favorable for a high degree of mental activity during the study hour. At the conclusion of a discussion, problems or topics, closely related to the discussion, may be suggested by pupils and teacher as a basis for the succeeding discussion. If the pupils have a hand in the assignment of their work, they will feel an individual responsibility in meeting the conditions. It may be necessary occasionally, however, for the teacher to make the assignment or at least present the material out of which the assignment naturally arises. The teacher attempts to present the initial material in such a way that the interests of the children are aroused in the material and in the problems suggested by the material; the teacher, in other words, should motivate the work. The motivation may be secured in the recitation work as a whole, in the recitation 
work in part, or in presentation material specially prepared and presented. The time required for the proper assignment of a lesson may vary from the whole period to a few minutes.

The study period. During the study period the pupil proceeds to attempt to find the answers to the questions that have been raised. He may become interested in supplementary problems and may attempt to solve them on his own initiative. $\mathrm{He}$ is not attempting merely to memorize certain statements imposed upon him by the teacher, but he is trying to meet the requirements of his own mental life. He wrestles with problems individually during the study hour and as a member of the group during the recitation period. In this way the individual and the social are admirably combined in promoting his development.

Sccuring motives during the study period. Books contain the treasured experiences of the race. Written articles are variably interesting to various individuals; they may arouse interest and motives as well as afford the materials necessary for the satisfying of motive. With increasing maturity pupils should come to depend more and more upon these sources of knowledge. If pupils are referred to books only to satisfy needs already aroused, they may come to depend on books as reference material for the satisfying of these needs. Books, however, should also arouse needs to be satisfied. Pupils should learn to evaluate material for themselves and to initiate, with the help of books, their own problems. Pupils, therefore, may study books and come to class with problems that were raised and answered and problems that were raised but not 
answered. An undue emphasis should not be placed on poor reading material, but the child should learn to discriminate between the good and the bad.

Motives and passing interests. The adult does not always follow his own instinctive interests in determining his activities. He must submit, in part, to the opportunities and requirements of the social group. His maximum service to society may be found in work that is not according to his own inclinations. His economic welfare and the welfare of those dependent upon him may demand that he continue. If as a pupil he were taught only to follow his own interests, or to pursue the problems that inherently were appealing to him, he would not be suitably prepared, in so far as the school is responsible, for shouldering his social responsibilities. In the lower grades it is desirable that the passing interests of the children shall be considered. They have not yet developed an ability to engage in a sustained, prolonged effort to reach a desired goal. They should have some practice in assigning themselves worth-while tasks or of doing tasks assigned, whether these tasks are agreeable or not. The worth-whileness of such tasks should be seen by the pupil.

Supcrvision of geography study. The geography book is placed in the child's hands in the lower grades, when his reading vocabulary is still very limited. While geography is studied primarily because of its richness of appropriate content, the pupil also enlarges his reading vocabulary. The pupil needs assistance in reading the page and in interpreting the maps and pictures. The recitation periorl may frequently become a supervised study period, in which the pupils are assisted to master the 
material of the book accurately and economically. An oral development of a topic may be given in which the words with which the pupils may have difficulty are placed on the board. The pupils may then be asked to read the discussion of the topic in the book. The oral presentation and the emphasis on the difficult words will prepare them to study individually.

The recitation period may be turned into a supervised study period whenever there is a unit of work in the mastery of which the pupil may need assistance or whenever there are certain habits of study that pupils should be assisted to form. As the tools of geography are mastered the need for supervised study will lessen, and the teacher will be able to give the pupils any needed assistance in connection with the assignment. The pupils should be gradually weaned away from dependence on the teacher during their study period to a dependence on their own abilities. There is no pedagogical objection to supervised study of all the study periods in geography, provided the teacher assists the pupil only to the extent that the pupil, unaided, will flounder. Since the pupil should have increasing opportunity to study independently, financial economy in the management of schools suggests the desirability of having a study period apart from the recitation period, the latter period when desirable serving the need for a supervised study period. As has been noted, the recitation period may be a study period in which pupils and teacher, studying together, may find problems for special study in their study hour.

Supervised study, in instances, has been abused by teachers who have felt that they must be constantly 
talking with the children. The independent study of the children has been interrupted; the pupils, through concert study, have not had an opportunity to reflect and master the material. Independent ability and initiative have been smothered. It is a wise teacher who has learned to assist enough but not too much.

Recitation and study as factors of the same lesson unit. The recitation and the study period should be regarded as interlocking parts of the same unit of study. The wideawake and efficient teacher will constantly vary her work so that whether the pupil is studying by himself or as a member of a group the two periods will mutually reënforce each other. Each period should afford information, interpretation, and inspiration for the valuable utilization of time in the other.

Teaching pupils how to study. The primary purpose of supervised or directed study is to teach the child how to study economically. The pupil needs training in the use of the textbook, supplementary readers, newspapers, magazines, the dictionary, the encyclopedia, and maps and globes. He needs training in learning how to express himself through maps, diagrams, charts, drawings, models, and language. He needs to learn how to read quickly and at the same time to understand, organize, and remember that which is read. He needs to know how to get appropriate material from a library. He needs to learn how to work desirably with other people. He needs to learn how to keep himself physically in good condition for sturly and how to secure a favorable physical and social environment for work. All these needs can be met through the study of geography. The teacher should not expect the 
pupils to learn all these things through the haphazard method, but she should supervise the work of each child sufficiently to insure that the needed knowledges, skills, habits, and attitudes have been formed. The pupil will learn through imitation, through reflection, and through trial-and-error experience.

If the pupil has acquired a wide range of subject matter indicating how man has adjusted himself to the earth, if the pupil has the ability to use the tools of geography in securing needed knowledge, if he has a broad, sympathetic outlook toward mankind, and if he has developed an interest in world as well as local affairs, then the teacher may confidently feel that she has been directing the geography work along desirable lines.

\section{Suggestions for Further Study:}

1. Has "supervised study" resulted in marked improvement in the educational program?

2. Select a topic in a textbook and indicate how you would teach a group of pupils how to study.

3. Assign a lesson to a class in such a way as to secure a maximum of study during the study period.

4. Attempt to evaluate a recitation period. Would the pupils have advanced more rapidly if a study period had been substituted?

\section{Sclected References:}

Farsmin, C. E. "Supervised Study," Eduation (1919), Vol. XL, pp. $171-177$.

Hal,-OLETT. A. L. "Supervised Study in the Grades," American Finuation (1920). Vol. XXIII, pp. 396-401.

Horx, ERNest. "Relation of silent Reading to Efficiency in Study." American Fiduation (1920). pp. 348-351.

Minok. Rvis. "Supervised Study," Sihool and Home Education (1920). Vol. AXXIA, pp. i68-170. 
PART FIVE. THE PROJECT, OR ACTIVE, METHOD 



\section{CHAPTER XII}

\section{THE MOTIVATION OF GEOGRAPHY}

Nature of motivation. The modern viewpoint in education has materially affected not only the content of geography but also its method. It is not enough that someone shall believe that certain topics should be studied by the child because of their value to adults. A child makes better progress in relation to those situations in which he has an inherent interest. An attempt should be made, therefore, to relate the materials to the child's interests and experiences and to arouse within him a motive that will cause him to attack the situation with enthusiasm and perseverance.

From the standpoint of the child the chief motives for worth-while geography work are:

I. Curiosity with reference to the world and its people. This may give a general interest in what is happening throughout the world, or what the people in other parts of the world are doing, or it may concern itself with the satisfaction of interest in important current happenings, as the war between Russia and Japan, internal strife in Mexico, and the efforts of President Wilson to bring about peace, the Balkan war, or the present [recent] European war.

2. The relation of geographical facts to economic values, as developed from real problems of the child.

3. The social value of geographical data, since they furnish a basis for the understanding of current happenings, the 
planning of trips and outings, and are constantly involved in reading and conversation.

4. The play motive involved in planning grown-up experiences and likewise in the use of geographical facts in games and contests.

5. The connection of geography with romance and adventure as needed in books of travel and adventure.

These separate motives seldom occur singly, but are usually combined in any worth-while problem in geography. ${ }^{1}$

Geography related to real conditions. The child should feel that he is studying about a real world, inhabited by real people, who are engaged in real activities. How many children have studied about Palestine at Sunday school and about another Palestine in school? How many children, ignorant of the fact that they were liying on or near a glacial moraine, have made a bookish study of glaciers and their work? How many children living within a natural region have recited glibly book information about the region without being aware that they were living within the region discussed? How many children, when discussing earth features, products, or regions at a distance, have thought of these regions as imaginary creations to be classed with Jack and the Beanstalk and Little Red Riding Hood?

Motivation through current events. Current events may frequently be used with excellent results in motivating geography topics. Almost every day the daily newspapers contain news items from such important cities as Chicago, New York, San Francisco, and Boston, and

${ }^{1}$ H. B. Wilson and G. M. Wilson, The Motivation of School Work (Houghton Mifilin Company, 1916), pp. 136-137. 
frequently from such important foreign cities as Rio de Janeiro, Buenos Aires, Tokyo, and Liverpool. There are accounts of economic activities, related to the production of rice, sugar, cotton, wheat, coffee, etc. If the pupil is interested in current events, the location of the places mentioned will add to their value. The atlas is a desirable reference book for place geography. "Get the atlas habit" is good advice. Not only does place geography assist in vitalizing current events, but the student may use current events as a basis for the interpretation of geographic situations.

Since many activities are closely related, when a motive for looking up materials is given through current events, the results of study will probably suggest other topics that it would be worth while to study, so that a whole series of related topics or problems will successively be uncovered, and the pupil will find himself spontaneously passing from topic to topic. The original interest created is genuine, having its origin in present-day activities. The successive interests aroused are genuine, because they have been aroused in relation to and as an extension of the original genuine interest. A few of the leading magazines which stress economic development should be available. The daily weather maps are valuable not only in arousing an interest in weather conditions but in helping to explain numerous economic situations. The publications of the United States Geological Survey, the Department of Agriculture, and state boards performing similar functions are valuable.

Motivation through local activities. Activities of the local community may frequently be used as a point of 
departure. The formal opening of the barge system on the Mississippi at St. Louis by the Federal government was used as a point of departure for an intensive discussion of the navigation of the Mississippi. The ceremony was attended by a number of students, and the press reports were used to supplement the first-hand observations. A visit to the weather bureau interested the children in a detailed study of the principles of weather forecasting. A visit to a small valley, and a study of forms and processes there, interested the children in a more detailed study of similar but larger forms elsewhere. A visit to an industrial establishment aroused an interest in knowing more about the economic world.

Motivation through construction work. A situation may frequently be made appealing through ihe use of construction materials.

"Illustrative handwork," as it is called, is all right if it is the result of free expression on the part of the child. Sometimes the "organizator" kills all handwork values. Not so long ago I wanted to photograph a table representation of a village of primitive peoples made by children in a third-grade class, but on making inquiries into the methods of teaching this particular project $I$ found that it was not handwork of the free expressional type but of the "exercise" type. There had been a series of lessons in dictated paper-construction work. The result was thirty to fifty huts, thirty to fifty boats, as many more trees. and so on, until each child had made at least one of each of the component parts of that village. It was not even a coöperative handwork project, because no individual or group of individuals were made to feel responsible for any particular part of the project. Was that village the outcome of the child's interest in the subject? Whose village 
was it - the child's, the teacher's, or the person's who planned the course of study? What had the children got out of the four to six hours of work? Perhaps a little more skill in handling paper, ruler, pencil, scissors, paste, and crayon. I doubt if the majority of children in grades one to four feel the need for skill, especially in paper construction, where so often the scissors come in so handily in rectifying a mistake in measuring or folding.

Let us make a contrast with another group of children who constructed an Eskimo village when the teacher used handwork to illustrate a story. In a second-grade class the children had been reading a story about two little Eskimo boys, and because of their interest in the story and in the illustrations in the book they had asked and obtained permission from the teacher to picture the story on the table. Realizing that if the project was to be effective it must be finished before the youngsters lost interest, the teacher had assisted wherever she felt the problem was beyond their capabilities. She had made the form for the igloo, and the wigs for the dolls; otherwise it was the children's own work. The children had placed mirrors to represent water; covered the table with cotton batting for snow; stained and dressed the dolls: made make-believe utensils and implements; and staged the dolls with the necessary "props" to illustrate the pursuits of the pupils. The teacher suggested that several of the children tell me the story represented. I selected three, who told me the story in serial form. Pointing to the various groups on the table, the children told me about the manners and customs of the Eskimos and were able to answer practically all my "why" questions which I had asked in order to test the depth of their knowledge. What had these children learned? First, they had handled a variety of materials: second, they had had some experience in coöperative work (the class had been divided into groups, each group being responsible for a scene); third, when doubts arose in any group concerning the scene they 
were depicting they had read and re-read, if necessary, those portions of the story which dealt with their project, and thus in giving concrete expression to their ideas they had clarified any hazy notions which they may have had, and the project took the place of a review. ${ }^{1}$

Motivation through other subjects. Experiences of children through other subjects may be used as an approach to a geographic topic. Literary selections may be used. "The Landing of the Pilgrims" may be used to arouse an interest in the New England States. History is very helpful. The explorations and settlements of the French in the Mississippi Basin may be used in arousing an interest in this region. The explorations of Mackenzie, Hudson, Magellan, Amundsen, and Peary are significant in arousing a present-day interest in the geography of the regions in question as they influenced these explorers and as they have influenced present-day activities. The teacher herself can frequently contribute something of considerable interest out of which problems may arise. Different members of the class may make contributions that will constitute an excellent basis for a more detailed discussion.

Interests and motives. Motivation suggests both a forward and a backward control. The new situation should hinge into the child's interests and experiences and at the same time should arouse a definite motive, prompting the child to act. Various subjects may furnish the means of motivating a geography topic, or work previously done in geography may be used. The unorganized

1. Adele Rurlolph, "Industry as an Elementary School Subject," Industrial-Arts Hasaine (May, 1920), Vol. IX, pp. I8I-I82. 
out-of-school experiences of the children are invaluable. Current events of the community or of other communities may be used. Recreational, economic, and political activities may furnish the needed stimuli. If an initial interest has been aroused, if a well-defined goal has been set up, the worth-whileness of which is felt by the pupils, the teacher will be helpful in directing the work in such a way that the children not only will feel the value of the work but will be interested in continuing their efforts until the goal is reached. Motivation does not mean that the pupils should be permitted to shift their activities as their passing interests shift. When a well-defined unit of activity has been adopted by the class, even though some of the steps involved in reaching the goal may not make a strong appeal, the pupils should be encouraged to stay with the unit until their efforts have been rewarded with success.

Suggestions for Further Study:

1. Show that there may be danger that motivation, improperly understood, may lead to a series of petty achievements on a low intellectual level.

2. Is geography a relatively easy subject to motivate? Explain.

3. Notivate a geographic topic by reference to some local situation with which the children are acquainted.

4. Notivate a geographic topic by reference to some currentevents topic as discussed in a newspaper.

5. Motivate a geographic topic through experiences the class has gained in studying some other subject.

6. What is the relation of "interests" and "motives" to motivation? 


\section{Selected References:}

Branom, M. E. The Project Method in Education, chap. v, Pp. 79-106.

Emeison, P. "Geography for the Grades," Journal of Education (1913), Vol. LXXVIII, pp. 579-580, 660-661.

HammoND, M. C. "School-room Suggestions for Geography," American Education (I9I7), Vol. XX, pp. 4I3-4I4.

Heniry, Rusy A. "A Kentucky Method in the Study of Commercial Geography," Joumal of Education (1914), Vol. LXXIX, p. 273.

Hodgson, E. "Motivation of School Work," American Education, Vol. XVIII, Pp. I 40-143.

Holtz, F. L. Principles and Methods in Teaching Geography, chap. ii, pp. 6-I 2 .

Kelton, M. E. "Current Events and Geography," Joumal of Geography (I9I I), Vol. X, pp. '57-59.

Nolan, ONA 1. "Ways of Raising Geography Teaching above the Commonplace," Joumal of Geosraphy (I9I8), Vol. XVII, pp. $4 \mathrm{I}-49$.

Von Exgels, O. D. "Utilizing Current Events in Geography Teaching," Joumal of Geography (1919), Vol. XVIII, pp. IO9-I I I.

Walther, E. "Suggestions for a Study of Latin America Based upon our Trade Relations," Joumal of Geography (I920), Vol. XIX, pp. $4 \mathrm{I}-55$.

Wilsox, II. I3. and G. M. Motivation of School Work (I9I6), pp. 3-57, 133-158.

Wilsux, J. R. "Children's Participation in War-Time Activities and its Influence in Educational Work," American Education (19I8), Vol. XXII, pp. 348-35I. 


\section{CHAPTER XIII}

\section{THE PROBLEM METHOD OF TEACHING}

GEOGRAPHY

The nature of a problem. In meeting the situations of life man depends on (I) instincts, (2) habits, (3) memory, and (4) reason.

I. In so far as the needed response is made instinctively, the intellect plays a minor part in bringing about the reaction.

2. Through an adequate number of repetitions of the same type of experience man forms a habit of definite response. When a situation can be met by a response on the habit level the thought processes are eliminated or reduced to a minimum.

3. Nany memory impressions are made on the mind of man through the stimuli of environing materials. The nervous system is constantly receiving stimuli. Various concrete objects, as buildings, topographic features, maps, and globes, may be observed; the words of a book may be memorized; the statement of another person may be remembered; a suggestion that has entered the mind may be retained. The more or less lasting impressions thus made are the results of direct, simple relations of the mind to materials. The quality of memory impression is dependent on the intensity with which the inclividual 
concentrates on the thing to be remembered and the number of repetitions. A considerable part of the education of man comes through memory impressions.

4. When instincts or habits or simple memory recalls are inadequate to meet the conditions of a situation successfully, the attention of the individual is intensively directed toward the situation. If the mind simply recognizes the new elements of the situation, the memory impressions are increased. If the new elements are not immediately absorbed, and if the situation that confronts the individual arouses a mental query that involves the marshaling of past experiences, the securing of additional information, or the exercise of reflective thinking and judgment for its interpretation, reason is called into play, and the individual is confronted with a genuine problem. The new elements in a situation requiring thought processes for their interpretation constitute the problem or problems arising out of the situation.

Problem work versus memory work. Problems as well as memory work have inevitably entered into the school activities of the past, but there has been a tendency unduly to emphasize the latter. The topical outline in geography may be taken up from the problem standpoint, but frequently the dominant and almost exclusive emphasis is placed on memory work. Much of the socalled problem work, in fact, is largely memory work with an improved organization of subject matter. If a pupil reads an article in which the material bearing on a problem has been selected, evaluated, and organized by another person, the chances are that he will accept unquestioningly the material thus presented. The one who wrote 
the article undoubtedly had a problem, but the one who reads the article may simply secure impressions of the details of the problem that belonged to another. The reading of such articles is valuable because the student, in following the solution of a problem by another, is becoming acquainted with approved methods of problemsolving.

The problem organization of material is preferable to a mere topical organization as memory textbook-material, since the article has a definite viewpoint that makes its consideration meaningful. There is a danger, however, that the pupil may learn to depend too readily on authorities. He may tend to become a mere transmitter of the ideas of another, thus developing few qualities of leadership or of initiative. The memoriter route of problemsolving tends to develop followers; the reasoning route of problem-solving tends to develop leaders. Each pupil should be given every possible chance to develop qualities of leadership as well as qualities of followship. Pupils should secure, evaluate, and organize material from various sources in solving problems of which detailed solutions are not available to them. A detailed solution of a geography problem bears much the same relation to the problem that a "pony" in a foreign language or in mathematics bears to the contents of those subjects, with all the attendant advantages and disadvantages.

Not only for self-realization but for the social welfare it is the duty of the schools to emphasize problem work. Progress is dependent on constructive changes and additions. In schools emphasizing memory work which is not related to problems the work of the pupil who can 
retain impressions, irrespective of whether he is a keen thinker, is at a premium. The ability of pupils in solving problems may not be tested. The pupils who have capacity for leadership may take very little interest in memory work simply as memory work, and may make a very poor showing. If memory work is related to worthwhile problems, however, it will frequently be found that some pupils with excellent memories have ceased to use their memories because they could not see the use of exerting themselves to memorize merely for the sake of memorizing. The school should place emphasis on the ability to observe and to retain, but in addition it should encourage and demand that each child shall be able to use information and to secure further needed information in relation to actual problems.

Relation of memory to problem work. Man can learn much through sense impressions and the storing up of these impressions in memory. Instinctively he becomes acquainted with his environment. The memory route tends to anticipate problems that may arise; the reasoning route tends to create a need for information as a basis for the solution of a problem. Problems, therefore, tend to supplement an instinctive interest in acquiring information with a rational interest because of the need of information in meeting the intellectual difficulty. Problems, in other words, furnish another motive, closely related to human accomplishment, for the acquiring of information.

A good memory is not to be disparaged, and every effort should be made to teach each child to memorize economically. In fact, while a person may have a good 
memory and be a poor reasoner, it is very difficult to be a good reasoner without having a very good memory. Problem-solving involves a consideration of past experiences in the interpretation of a situation, and a treacherous memory will not permit these experiences to be readily recalled. Problem-solving frequently involves the securing of additional material in relation to the situation, and a poor memory will seriously handicap the person in his attempt to retain, interpret, and apply the material secured.

In the school with a well-balanced curriculum both memorizing and reasoning will be emphasized. In spite of an equal opportunity to all, it will be found that pupils, because of lack of capacity or because of lack of application, will group themselves. Some pupils accept blindly and unquestioningly the detailed solution of a problem by another; some follow readily and thoughtfully the reasoning of another, approving or disapproving according to personal opinion; some are able to make partial but inadequate contributions toward the solving of a problem; while others not only can follow critically the interpretation of a problem by another but have sufficient initiative and reasoning ability to solve problems with but little assistance. The teacher will not arbitrarily group the pupils into leaders and followers; but, because of the varying capacities and abilities, if opportunity is given all for real problem-solving this grouping will tend to appear. The proper emphasis of problem work will enable a teacher to grade the pupils on information retained, but, what is far more important, the pupils can be graded with respect to their ability to 
use information in relation to new situations requiring analysis and interpretation.

A pressing practical question among teachers concerns the relation of problems to the information necessary for their solution. Among the varying viewpoints presented are the following: (I) the pupil should study the information first and then should be confronted with a problem that will test his ability to use the information acquired; (2) the pupil should have a problem first, which can be used as a motive in inducing him to secure the needed information; (3) the problem should be so far related to the acquired experiences of the child that he can use them, but its solution should also involve the securing of additional information. While there may be occasions that justify the application of the first two viewpoints, in general the third viewpoint is educationally the most promising, since the child, in the same problem, not only relates the problem to some of his past experiences and interests but at the same time enlarges or supplements his experiences.

Evolution of the problem method. In organizing the content of scientific geography a standardized outline has been employed. In the days when the pupil was forced to arljust himself to content, the standardized outline was adopted in the writing of textbooks. The topical outline, including location, area, topography, climate, soils, plant and animal life, and human activities, was used in the consideration of each country. Serious overlapping was avoided, the country was systematically studied, and the pupil could study the last topic of the outline with a 
feeling of finality, for had he not mastered the whole outline applied to a particular country?

When the emphasis was shifted from descriptive to interpretative geography the outline organization was retained, but, in addition to the statement of facts concerning each topic, as climate, an attempt was made to explain the particular climate and to determine the effects of climate on life forms. This was a decided improvement over the loose clustering of material about topics. A consideration of the effects of a single fact, as climate, on the activities of the people tended to focus the attention of students of geography on the life responses. It was clearly seen, however, that a complex of physical factors combines to influence human responses. There has been a tendency, consequently, to consider life responses and to attempt to evaluate all physical factors that have influenced these responses. Even the singling out of a certain type of activity for interpretation is regarded as inadequate. The present tendency is to emphasize regional geography by attempting to interpret the complex of life activities in relation to the complex of the physical environs.

The trend in the evolution of geography method is in harmony with the trend in the evolution of scientific geography. Since teaching has been largely by the textbook method, the standardized topical outline of the book has prevailed. The pupil memorized more or less literally the words of the book and the locations of places as indicated by the maps. As interpretative material has been included in the textbooks the pupils have also memorized this type 
of material. The organization of parts of the textbook about problems has made the textbook much more appealing to pupils. Some provision has been made for independent problem-solving. The scientific geographer insists that a geographer in training must do independent work in geography, which, according to the modern viewpoint of geography, is equivalent to problem-solving. The teacher likewise insists that the pupil shall do a certain amount of independent problem-solving, not for the purpose of becoming a trained geographer but for the purpose of securing a maximum development.

Some materials for problem-solving. What should be the nature of a geography textbook in order that problem work may be properly emphasized? There should be topics developed in detail from the problem standpoin $t$, both for the benefit of the pupils who primarily follow the reasoning of another and for the benefit of the pupils who carefully check the statements made. It is altogether legitimate to profit from the experiences of others, and many more problems can be taken up in a limited time, although extensity of experience is substituted for intensity of experience. The textbook should in part be so arranged that a considerable amount of original problemsolving is possible. There should be a gradation from developed problems to problems to be developed. Some problems may be worked out in part, including a statement of appropriate pages on which pertinent material may be found. Some problems may be outlined witl appropriate references. Problems should involve the use of pictures, maps, diagrams, encyclopedias, statistical tables, 
the dictionary, supplementary articles of books and magazines, and collections of illustrative material.

A standardized outline organization of material, if the material has been written with problems in mind, may be used to good advantage. The developed problem of the book may contain information which may be selected and assembled in the interpretation of a problem. Problemsolving which involves the use of sweeping generalizations of the book should be cautiously undertaken. Undeveloped generalizations not only are almost meaningless but, in addition, tend to make the study of geography exceedingly superficial. The pictures of the textbook should be selected with a well-defined purpose and should be accompanied by appropriate explanations and questions. The maps should be as accurate as possible. If a city is located on a railroad or on a water route, a map that represents the city as located some distance from the transportation route is of little value in so far as transportation relations are concerned. If variations in altitude are significant as a phase of a problem, there should be a map that will indicate this difference. If a detailed study of a small area is to be made, a map on a large scale should be available. Too frequently in problemsolving we must make statements which a pupil must read into a map; many of these statements a pupil should be able to read from a map.

In elaborating the topics of a textbook or in connection with problem work, it is frequently desirable to permit some student to make a special report. Preferably these individual contributions should be raised to a problem 
level. Too often the pupil is merely a transmitter of the printed page, whether he has copied the contents to be read to the class or whether he has read the article a sufficient number of times to give it virtually from memory. If the special report is raised to the problem level, the pupil secures memory impressions of the article, but, in addition, he attempts to weigh the relative importance of the topics, to eliminate the irrelevant and insignificant, to consult the dictionary for proper pronunciation and definition of words, and to clear up any poorly understood parts by referring to the encyclopedia or other books. He similarly studies the pictures and makes a sketch map that will show the general and special location. After making this detailed study he attempts to reorganize the material so that it will maximally interest and instruct the class. Most pupils can give satisfactory memory reports. More attention should be devoted to problem reports of special articles.

Securing problcms. The scientific geographer, interested in making a thoroughgoing, painstaking study of content, may incorporate into his studies many problems that relatively are insignificant. From this great field of knowledge both the geographer and the educator are interested in selecting for school use the problems of greatest worth. Equal emphasis, therefore, will not be placed on all the geographic factors of an area, but each area will be studied in relation to its more significant problems.

Problems may be selected that will account for past conditions; as. "Why did the religion of the Egyptians center about the Nile?" or, "How did the environment of the Phœnicians influence them to become a great 
maritime power ?" The problems may attempt to account for present conditions; as, "Account for the dominating influence of the inland city of Chicago," or, "Account for the dominance of the pampas in Argentina." The problem may deal with future possibilities; as, "Should the United States intervene to force Mexico to set up a stable form of government?" "Is the predicted Yellow Peril real or fancied?" "What may be the practical outcome of the apportioning of Africa among the nations?" and "Will the more important future development of the St. Louis industrial area probably be on the Illinois or the Missouri side of the Mississippi River?" Our present courses of study ordinarily provide an insufficient amount of problem-solving of the latter type. Few would question the value of making a study of how the geography of the past and present helps to account for present-day realities, but there is increasing need that our schools shall not simply follow the world's progress but shall give constructive assistance in pointing the way to a better day. Geography can help substantially in indicating the direction in which future development should proceed.

In teaching geography through problems in which geographic factors are significant, rather than through a topical outline, the teacher may well hold in mind an organized outline of the minimum essentials in geography that should be taught with reference to the region concerned. The teacher should check accomplishment with reference to her list of minimum essentials, and she should make supplementary provision for any minimum essentials that are omitted in the problem studies. 
The problem may be expressed in a variety of ways. It may be (I) a question, as, "What use should Poland make of her resources in order that she may become a strong nation?" (2) a debate, as, "Poland has a better opportunity than Czechoslovakia for an important national development"; (3) a suggested scoring, as, "Purpose, to find whether Poland or Czechoslovakia has the better opportunity for an important national development"; (4) a prejudicial declarative statement, as, "Why Poland must become a powerful nation"; (5) a topical outline, as, "Poland, location, area, topography, climate, plant and animal life, and human activities," each topic being a condensed statement of a problem, as, "How has the location of Poland affected its development?" It is not the particular form of a problem that is significant, it is the existence of a problem.

The pedagogy of problem-solving. The trained geographer may readily pick out the more important problems in geography. If the child is merely assigned problem after problem, however, and told that he must master each one, the teacher is following the old-fashioned practice of adapting the child to the material. The pedagogical viewpoint affirms that socially valuable problems should be taught, but that the problem, if possible, should make an appeal to the child's interests and experiences. If a mere statement of the problem is sufficient to stimulate the child to attempt its solution in a wholehearted, purposeful manner, further attempts to arouse interest in the problem would be superfluous. Frequently, however, it is desirable to enter into a discussion of material which will recall pertinent experiences and which 
will provide initial material out of which the problem may arise. The problem may be stated first, and then an attempt may be made to arouse interest in it, or the problem may be raised out of the introductory material.

While there is no set formula that will insure success in this initial step, the following types of assignments will be found suggestive: (I) Assignment: For the next recitation take the problem "Can Palestine again become a land 'flowing with milk and honey'?" In securing material as a basis for your conclusion consult your textbook and supplementary material on the shelf. (2) The problem may be assigned, and the Bible reference concerning milk and honey may be recalled, the former productiveness of the Holy Land may be discussed, and the Zionist movement to Palestine may be noted. The problem may become meaningful as a result of this discussion. (3) The discussion concerning the former productiveness of the Holy Land etc. may lead naturally to the problem, so that the problem arises out of the introductory material. (4) The pupils in their out-of-school experiences may hear about or read about the Zionist movement and the attempts that are to be made to restore Palestine to its former productivity, and the teacher may utilize the interests and experiences that they bring to school by helping them to interpret the problem as to whether the hopes of the Zionists are well founded. There is no infallible rule. The wise teacher may occasionally use every type of assignment indicated. The responsibility of getting the problem before the child in such a way that it appeals to him and arouses his enthusiasm belongs to the teacher. 
In the interpretation of a problem there are all gradations, from the detailed working out of the problem by the teacher - the pupils merely following the interpretation more or less thoughtfully - to the independent interpretation of the problem with absolutely no assistance from the teacher. The degree of assistance that is given will depend on the difficulty of the problem on the one hand, and on the capacity and ability of the pupil on the other hand. Suggestions concerning various ways of assisting can be given, but the trained teacher must constantly diagnose the situation and direct her course accordingly. In the securing of materials, such as maps, giobes, pictures, textbook articles, statistics, samples of products, newspaper and magazine articles, etc., the pupils should be aided by a reasonable accumulation that can readily be secured, although they should always be encouraged to supplement the school materials with contributions from the home, the library, and miscellaneous sources.

In most cases it is better to induce a pupil to stay with a problem until the interpretation has been made. It may be helpful at the outset to give the pupil an overview of the problem and the nature of the study that will be necessary, in order that he may have a reasonably adequate conception of the task that is before him. If a pupil undertakes the solution of a problem that he abandons because he tires of it, bad habits and attitudes may be formed. It is not always necessary that the pupil shall come to a final conclusion, but as a final step the solution of the problem shoull be indicated in concise form or the materials interpreted should be summarized. If it is 
probable that other factors than those discussed should enter into the problem, the pupil should indicate that, with respect to the factors studied, certain conclusions have been reached. Pupils should not be permitted to feel that they have made an exhaustive final study of a problem, when necessarily, in most instances, they have studied only the more significant or more accessible factors.

If a conclusion is reached, what use can be made of it? If the problem refers to the reasons for a past or a present condition, the instinctive desire of the child to understand has been satisfied. He has secured a viewpoint and information that potentially will be a fundamental background in helping him to solve the living problems of the world. If the problem deals with an economic and social policy that is being pursued, or that may be pursued, with the view of determining the best policy, the pupil is not only satisfying an instinctive desire to master the problem but has also come to a conclusion that may result in practical accomplishment.

Practical difficulties in the use of the problem method. It has been very difficult for many teachers to get away from the topical outline. An examination of various courses of study developed from the problem standpoint indicates that the old detailed topical outline of a country has been retained and that the outline has simply been capped with a problem, orcinarily in the form of a question. The topical method, in other words, has been sugarcoated with a problem in an attempt to make it more palatable. Much confusion arises, for many of the details of the outline can be applied to the problem only by the wildest stretches of the imagination. Because of this 
distant relation of material, the pupil and possibly the teacher lose sight of the problem and proceed to master the material by the topical method.

The reason for this misuse of problems can be readily understood. The topical outline presents, with but little overlapping, the detailed content of the region. If a problem can be secured that will require the use of the various topics in the outline, the material can be taken up systematically and without serious overlapping. The teacher needs to secure real problems that will involve the necessary content of the topical organization. Frequently this can be done by the consideration of a number of problems dealing with the area, the resulting overlapping of content being regarded as a desirable form of review. The problem method is of little or no value if the topical outline is forced into the problem mold. Each problem, irrespective of the topical outline, should be solved according to its own requirements.

The problem method may be overworked. As has been indicated, much human development proceeds more or less haphazardly, more or less accidentally, through observations and impressions. The problem method seeks to substitute scientific advancement for accidental advancement. Not only does memory work meet individual needs, however, but it also furnishes much of the raw material for problem-solving. The human being is so constituted that it may tire of problem work, but may find relaxation in falling back on instincts, habits, impressions, and recall. True problem-solving, being the most intensely intellectualized form of action, is the most exacting work that an individual can experience. 
The problem may not be adapted to the child. Merely telling the child that he has a problem to solve does not make it so. The pupil must be led to see the problem involved. The problem should be related to his interests and experiences. It is not sufficient that the problem shall be worth while from the teacher's standpoint; it must also be worth while from the pupil's standpoint. The technic of the teacher is tested as she attempts to get the pupil enthusiastically and purposefully interested in a problem which she believes he should interpret as a part of his educational development.

Appropriate materials for the solution of the problem may not be available. This difficulty is gradually disappearing. Better textbooks are being published, special studies are being made, better maps and maps in greater variety are being published, the homes are using more reading material, and public libraries are becoming increasingly numerous. Under modern conditions no teacher should excuse herself from problem work with the explanation that she has inadequate equipment for this type of work.

\section{EXAMPLE OF A PROBLEM}

I. Preparatory step: In a large city an investigation by federal representatives indicated that the milk supply was dangerous to health, and the people using the milk believed that the price charged was exorbitant. There was free discussion, therefore, among the people concerning the high price of unsatisfactory milk. The children, as ultimate consumers, were well acquainted with milk and its uses, and they became interested in the public agitation. In a life situation with 
which the children had adequate points of contact arose conditions favorable for a problem interpretation.

2. Problem raised and concisely stated: The teacher eagerly grasped the opportunity presented through the interest of the children in the situation, and out of their questions arose the problem, which was stated by different pupils, and the final form agreed upon by the class as follows: "Is it true that our milk supply is dangerous and that exorbitant prices are being charged by the dairy companies?" It will be seen that in reality there were two distinct but overlapping problems involved.

3. Matcrials secured and interpreted: Each problem was considered separately. The condition of the milk supply involved a consideration of the significance of having dairy cattle free from disease, of observing the utmost cleanliness in milking the cows, in caring for the milk at all times until it had reached the consumer, of maintaining a sufficiently low temperature to maintain the desirable qualities of the milk, and of pasteurizing all milk coming into the city. The conditions as they ought to have been were contrasted with the conditions that actually existed, and the pupils had definite data on which to base their conclusions.

4. Problem solved: The pupils, as a result of their study, were convinced in most instances that the milk supply was unsafe.

5. Application: Many of the problems that have been used in geography classes cannot be immediately used in some positive, useful way. In this instance the conclusions reached by the students were used in enlightening other members of the family, and the pupils undoubtedly had a helpful influence in creating sufficient public sentiment to bring about a partial correction of the evil.

The second problem involved a study of the cost factors entering into the production, transportation, and pasteurization of milk, and its distribution to the ultimate 
consumer. The first problem had made the pupils aware of the importance of a desirable milk supply, and consequently they were eager to have any reasonable expenditures made to guard the health of the community.

The type problem suggested has been analyzed into its respective parts in order that the nature of a problem may be more clearly indicated. In actual practice these steps should be carefully interlocked, so that no step will be painfully evident. The teacher is not primarily interested in the realization of each step as a distinct accomplishment, but in the step as a vital part of a larger whole, the problem unit.

\section{Suggestions for Further Study:}

1. Should all the work of the school be on the problem level?

2. What is the relation of a good memory to problem-solving?

3. Prepare a special report in geography and attempt to raise it to a problem level.

4. Select a problem and state it in as many different ways as possible.

5. Select a problem and work it out in detail with respect to the five steps indicated.

6. What are the factors that may cause a teacher to fail in teaching by the problem method? What are the factors that favor successful teaching through the problem method?

\section{Selected References :}

Braxon, M. E. The Project Method in Education, chap. $x$, pp. $1+5-171$.

Brow, R. M. "Problem-Study Procedure in Geography: Africa." Elementary sichool Joumul, Vol. XVII, pp. 276-280.

Charters. J. A. "The I'roblem Method of Teaching Ideals." English Joumal (1919), Vol. VHII, pp. $461-473$. 
Cook, Charles IV. "Importance of Geographic Factors in the Birmingham, Alabama, Iron District," Joumal of Geography (1918), Vol. XVI, pp. I80-I 84 .

Freeland, George E. Modern Elementary-School Practice, chap. ii, pp. 6-44.

LACKEY, EARL E. Studies in the Principles of Geography, p. 1 i 6. McMurri, Charles A. and Frank M. Method of the Recita. tion, chap. x, pp. 257-270.

Mixor, Rubr. "Problem Teaching: How to Plan for it," Joumal of Geography (1920), Vol. XIX, pp. 6I-69.

Parker, Edith P. "Partition of Africa- $\Lambda$ Seventh-Grade Geography Unit," Elementary Sihool Joumal (I9I9), Vol. XX, pp. isS-202; Journal of Geography (19i9), Vol. XVIII, pp. $359-364$.

Parker, Sanuel Chester. "Problem-Solving, or, Practice in Thinking." Elementary School Journal (Scpt., Oct., Nov., 1920). Setherlaxd, William. "Improvement in Geography Teaching," Journal of Geography (1910), Vol. IX, pp. 99-Ior.

Sutherland, William. The Teaching of Geography, chap. ii, pp. I 45-I55; chap. xii, pp. I55-I60; chap. xiv, pp. I66-172. Vismer, S. S. "Some Results of the Location of Australia," Jour. nat of Geograthy" (I918), Vol. XVI, pp. 305-309.

"Minneapolis Outline for Teaching Japan and China," Journal of Geography (I9IS), Vol. XVI, pp. 228-233. 


\section{CHAPTER XIV}

\section{THE ARGUMENTATIVE LESSON}

A special type of problem. In the competitive life of the world it is necessary that a person shall be able to marshal the facts concerning a situation and to come to a desirable conclusion. He should be able effectively to defend and justify any stand that he may have taken. He should be able to do this quickly, accurately, and convincingly. Since there is practically no situation in life that is devoid of its geographic aspect, every pupil should have training in the proper evaluation of the physical factors. There are two special types of problems requiring the individual to adopt a particular conclusion in contrast to one or more other conclusions that might be reached. In a scoring lesson the pupil lists the advantages and clisadvantages with respect to two or more possible conciusions, and through a pitting of the advantages on the one side against the advantages on the other side attempts to come to a rational conclusion. Scoring is a type of debate in which the affirmative and the negative are represented by the same person.

Scoring. Countries, cities, mountains, rivers, products, and groups of people may be compared. The comparative method is all the more effective if the comparisons are made with the view of coming intelligently and impartially to a well-defined conclusion. The various points to be 
noted in comparing two countries may be listed, and each point may be given a definite value, the sum of all the values to be roo or any other desired sum. The countries may then be scored point by point. If the country has been given a perfect score, the sum of the points should be ıoo. No geographic topic, probably, would be given a score of roo per cent, but the country registering the highest per cent would be considered the superior country.

A simple method of scoring is indicated in the following illustration and in the table on the opposite page:

Problem: To determine whether Uruguay or Paraguay will make the most rapid advancement.

BOOKS CONSULTED: Textbooks and supplementary readers.

If the factor was favorable in each country and no superiority could be determined, each country was given a point. If the factor was unfavorable in each country, each country was given no score. The data unfortunately are not always readily secured, and too much of the material available makes sweeping generalizations which it is difficult to verify. In spite of these difficulties practice in scoring based on the data available is worth while because of the careful evaluation, discrimination, and recognition of shortcomings involved.

The class may agree on the topics that will be considered in the scoring. Each pupil may score independently. The class recitation may be devoted to an exchange of opinion concerning the scoring of the countries. Pupils should be able to back up their conclusions with exact references. The particular advantage of scoring lies in 


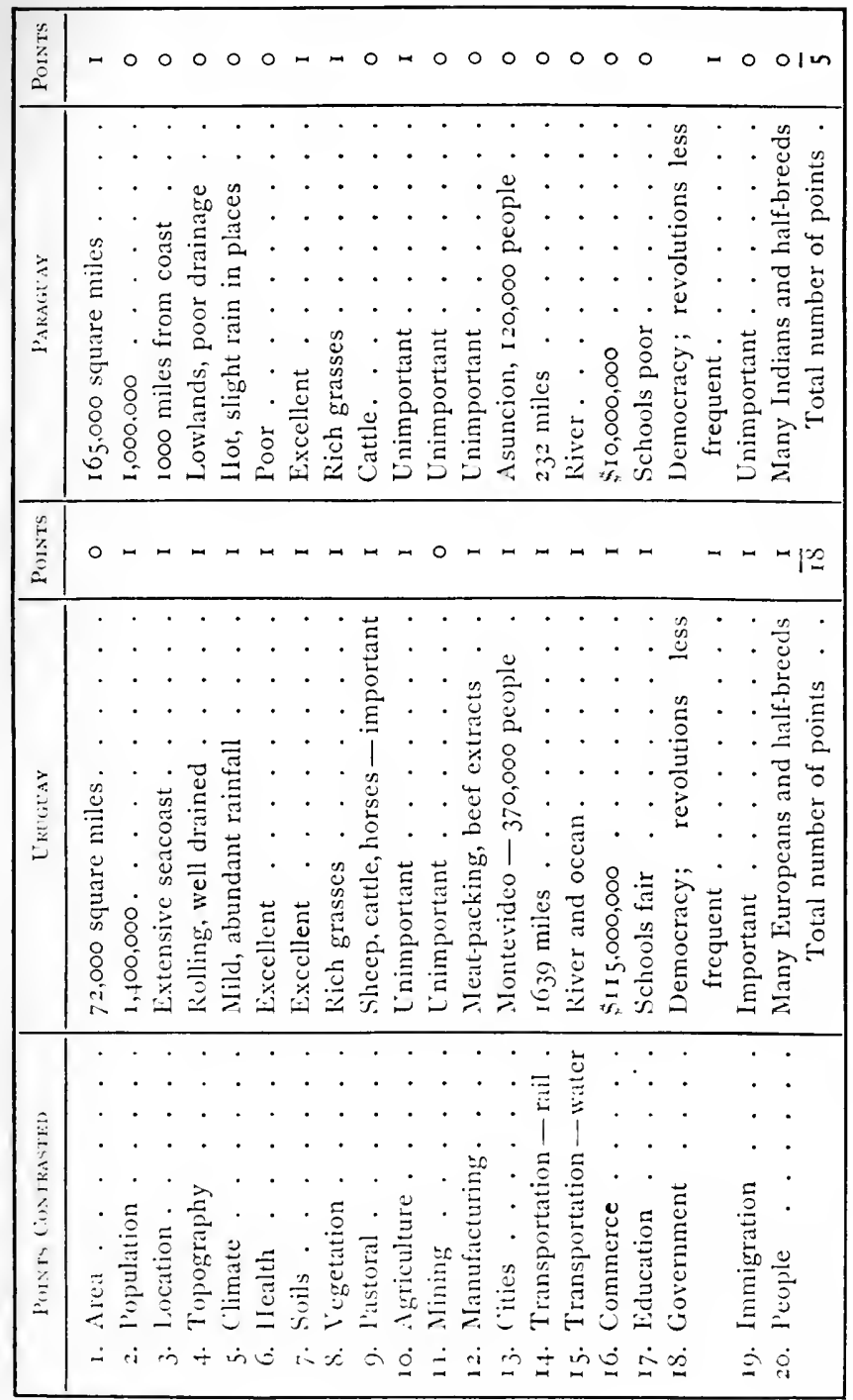


the fact that the students are attempting presumably to arrive at an absolutely impartial conclusion. They are not seeking to determine that one side or the other is superior, but are merely seeking to determine the actual situation. This type of work, if carefully done, helps to overcome the tendency to accept conclusions prejudicially and then to distort the facts in order to sustain the viewpoint adopted.

Debating. The debate tends to accomplish for a group what the scoring accomplishes for an individual. The debate calls for a more highly socialized organization. Not only are the students engaged in comparing materials but their ability is being matched with that of other students. An individual needs to learn how to weigh the evidence carefully and to come to a desirable conclusion. A considerable part of his success, however, depends upon the influence that he can wield in causing others to accept his views.

The need of making the same careful study as in the scoring method is present, but the study is made with a somewhat different aim in view. The pupil is interested in proving his side of the argument. He is interested in the psychology of the situation as well as the bare facts. He will appeal to both the head and the heart. He will emphasize those factors that put his side in a favorable light, and he will seek to minimize the advantages of the opposition.

Pupils should agree upon the subject to be debated, and they should also agree upon its phraseology. The subject for debate may originate in a difference of opinion 
in the regular class work. Pupils may take sides according to their opinions. As a result of the differences the questions may be clearly stated, the study hour may be devoted to the securing of pertinent material, and pupils may return with facts to strengthen the stand they have taken. If the pupils return to the classroom in perfect agreement, the detailed study has been the means of clearing up the difficulties, and the reason for the debate has been removed. If the class on reassembling is still divided, the two groups may proceed to present the evidence. The leader, the teacher, or a pupil may act as chairman, and representatives of the two sides may be allowed to talk alternately. A time limit to each speech may or may not be desirable. The chairman will attempt to secure a general participation. The class may vote on the outcome either publicly or by ballot, the latter method ordinarily being preferable, or a committee from another room may be selected to judge.

Through the debate the pupil learns that there is something of greater value than being an "ace" in this world. He learns to sacrifice himself, if necessary, for the welfare of the group with which he is working. The work must be distributed among the members of a team so as coördinately to bring about the most effective results.

Debates, in general, should center about an honest difference of opinion. It is not desirable to encourage pupils to take the opposite side merely for the sake of arguing. This teaches pupils to be dishonest with themselves. There are enough geographic problems over which pupils may honestly disagree without the setting up of artificial 
problems for debate. Unless a pupil thoroughly believes in his side his work cannot be thoroughly and desirably motivated.

Students should be encouraged to make honest statements. Children may be so carried away by their enthusiasm to win that they, as unfortunately is true of many adults, are willing to resort to misrepresentation to secure the desired victory. By holding a debater to exact references the tendency to make sweeping statements can be held in check. The well-conducted debate brings vividly before the pupils the reasons for differences of opinion and tends to make them, while disagreeing, tolerant of each other's views.

The subject for debate may involve a geographic problem approached from the physical viewpoint; as, "The unfavorable climate of the Amazon basin makes it highly improbable that this basin will ever be as densely populated as the United States." The subject may be approached from the life standpoint; as, "The people of the southern part of the United States are less progressive than those of the northern part on account of climatic differences." The subject may be of a social or political nature, with the possibilities of a very important physical interpretation; as, "A stable, progressive government cannot be established in tropical countries without assistance from temperate regions."

The subject for debate may involve events that have passed; as. "The discovery of the south pole was fraught with more dangers than the discovery of the north pole." The subject may involve an interpretation of a present situation; as, "The physical factors have been more 
important than the social factors in bringing about the unsatisfactory political condition in Mexico." The subject may involve a consideration of future possibilities; as, "The forested area of southern Chile within fifty years will be more important to Chile than the desert region of the north."

The argumentative lesson involves a special type of problem. The subject for debate should be motivated, arising out of the discussions of other problems and topics or arising out of an initial situation. If difference in opinion exists, conditions may be favorable for the holding of a formal debate. In some instances an informal debate or argument may be sufficient. The debate presents a social challenge to the participants that sometimes makes a stronger appeal than the solution of the problem. The debate offers an excellent opportunity not only of securing intense mental activity in marshaling evidence but also of giving training in coöperative living in a representative democracy with its divergent opinions.

\section{Suggestions for Further Study:}

1. Make a list of criteria by means of which you think that cities should be scored. Select two cities, and through scoring seek to determine which has the better future.

2. Select a geographic subject that you consider excellent for a debate and give reasons for your selection.

3. Select a geographic topic that you do not consider suitable for a debate and give reasons for your selection.

4. Is the debate or the score the more valuable type of argumentative lesson?

5. Describe a geographic debate in which all the factors are as nearly ideal as possible. 
6. Select two of the new countries of Europe, and by the score card seek to determine which has the better opportunity for an important national development.

7. Consult a rhetoric for a detailed analysis of the parts of a debate.

8. What are the limitations of the argumentative lesson in the teaching of geography?

\section{Selected References:}

Foster, William Hortox. Debating for Boys. Sturgis and

Walton Co.. New York, I9I 5.

Hextixgton, Elisworth, and Ceshing, Sunner W. Principles of Human Geography (I921), chap. iv, pp. 78-IOI; chap. xvi, pp. 309-3 I 8 .

MCCoxiela, W. R. "Geography and the Irish Question," Joumal of Geography, Vol. XVIII, pp. 259-267.

Riciarus, E. B. "The Game of Debate," English Journal (1920),

Vol. IX, pp. 147-152. 


\section{CHAPTER XV}

\section{THE TOPICAL OUTLINE}

Nature of the topical outline. The various subjects recognized in a curriculum may be regarded as the large topics with which the school deals. In organizing each subject it has been convenient to have some systematic topical arrangement of the material, while frequently a more detailed consideration of one of the numerous subdivisions of a subject has involved still more topics. A topic is a content nucieus about which the subject matter may be arranged in an orderly, coherent, and compehensive manner.

The scientific organization of materials is desirable from the standpoint of insuring that the social inheritance shall be preserved in its entirety. The topical outline insures the organization of this knowledge in detail and with a minimum of duplication. The systematic, topical organization of content presents a definite body of material. One subtopic after another can be taken up, discussed, and definitely disposed of. When the material is once scientifically organized, successive classes will be able to use the same organization, and the work is reduced to a s.rstem.

With the improvement in the technic of teaching has come a careful scrutiny of the topical outline, not on as a basis for the organization of content but as a means 
for economically giving the child that development as a social being which he ought to have.

A topical outline may be applicable to one large topic, or it may be sufficiently general to be applied to any one of a number in the same class. If an outline is standardized so that it can be applied to numerous topics of the same class, a mode of attack may be worked out that will simplify the mastery of a topic. An outline may be evolved that can be applied to any agricultural product, to any mineral product, or to any animal product; that can be applied to any geographic or political unit; that can be applied to any type group of people; that can be applied to any city. Outlines are helpful in the classification of knowledge and also as a working basis for the securing of knowledge.

The topical outline in geography. The generalized topical organization has been worked out effectively in geography in a consideration of political and geographic units. While the outline may vary somewhat, it ordinarily inciudes location, area, topography, climate, life forms, human activities, and distribution of population. All the topics listed are fundamental in the consideration of any areal unit. A common method is to place in the hands of the pupil an outline for his general guidance. The pupil may desire the outline as a basis for work. Imitation without appropriate analysis, however, is undesirable.

The child should have training in the organization and classification of content through the topical outline. Pedagogically it makes a difference how the outline is evolved. An objection raised to the use of the outline has been the formalizing of procedure through the dictation of the 
teacher. There are at least four ways that an outline may be evolved: ( I) the outline may be given the child, who may be forced to conform to it; (2) the outline may be presented and analyzed by the teacher in an attempt to get the pupils to see its value; (3) the outline may be presented, and the pupils, with the help of the teacher, may analyze, evaluate, improve, and use it; (4) the pupils may consider any part of the larger unit that appeals, finally reorganizing the details of the discussion, thus proceeding toward rather than from an outline organization. In (I) the external organization is the dominant aspect; from (I) to (4) the emphasis is shifted increasingly from the subject matter and its organization to the child and his mental processes. It is significant educationally how results are secured.

Illustrations. An excellent way to handle a topical outline so that the needed interest may be secured is to select a subject sufficiently comprehensive for almost everyone to find some topic within his interests. The skill of the teacher is shown in the selection of the unit. Argentina may be suitable, or with some classes it may be desirable to select a more comprehensive unit, as South America. With one class the teacher entered into a brief discussion of Argentina with the purpose of giving the children a friendly interest in the country. She had placed on the shelves the regular books of the library dealing with South America and its parts and had supplemented this list with books and magazines from the library. The children were permitted to read and study anything that they cared to, with the one limitation - the material should concern Argentina. The pupils selected 
and studied articles. During the class period contributions were made by different members of the class, and discussions followed. As the topics were discussed they were listed on the board. Questions that could not be answered stimulated pupils to further study. Fresh preparation, either dealing with a topic previously studied or with a different topic, was required before each recitation. Gradually the number of topics increased, and the necessary details wcre supplied. After some days the time seemed ripe for the next step. The topics had been supplied in any order, and additional contributions or corrections had been accepted. Not even in the final reorganization of the topics did the teacher impose what she considered the best organization upon the class. She raised the question concerning the order in which the topics had been discussed, and the class entered into a lively discussion. Through the combined efforts of the class a final outline topical organization of material was effected. The pupils had worked to a topical organization as the last step in the study of the country, Argentina, and had arranged the material out of their experience. The country of Chile was similarly studied. While the details varied, there were in each case certain general topics that stood out in relation to each country, particularly location, area, topography, climate, life forms, and human activities. The pupils compared the two topical outlines and derived therefrom an outline that could be applied to either country. They then used the outline in the sturiy of Brazil and other areal units. The topical outline thus secured was practically the same that ordinarily is given 
to a class by the teacher. As the pupils worked upon the details they had felt the need of guiding principles in the selection and study of materials, and had met this need by efiecting a topical outline from the two countries studied so that in the study of other countries the result should be an economy of time and systematically planned purposefulness of effort. They appreciated the help of the outline and used it much more enthusiastically and effectively than if they had merely followed the directions of another. Pupils learn through experience what to look for in the study of a country, and the objective outline becomes merely an organized indication of their habitual attitudes that they tend to adopt toward a country to be studied.

The study of topics in relation. The topical outine, once adopted, should be used effectively. If a class is merely told to find out as much about the climate of Chile as possible, even though it may appreciate the reason for the outline, there is no assurance that such a topic will make a strong appeal or result in the gain of valuable knowledge. The topical outline was formerly much abused by the study of the topics in relative isolation. In a consideration of climate little or no attempt was made to establish controls of climate on man's activities. If climate were considered it was primarily descriptive rather than causal discussion. The viewpoint in geography should be the significance of the physical environment to man, and in the consideration of every topic of an outline this viewpoint should constantly dominate. The alliustment of man to his social and physical environment is a 
problem of perpetual interest and value. If geographic relationships adapted to the child are emphasized, the work may be made exceedingly appealing.

If relationships and their interpretations are emphasized, the topical outline may involve much reflective thinking as well as questions of mere fact. Each topic becomes a nucleus about which numerous problems cluster. Properly handled, the topics become condensed problems. The outline concerning Argentina-location, area, topography, climate, and life forms - might mean to the person with the proper viewpoint, What effect has the location of Argentina had upon its development? and similar problems might be presented for each of the topics. The outline may become formalized under such conditions, but the work need not and should not, inasmuch as the details of interpretation depend upon the particular importance of these factors in dealing with a certain country.

Danger of generalizations. Topical work may be of little value if generalized statements are permitted without the appropriate details. In agricultural production the factors of special significance are temperature, rainfall, soils, and topography. These topics may be included as a part of the topical outline. The pupil may say that coffee is produced in Brazil because Brazil has a favorable temperature, a favorable rainfall, a favorable soil, and a favorable topography. A similar response may be made for any other farm product. The statement necessarily is truthful, but is of little value because it does not indicate the kind of temperature, rainfall, topography, and soil that is desirable. 
The topical outline and problem work. There is a very close relation between the topical outline and problem work. Children may approach the study of a country from the life side, using such physical factors as seem necessary for understanding the problems. Knowledge of the significance of location, climate, etc. will be incidentally secured as needed in the interpretation of the problems arising. If the details of the country are grasped through problems that do not isolate the physical factors, an opportunity for organizing and reviewing the material by means of a topical outline is presented. On the other hand, if a country is studied by means of a topical outline, the pupils have in mind the details of the country necessary for the solution of life problems, and their ability to utilize this knowledge may be tested and increased by their attempts to solve normal problems involving the varying physical factors. Neither method of procedure can be exclusively justified. The topical outline may be used at times as an introduction and at times as a means of reviewing and organizing the details of the country studied.

Distribution of topical work in the grades. In the observational work of the lower grades the oral discussions offer an excellent opportunity for organizing the work topically. After visiting some factory or topographic form the class may discuss the topics as they are suggested by pupils, and the topics may be reorganized at the close; or pupils may suggest topics, and the topics may be rearranged by the class before the detailed discussion begins.

In the developmental oral work in the lower grades the teacher develops a topic orally with the help of various 
illustrative materials. The teacher may have an outline organization on the board and may merely develop this outline, or she may place the topics on the board as she discusses them, or she may center the attention of the children on the oral presentation, making an easy transition from one topic to another. At the close of the developmental exercise the teacher may ask the children to name the topics discussed. The pupils will assist in noting and rearranging the topics. The last-named method, ordinarily, is preferable.

In the upper grades, because of the pupil's ability to use the symbols of geography and because of his experience, the emphasis is shifted from observational and oral presentation to symbolic presentation. The pupil will read and outline articles. He will attempt to evaluate the topical organization of writers. The topical organization of the textbook may be followed, and each topic may be enriched from supplementary materials. A topical outline without reference to a textbook may be followed, the various materials of geography being used to secure the needed amplification.

Value of the topical outline. The above considerations suggest the value of the topical outline. Even in the problem work the esteem in which the topical outline is held is inclicated by the fact that most of the problems thus far presented have involved the raising of problems the solution of which includes a discussion of the former topical outline of a country. The problem is simply an attempt to make such work purposeful.

The value of the tonical outline depends on the way it is handled. If the teacher works out a topical 
organization or adopts the topical outline of another, and merely tells the class to study the topics; if the topics are studied without any particular problem's being secured and interpreted, the chief emphasis being placed on memory work; if there is no relating of topics, but each topic is considered in relative isolation; if the mere amplification of topic after topic, with the feeling that the work is completed when the last topic is studied, is permitted; if there is no attempt to use the topical material in important, vital life situations, - then it may be said that the value of the topical exercise is at a low ebb.

If the topical outline is secured by the class because of its need for and recognition of the value of organization and classification of details; if the outline is tested on other countries so that its adequacy is ascertained; if the outline is applied so that each topic is resolved into important problems making a strong appeal; if the pupil, through the solution of problems involving a combination of physical factors, shows his ability to use the materials topically organized,- - then the high value of the topical lesson cannot be seriously questioned.

Suggestions for Furtler Study:

1. Nake a topical outline that you think should be applied to (a) a city, (b) a country, and (c) a continent.

2. Distinguish between "developing" an outline with a class and "imposing" an outline on a class.

3. Can the problem method be effectively utilized through the topical outline?

1. What are the advantages and disadvantages of a topical outline in geography? 


\section{Selected References:}

Andersox, Esther S. "Beet Sugar Production in Nebraska," foumal of Geography (1920). Vol. XIX, pp. 121-130.

BABER, Zowa. "Eurasia: The Teaching of the Continent of," Elementary Sihool Teachir. Vol. Vil. p. 519.

Browx, R. M. "An Outline for the P'resentation of a CountryAfrica," Elementary Sichol Tiacher. Vol. IX. pp. 293-308.

Gregors, W. M. "The Cotton Industry." Joumal of Education. (I9I I), Vol. LXXIT, pp. $462-46_{3}$.

Reed, Williain G. "Outline for the Study of Frost," Joumal of Geography (I9I 5). Vol. NIV. pp. 5t-55.

Ruediger, W. C. "Topical Method." Joumal of Geography", Vol. IV. pp. $43 s-439$.

"Topical Method," Joumal of Education (igo6), Vol. LXIV, pp. 650-65I. 


\section{CHAPTER XVI}

\section{JOURNEY GEOGRAPHY}

Nature of journey geography. Journey geography involves the consideration of a region with reference to its transportation routes. Pupils may take (I) real journeys and (2) imaginary journeys. Journey-geography trips, which are actually taken, ordinarily are confined to the local area. The imaginary-journey lesson is fundamental in acquainting the child with those areas beyond his immediate observation. An attempt is made to make the imaginary journey as vivid as possible through the use of visualization materials.

Illustration of actual journeys. In connection with a study of dairying arose the problem "Why should the consumer of the city pay fourteen cents a quart for milk for which the producer receives but seven cents?" The class, under the direction of the teacher, was not satisfied with a verbal explanation. Arrangements were made to inspect a dairy plant. The pupils indicated in a rough sketch the relative positions of the school building and the clairy plant, the route taken, and important landmarks noted along the route. They verified their sketch map from a large map of the city.

At the plant the children noticed the unloading of the filled milk cans from the auto trucks, the elevating of the milk cans to the fourth floor, the testing, the clarifying, 
the pasteurizing, and the bottling of the milk, and the cold-storage room in which the milk was kept. They noticed the handwork required in cleaning the empty bottles, the work of the bottie-washer machines, and the large number of broken and discarded bottles. They noticed the large office force and the numerous milk wagons and drivers. While the pupils were not able to determine mathematically the exact increase in the cost of milk, they readily understood that the expense involved in protecting the milk supply of a large city justified the milk distributors in charging considerably more than the original cost of seven cents a quart.

The cream was removed from the whole milk for which there was no sale. This cream was soured, churned, and made into butter and buttermilk. An inquiry revealed that margarine had taken the place of butter in most of the homes of the children because two pounds of margarine could be purchased for the price of one pound of butier. Out of this discussion arose the question "Why is margarine cheaper than butter?"

A visit to a margarine plant and to a dairy farm seemed desirable to assist in understanding the substantial clifference in the price of butter and margarine. At the dairy farm the investment in land, buildings, and dairy cattle was noted. The care of the cows, the production and purchase of foods, the care of the milk, and the separation of the milk were considered. A study was made of the possibility of producing food for direct use by man in larger quantities than was secured by permitting the cow to change the plant foods into milk. It was seen that dairying requires attention to numerous details. 
At the margarine plant the pupils noted the melting and mixing of the animal and vegetable oils, the pasteurizing of the whole milk in which the oils were churned, the plunging of the emulsion into ice-cold water (where the fat globules were crystallized), the withdrawal of the crystaliized fiakes from the cold water by means of cheesecloth, the working of salt into the margarine and of water out of the margarine, the molding of the butter, and the forming of prints. They were led, through this observation, to make a detailed study of the reason for the low price of vegetable oils - as coconut, peanut, and cottonseed oil - in contrast to the cream of milk.

The children had taken bottles to the plants, and on returning to school they pooled their samples. The cream gathered at the top of the milk and was then skimmed off and churned into butter in a milk jar. The children had a liberal supply of coconut, cottonseed, and animal oils from the margarine plant. Under the direction of the teacher they considered the materials used and the processes employed. They then pasteurized the milk over an alcohol lamp. using a thermometer to maintain the proper temperatures. melted the oils in pans, and mixed the oils. The oils were then poured into a glass churn with the whole milk. After churning the emulsion the children poured it into a pan of ice-cold water, in which, after agitation, the fat globules began to crystallize. They took a small piece of cheesecloth, dipped it slantingly in the ice water, and withdrew the flakes of margarine, the whey draining through the cloth. They then salted and colored the margarine.

In each instance rough sketch maps were made. The experiments set up in the schoolroom indicated clearly 
the notions that the children had derived from the trips. Language was significant, but the additional means of expression guarded against a mere mastery of language without corresponding ideas. It will be noted that all these trips were closely related to the work of the schoolroom. The class, through field work, came into appropriate contact with the active work of the world.

Verification and discovery. Trips may be taken to verify conclusions reached in the schoolroom or to make discoveries as a basis for discussion. In most instances it is preferable to arouse an initial interest in any field trip that is to be taken. Most trips involve both discovery and verification. If a child believes that certain conditions exist, the field trip may enable him to verify his conclusions. If a child does not know whether certain conditions exist, but feels the need of knowing, the field trip may enable him to discover the true conditions. Since the experiences of children in the same class vary considerably, the same field trip may be primarily a trip of discovery for one child but primarily a trip of verification for another child.

Pupils may make trips of discovery with definite motives in mind. Columbus sailed west with the desire to reach the Indies. He found not the Indies but a new world. Captain Amundsen moved southward in an attempt to discover the south pole. He was successful and, in addition, made other important discoveries that he had not anticipated. Pupils may desire to find the source of water in a small creek, a good swimming hole, a place to fish, typical meanders, a flood plain, evidences of valley growth, or a fault. They may desire to find out how 
milk is handled at the dairy plant, how a dairy farm is conducted, or how margarine is made. The type of experience they should have may be drawn from the actual experiences of explorers and discoverers. They should frequently realize their desires, and they should also make additional discoveries.

While the trip may be one of discovery for the child, the teacher has a thorough knowledge of the ground covered and relates the materials to the child's interests and experiences. She directs the motives of the children in such a way that through the journeys she may realize definite educational aims. She has a flexible organization of content which enables her to adapt. The teacher does not force her personality or her opinions upon the group, but she tries to help the pupils to come to their own conclusions in the light of the evidence presented. She asks questions, calls the attention of the children to important phenomena which they are overlooking, and helps to maintain interest in worth-while observations.

When a child is planning a trip to the country, to another city, or to a picnic or a Fourth of July celebration, he looks forward to the event with pleasurable anticipation. When the time comes he is in a frame of mind that will enable him to secure numerous and vivid impressions of the incidents of the day. Reasoning from this standpoint, through a discussion of a planned field trip a pleasurable, anticipative interest can be aroused which will increase the educational possibilities of the trip.

On a physical-geography trip the pupils may note topographic forms and processes and the importance of processes in changing the physical features; on an 
economic-geography trip the pupils may note what is being made, the processes, the raw materials, and whether the results are secured in the most desirable and efficient manner.

In the study of an industry there is danger that a child will pass through the factory with a dazed impression of something worth while. The factory lecturer frequently has little conception of educational methods. A tactful teacher may take charge of the pupils and direct the work. The lecturer will accompany the group to assist when needed. If time will not permit the pupils to study every part of the factory thoroughly, certain significant parts within the comprehension of the group should be seiected for detailed study. If the noise is too great for a discussion at the time of observation, the teacher discusses the process with the class immediately before the observation and immediately after, in order that she may assist the pupil, clarify thought, and insure results.

Field notes wiil not be emphasized in the lower grades; in the upper grades the taking of notes will be increasingly emphasized. Field notes reënforce the memory in subsequent discussions or reorganizations of material. The pupil takes field notes because he finds them of value; the teacher is interested in the slill developed in recording neatly, effectively, and pointedily the impressions receiverl.

A detailed discussion should follow a journey. The child will live over in imagination the journey actually taken. The discussion should be vivid and enthusiastic. The details of the trip may be organizerl. The child through his recall of the details of the real journey will 
appreciate more readily the possibilities of the imaginary journey, the details of which must be worked out largely through symbolic materials.

Illustration of imaginary journeys. The teacher drew upon the travel experiences of the children. The pupils mentioned acquaintances who had traveled. These people had traveled for business reasons, to renew acquaintances, to improve their health, for recreation, to learn what the rest of the world was doing, or to see beautiful scenery and famous places. A number had traveled to "see America first." The places that had been visited were mentioned. Considerable interest was aroused in other people and in other lands. Members of the class desired to see New York City. They wanted to see the buildings and the people, especially how the people live. Among other places were mentioned Niagara Falis, Asheville (North Carolina), the Hudson River, Mount Vernon, the Blue Grass country, Florida, and southern California. The class decided to become acquainted with the circle tours offered by the railroad companies and to se'ect the circle tour which would include those places in which the keenest interest had been aroused. It was found that the eastern objective of many of the circle tours was New York City. It was agreed that New York City should be the destination and that the return journey should be by a difierent route.

The pupils inferred from a map the principal routes connecting St. Louis and New York City. These inferences were checked by inquiry at the Information Bureau. Railrcad folders advertising the several routes were secured. The difierent routes were compared as to cost, 
time required, important places, and beautiful scenery. The route finally selected was from St. Louis via Cincinnati, Lexington (Kentucky), Chattanooga (Tennessee), Asheville (North Carolina), Norfolk (Virginia), and the Atlantic Ocean to New York City. The return journey was via Albany, Rochester, Buffalo, Detroit, and Chicago.

The attractions along the route selected were studied in detail. The time-tables were frequently consulted. A coal mine was visited and studied in southern Illinois. A fast afternoon train stopped near the mine for water. This train was boarded, and the party proceeded to Vincennes (Indiana), where the night was spent. The next day the party proceeded to Cincinnati, where the pottery works and the "zoo" were visited. The party proceeded southward across the Ohio River to the heart of the Blue Grass region at Lexington (Kentucky), where it visited a dairy farm and the Blue Grass Fair. Between Lexington and Chattanooga (Tennessee) the Cumberland Mountains offered an opportunity to study the life of the mountaineer. At Chattanooga the class studied Lookout Mountain and the Chickamauga battlefields. The party proceeded northeast through the famous Great Valley of East Tennessee and noted the crops and the pink-marble quarries about Knoxville. An observation car was taken the succeeding day to get a better glimpse of the "Land of the Sky" region. Arrangements were made to ascend the slopes of Mit. Mitchell, the "top of eastern America," on a log train. The party walked to the top of the peak, where it noted a monument erected in memory of Professor Mitchell, learned the story of the naming of the mountain, and observed 
beautiful panoramic views, hidden occasionally by drifting banks of fog. At Norfolk the ships were noted, a few hours were spent among the sand dunes at the entrance to Chesapeake Bay, and the party for the first time went bathing in the ocean. The party left Norfolk on a coastwise steamer Saturday evening, arriving at New York Sunday afternoon. The harbor and city were studied, and a boat ride was taken around Manhattan Island. The return journey was begun. This involved a daylight ride up the Hudson; an early morning ride out of Albany on a milk train to Canajoharie, where a large factory was inspected and an automobile ride taken into the adjoining country; an inspection of Buffalo factories and a side trip to Niagara Falls; a night ride on Lake Erie to Detroit, where an automobile factory was visited; a ride in a sleeper to Chicago, with its stockyards and lake front; and a daylight ride through the famous corn belt of central Illinois back to St. Louis, the starting point.

Through the wealth of detail presented the pupils had come to appreciate the varied industries and scenery of the eastern United States, and with the use of illustrative materials, as maps, pictures, diagrams, and products, had taken in imagination a journey that many people take every year. The imaginary journey, as nearly as possible, duplicated a real journey, thus bringing a part of the real world close to the life of each child. In this particular instance the pupils talked in terms of the future in deciding on the journey, and in terms of the present tense in studying the details of the journey. This can be varied according to the attitude of the class. With some classes it may be preferable to speak of the journey in detail in 
the future tense, the pupils merely visualizing the details that might be noted if the journey were actually taken.

Imitate real travel experiences. In the extended imaginary journeys it is desirable that the journey shall be as nearly real as possible. If an adult were planning a trip he would find out the various routes and their attractions and the probable expenses. After deciding on a particular journey he would begin to make a special study of the attractions along the route. After thorough preparation in order that he might travel intelligently, he would proceed on the journey. He would verify impressions he had received while anticipating the journey, and he would discover things that had not before come to his attention. After the completion of the journey he would probably be interested in discussing and organizing his experiences. These conditions would prevail, provided the traveler desired to secure a maximum of benefit from the trip. It may be admitted, however, that many people travel without securing much travel experience. They become acquainted with the hotels, but otherwise restrict their experiences to the social group with whom they are traveling. They carry their local environment with them not as a basis for the interpretation of new environments but as an artificial situation in which to live. If journey geography is to yield a maximum of benefit to the children, the journeys must be planned and executed according to the manner of those who travel intelligently.

The teacher has the responsibility of stimulating the pupils to become interested in travel routes. In the planning of the trip she will not tell them all the interesting things about the route. The profitable journey includes 
a confirmation of the anticipated, but also the opening up of new vistas. An abundance of varied and well-selected representative material of choice readings, pictures, maps, diagrams, drawings, etc. is desirable as a school nucleus for the work, and pupils will supplement these materials with out-of-school sources. Outline maps can be proitably used as the work progresses. At the conclusion of the journey the material may be organized into a logical whole.

Nature of the imaginary journey. Transportation routes constitute the organizing nuclei for journey geography. The reader or listener is taken in imagination from one place to another. The customary means of transporting is employed, and an attempt is made to interpret the phenomena observed. The impressions that a traveler receives concerning the customs and the economic activities are given. Journey geography involves several possibilities: (I) the writer may give a personal account, and the reader may follow appreciatively the journey actually taken; (2) the writer may attempt to make his reader, in imagination, a member of the party; (3) the writer may not have taken the journey, but with a detailed second-hand knowledge of the region may write an account of a journey that might be taken; (4) the pupil may draw upon various appropriate materials in selecting and planning and executing a journey that might be taken.

The journey may be developed so that the author does most of the thinking for the reader. When a pupil follows the cletailed account of a journey, reflective, independent thinking is not necessarily eliminated, but the pupil who 
follows the line of least resistance will read the account primarily on an unanalyzed memory level. If the pupils assist in initiating the journey, and if they work out the details of the journey, the siluation is much more favorable for problem activity and vigorous mental reactions involving development.

The pupil inductively builds up his conception of the region. This method does not preclude the possibilities of generalizing or of relating the area observed to a larger area, for the traveler occasionally may attempt, through reflection, to secure a unit picture of an area through the parts directly observed. The pupil proceeds from a study of parts to a concept of the region, which is essentially different from the topical consideration of a large area. Since the impressions of larger areas are secured from the local studies, it is desirable that the typical rather than the peculiar and exceptional shall be emphasized.

A journey may include any aspects of the environment that a traveler may consider sufficiently important or interesting. It may be adapted to small children; it may be sufficiently difficult for the most accomplished scholar. Journey geography should involve a consideration of (I) the economic activities of people; (2) explanations of the localization of industries and people; $(3)$ the effects of physical factors, particularly climate, topography, and soils on the people; (4) the relations of the people to other regions; (5) the possibilities of making a more nearly perfect adjustment to the environment; and (6) natural phenomena of special significance, as hot springs, beautiful scenery, glaciers, volcanoes, etc. The earliest geography work of the school has been concerned 
with the immediate environment of the child. Through actual journeys the child's acquaintance with the local environment has been enlarged. Imaginary geographic journeys which reproduce as nearly as possible the vividness of the actual journeys build upon and naturally succeed the actual journey work. Through the imaginary journey the child gradually secures a conception of the world as a whole. In the upper grades, where the emphasis is placed on regional geography, the journey geography may still be used as a basis for becoming better acquainted with a region, or after a detailed study of a region the pupil may review the region by mapping out a journey that might be taken.

\section{Suggestions for Further Study:}

1. Discuss a local trip that you have taken, from the standpoint of its geography.

2. Discuss an extended trip that you have taken, from the standpoint of its geography.

3. By means of an illustration indicate what is meant by an imaginary journey.

4. Should journeys be taken primarily for verification or for discovery?

5. How will travel help a teacher in presenting journey-geography lessons?

Selected References:

BAsFer. Zoxil. "A Lesson in Geography from Chicago to the Atlantic." Elementary whon Tiacher, Vol. VII, p. +5 S.

13.AkNe. Eari. Studies in Education (1902), Vol. If.

IRANoM. FiEI) K. "Some Important Phases in Geography."

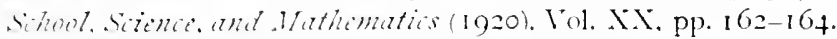

Colvix. S. S. "Child's World of Imagination." Elementary School

Tiulker (1905). Vol. VI, pp. 327-372. 


\section{CHAPTER XVII}

\section{TYPE STUDIES}

Nature of a type. A detailed study of a representative member of a class, with the purpose of securing an understanding of the various members of the class, is called a type study.

A type is a topic that stands for a group or a class, a standard of comparison, and an interpreter of other similar facts. Type study in geography means the selection of representative topics or features of the subject for especial emphasis or detailed study, for the purpose of using them as illustrations of their class. ${ }^{1}$

The type may be used in the study of both large and small zinits. An intensive study of a cotton plantation of the southern United States may be made as a type of cotton plantations in general. A study of conditions affecting creton production in the United States may be made as a basis for an understanding of cotton production in other regions. A cotton mill may be studied intensively as representative of its class. Type cities, as a river city (St. Louis), a lake city (Chicago), a river-gate city (New Orleans), a railroad center (Indianapolis), a mountain city (Ashevile), a mountain-gate city (Denver), and a

${ }^{1}$ F. L. Holtz, l'rinciples and Methods of Teaching Geography, p. $24 \mathrm{r}$. 
capital city (Washington), may be studied. Some particular mountain, valley, river system, volcano, glacier, desert, or forest may be selected for representative study.

Types are selected with reference to their significance in the local areas or with reference to their relative significance in the world as a whole. In the lower grades the type directly related to the local area is prominent; in the upper grades the type with the world-wide viewpoint is emphasized. Although dairying may not be relatively very important in the rural area adjacent to a city, a pupil may make a detailed study of dairying as representative of the way that every large city is supplied with dairy products. If dairying as a world-wide activity is being considered in the upper grades, the type may be selected from some area as central New York, Wisconsin, Ontario, or Holland, where dairying is very important in contrast to other industries. Local types eventually should give way to the most representative type that can be found, irrespective of locality.

Represcntative character of the type. A type study should be representative of general conditions. It is scarcely conveying a correct impression to take the poorest dairy farm or the best dairy farm in the community to study unless contrasts are emphasized. The normal conditions ather than the exceptional are the immediately significant factors. The exceptional conditions, however, may be nuclei that will increase until they have in turn become normal and representative. As an ideal, consequently, it is desirable that the best rather than the poorest unit shall be studied, care being taken to indicate the ordinary departures from this type. 
$A$ wealth of details. A type should involve a wealth of details. Too frequently generalizations are memorized and not developed. If equal emphasis is placed upon all facts of geography, the work must be largely superficial. The selection of a few situations for intensive study enables the class to secure a grasp of details that makes the work concrete, vivid, and meaningful. Any summary of the study that may follow is bristling with significant statements, for the "condensed knowledge" has been secured through the study of details. It is not desirable to emphasize similarly every detail of a type study, since the same objections are valid that have been raised to the placing of equal emphasis upon all geographic topics. Neither is it necessarily desirable to discuss every detail that may have a bearing upon the type study. Not all details are vital either as information or as coloring material to the type. The facts selected should be adapted to the children involved in the type study.

Nucleus for further study. The type is a nucleus for further study. In the early grades, in a consideration of the interdependence of city and country, if wheat is produced in the local neighborhood a study of local production is made. In the regional work an intensive study of wheat production is made in an area where this product is very important. As successive regions are taken up no further intensive study is necessary; but the earlier work is reviewed, and through comparisons and contrasts wheat production in the new areas is interpreted and a detailed study is made of new factors that enter into the situation. Finally a world-whole view of the product is secured, the comparisons and contrasts involved tending to bring 
together in a unified whole the significance of the product to the world. Thus type studies in the lower grades become organizing centers about which details are increasingly clustered and upon which much of the uppergrade work is based. An economy of time may be effected through the use of the type. Wheat is raised in many different regions. If a detailed study of wheat production in the United States is made in connection with the regional geography, it will be unnecessary to enter into a detailed discussion in connection with each of the wheat-producing regions.

Opportunity for review. The type offers an opportunity for an intelligent review. Many of the details of the type study may be forgotten. A consideration of wheat production in various regions, as the regions of the world are successively considered, offers an opportunity for the use of the type-study content in new situations a sufficient number of times to insure relative permanency of impression. Because of the vividness of the type study the details will be more readily recalled.

Organizing centers. The field of geography is entirely too comprehensive to be covered in a detailed fashion in grade geography. From the mass of details it is necessary to select the more important. Material that is selected should offer a ready nucleus for further growth and should be an organizing center about which additional material can be clustered. In every region there is a complex of geographic material. Some of this material is very significant or characteristic of the district. Much of the material does not differentiate the community from many other communities. The dominating materials of 
various districts differ. In selecting essential material the significant or characteristic factors should be emphasized. The type permits the proper evaluation of material. Many incidental factors of a region are neglected to make room for the type, but the type gives to a region its distinguishing characteristics. The type will not give a child a correct conception of a region, nor will an equal emphasis of topics. Very few complete pictures of the complex relations of man to the earth are secured by anyone. The type enables the individual to regard a region from the standpoint of its characteristic or dominant contribution to man's welfare, particularly to the welfare of man in other communities through the commodities produced in surplus quantities.

Shortcomings. A type study is not misleading if it describes an actual condition. A type study becomes misleading, however, if pupils believe that exactly the same conditions prevail with respect to all members of the class. It is better to adhere to the truth, but it only complicates a situation if the teacher tries to note all the exceptions to the type. Children gradually come into a more nearly complete knowledge of the truth as a whole. Human beings always have a more or less imperfect vision of generalized truth. To secure even a moderately complete and correct picture of the world requires time. The teacher will feel content, therefore, if the children, through their type study, have correctly imaged a concrete situation. Conditions may or may not be the same elsewhere. This will be determined finally when the children have noted elsewhere conditions illustrating other members of the class. 
Advantages. Charles McMurry, ${ }^{1}$ who has been a distinct influence in calling the attention of educators to the value of types, notes the following advantages:

( 1) A clear and detailed comprehension of a typical object in geography (however small this object may be) is the key to a lirge area of geographical knowledge; (2) a type subject is the basis of a series of comparisons; (3) the number of type studies being few, much time is available for a lively, descriptive, and interesting investigation into details; (4) one of the chief reasons why children are interested in such a study of a type is that it is at every step a study of causes; (5) a type study expands gradually to embrace a large collection of geographical facts; (6) the series of types furnishes a safe central line of operations; (7) physiographic facts are brought into such close relation to human needs as to make both of them tangible, realistic, and often picturesque.

A liberal use of types in teaching will go far toward vitalizing the course of study. Type studies are desirable because they (I) tend to emphasize the more important topics, (2) are economical in time, (3) permit a detailed consideration that adds realism to the work, (4) afford a secure foundation on which to enlarge one's knowledge, (5) avoid the teaching of perfectly true but meaningless generalizations, and (6) are inherently valuable.

\section{Suggestions for Further Study:}

1. What constitutes a type study?

2. What is the relation between a type study and the topical outline?

3. Should type studies be heavily emphasized in a geography course of study?

${ }^{1}$ Special Method in Geomerty, in, 57-67. 
4. Select a type study from your geography or a supplementary reader and tell why you believe the article selected is a type study.

5. What is meant by an "organizing center"?

6. Develop in detail a type study of a city.

Selected References:

Dodge, R. E., and Kirchwey, C. B. The Teaching of Geography, chap. xv, pp. 193-205.

Holtz, F. L. Principles and Methods of Teaching Geography, chap. $x x$, pp. 254-272; chap. xviii, pp. 222-237; chap. xix, pp. $238-253$.

McMurry, Charles. Special Method in Geography, chap. iv, pp. 50-75; chap. v, pp. 76-90; chap. vi, pp. 90-101; chap. $x$, pp. $139-165$.

Ruemiger, W. C. "Type Studies," Joumal of Geography, Vol. IV, pp. 439-440.

Sutherlani, William. The Teaching of Geography, chap. $x$, pp. $137-145$. 


\section{CHAPTER XVIII}

\section{THE STORY}

Relation of the story to gcography. A story can be made more appealing if the geographic setting is clearly understood. Much geographic material can be presented to children through stories. An appealing story must have action and must represent characters and activities that the child can readily understand and appreciate. The story may center about the lives of a group of people, as the Eskimo, the Dutch, or the Negro ; about some important product, as coffee, cotton, or rubber; about some phenomenon of nature, as a flood, a spring, or a volcano. The child's attention may be directed toward the changing relationships involved, and the geographic influences may be incidentally introduced as a pertinent part of the story. The story "How the Bear was Caught" may be told in such a way that the use of trees by bees for the storing of honey, the nature of a mountain stream, and the formation of caves are revealed.

A story may be a true account or imaginary. Since geography is a study of the actual relations that man sustains to his physical environment, stories of actual events are desirable. The imaginary story, which pictures typical relations of man to nature, may be profitable. The improbable story is of little assistance to geography, although geography may occasionally be of assistance to 
the story-teller. The Indian story concerning the formation of Niagara Falls should have no place in a geography course. According to the story a huge monster was struck by lightning while crossing the Niagara River, the dead body forming a dam across which the water has flowed unto this day. On the other hand, the narration of Indian stories dealing with Niagara Falls can be more vividly presented if the improbable stories are woven about a definitely located region. There are stories of the tree dwellers and the cave dwellers, which, while unverified, represent probable happenings.

Telling a good story. The story may be oral or written. The oral developmental story is particularly adapted to the lower grades, although throughout life this method of presentation appeals. The teacher transmits the story to the child through the charm of her personality. The teacher thoroughly informs herself concerning the details of the story, although she makes no attempt to memorize the form of the story. With her knowledge of the children's experiences and interests she enters into an account of the story in an enthusiastic, inviting way. Occasionally she asks questions intended to hold the interest by making the children feel that they are contributing. Questions may be asked, in order that the pupils may make suggestions or in order that the children unable to answer may be in a receptive attitude to receive the answer.

The teacher, through the story, attempts to secure and retain the interest of every child. She may have pictures, miniature reproductions, charts, maps, and products, perhaps concealerl in such a way that each article is shown the class at the "psychological moment" as the story is 
unfolded. She may make use of construction materials, as clay and sand, and she may use the blackboard to illustrate certain parts of the story. She is interested in cirawing on all the materials of geography, both actual and symbolic, to bring the details of the story vividly before the children.

Relation of the story to geography readers. The story may be used as a preliminary step leading to the reading of a similar account. Such a reading experience will be primarily for appreciation and enjoyment. The story can be read the more easily because of the knowledge received through the oral account. The story may be used as a basis for a topical organization of the narrative, the class, through the organization, attempting to recall the story. After the reading or telling of the story the class may indicate the main divisions, each division may be called an act, and the story may be informally dramatized.

Story-telling by pupils. Pupils may be given an opportunity to tell stories. A geographical story may be read, and each pupil may attempt to tell the story in an appealing way. The Eslimo type, a coffee plantation, or transportation on the Mississippi may be studied, and the pupils, with the fundamental geographic material in mind, may attempt to write a story depicting a day's work on a plantation, a day's work of an Eskimo, or a day's events on a steamboat. A picture in which the relations of man to the physical enviromment are prominent - as a harvesting scene, a desert scene with a caravan, a snow and ice scene with an Eskimo and a seal, an Indian tapping rubber trees-may be used as a basis for a story. Pictures also are frequently used to illustrate stories. 
Nature stories versus fairy tales. The tendency to shift the emphasis in story-telling from fairy tales to the wonderful stories of nature and the stories of the achievements of man increases the usefulness of story-telling in connection with geography.

Cyril Bruyn Andrews, in writing of the dangers of fairy tales, has said : ${ }^{1}$

Is it not possible that we grown-up people are also living too much in a fairy land which we know to be unreal? Do we not often take a vicious delight in making others believe things that we know to be untrue? Would not politics be purer, religion more sincere, art more vital and significant if grown-up people were taught from their earliest childhood to worship truth and sincerity and not to cultivate a formless ignorant mysticism as foolish as the most foolish fairy tale, but using the garments and usurping the power of serious fundamental fact?... Civilization seems to have grown tired and often prefers to imagine than to act, and sometimes as in a final stage of decay actually glories in the unworldliness of its outlook. . . . Children, chiefly by their own efforts, have discarded fairy tales and wish more substantial outlets for their imagination.

Many of the stories which have been written for children are highly imaginative and improbable. There is need for an accumulation of nature and geography stories, entertainingly written and presenting the wonders of the world and man's relations to Mother Nature in an appealing manner.

Place of the story in geography. The geographical story has important educational possibilities.

1 "The Danger of Fairy Tales," The Child (February, r920), Vol. X, pp. 206-208. 
The place of the story in geography seems clear. Geography should be, for the child, a vicarious mode of travel through time and space. We wish the child to see the world as it is and as it has been, as though he were an eye-witness of its events and busy scenes. It has been a hard struggle to rescue geography from the enumerative, cataloguing methods which it has employed in the past, which put all the stress upon memory and none upon observation and imagination. The school geography of the past stands as an example of all that is inartistic in education. It is the direct opposite of the selective way of treating facts, which is essentially æsthetic. It aimed to be all-inclusive, cataloguing everything without unity of theme. Just so far as connected narrative may be made to take the place of detached and fragmentary description and classification is it brought into line with the methods we are here advocating. Geography is largely the story of the world. It is not an inventory of its contents. It is better to teach less of facts and to see that the facts taught are precisely those which give to the child vivid pictures of the world as it is in its relations to man's practical and æsthetic interests.

Once the mind is put to the task of reading nature to the child as a story, there will be no lack of opportunity. The story form and method have a place throughout all the nature work. By the story more than the mere fact is carried to the child's mind. He learns the interconnectedness and harmony of facts in such a way that his inner nature is aroused while his intellect is instructed. One may say that the only limit to the use of the story in the nature subjects is likely to be the capacity of the teacher to organize the materials in the dramatic and artistic form required. The child's interest in a rood nature story is very strong; and the world is full of nature tales, some ready at hand, some that must still be worked over by the story-teller himself. ${ }^{1}$

${ }^{1}$ Emelyn Newcomb Partridge, Story-Telling in School and Home, pp. 103-105. 
The organization of geographic stories about life centers. The recasting of geographic material in story form involves the organization of geographic material about life centers. David Starr Jordan's "The Story of a Salmon" has the life of the salmon as the organizing center; Spyri's "Heidi" depicts the adjustments of the Swiss to their environment. The pupil will not study soils, rainfall, temperature, drainage, and topography as topics in a narrative that properly may be called a story, but he will study about "How the worn-out farm was built up," "How the swamp land was reclaimed," "How the truck gardener succeeded," or "How the miner saved his comrades." Through appropriate stories which make a strong appeal the geographic topics will incidentally be considered. Through the story the pupils will work in the direction of a logical topical organization that includes the topics with which too frequently the child begins his study.

Suggestions for Further Study:

1. Select a story in which geography is necessary for an adequate interpretation, and give reasons for your selection.

2. Select a story through which valuable geographic knowledge is taught.

3. Compose a story adapted to a lower-grade geography class.

4. Shrold a geography story involve an account of actual happening or an account of imaginary happenings?

5. In oral story-tellins, in what ways is the personality of the teacher significant?

6. What is a geographic story? 


\section{THE STORY}

\section{Selected References:}

Andus, Jomx. Exposition and Illustration in Teaching, chap. $x$, pp. $250-275,33^{6}-354$ : chap. xv, pp. 35t-391.

ANinsws, C. 13. "The Danger of Fairy Tales," The Child (1920),

pp. $206-209$.

li.ullir, C. S. "The Harvesting," Kindersurten and First Grade,

Vol. I, pp. $+5^{6-+78}$.

Catilek, Kitmerise: D. Educating by Story-Telling, chap. xv, pp. $16 S_{-17} 8$.

CukTis, Elxord W. The Dramatic Instinct in Education, chap. viii, pp. 135-153: chap. ix, pp. 153-176; chap. ii, pp. 5-25.

IIALL. J. W. and A. C. K. The (yuestion as a Factor in Teaching, chap. i. pp. 1-6.

P.ARTRIDGe, G. E. and E. N. Story-Telling in School and Home

(1913). pp. 3-39, 71-87, 98-10S.

Sininlock, Marie L. Art of the Story-Teller (19i6), pp. 3-161.

Stwwak, Mary. "How to Tell a Story," School and Home Ed cation (1919). Vol. XXXIX, pp. 29-33.

STooker, Florencl. "The Miner," Kindergaten and First Grade, Vol. I, pp. $358_{-3} 39$.

Wreke, Ricilak1) T. "Story-Telling," Education, Vol. XXVIII, pp. $76-79$. 


\section{CHAPTER XIX}

\section{DRAMATIZATION}

Relation of dramatization to geography. Dramatization as a means of teaching geography is of moderate importance, but as a means of vitalizing the work, of deepening impressions, and of giving practice in coöperative endeavor it is very helpful. The dramatic work may involve (I) a play that has been written for children or (2) a play that children plan for themselves. The execution of a written play emphasizes imitation and conformity to the suggestions of another. A written play that is rich in geographic content and that gives abundant opportunity for forming correct social relations is valuable.

Goography plays produced by students. Dramatization in geography may go a step further, and the pupils themselves may plan the play, name the acts, distribute the parts, practice, and perform. The pupils draw upon their experiences, exercise their own initiative, and enter into earnest discussions in order that the group creative work may be a success. They become more interested in the play because they have assumed a certain responsibility in its construction. The teacher assists and directs the pupils according to need, for her opportunity is found in the arousal and direction of initiative along desirable social lines. 
Pupils can frequently discover latent talent among themselves. They should be guided by a spirit of fair play that will permit each child to participate according to ability. The numerous problems that will come up for settlement challenge the ability of the students to make valuable suggestions. The class will follow the suggestions that make the strongest appeal, and temporary leadership will be assumed by the one making the adopted suggestion. The teacher will help the pupils to analyze so that maximum possibilities of the socializing exercise can be realized.

Gcography rich in dramatization possibilities. Geography, dealing with the relations of people to earth resources and to the earth in general, is particularly adapted to the furnishing of appropriate material for dramatization work. A study of human types, the study of industries, the study of physical forms, - all offer manifold opportunities for dramatization. The modern emphasis upon interpretative geography, which attempts to describe and explain life forms in action, increases the possibilities of dramatizing because of the life situations presented.

Relation of dramatization to other forms of presentation. If the children make up their own play it is obvious that dramatization will come toward the close of a detailed consideration of a topic. The children must have appropriate experiences on which they can draw for their play. After a detailed study of the Eskimo type, for instance, the children may make a suggestion, or the teacher may cultivate the idea, that a dramatization of Eskimo activities would be desirable. Dramatization in this instance becomes primarily a means of reviewing the work from a 
different standpoint. The teacher participates, but throws as much of the responsibility upon the pupils as they can readily shoulder. The children decide on the scenes to be represented, select individuals for the various parts, and without elaborate preparation stage their play. There is no formal memorizing of statements, but each character thinks over the activities in which he might engage, and the play takes on the nature of an informal discussion, each child acting his part with the help of simple materials at hand.

The study may pertain to some product, as wheat. After a detailed study of wheat production the children may decide to engage in the buying and selling of wheat, and through their dramatized discussion the condition of the crop, factors affecting the yield, the distribution of production, the primary centers, the manufacture of flour, and other closely related topics may be introduced in connection with the exchanges of ideas that arise in the course of business transactions. Traveling salesmen may represent various manufacturing establishments. These salesmen may attempt to sell agricultural implements to groups of farmers, represented by other children. The farmers may represent different types of agriculture, and through the rliscussions many geographic factors conditioning agriculture may be noted. Similarly, other economic activities-as mining, lumbering, and hunting - may be dramatizerl.

Professional versus colucational dramatization. No elaborate equipment is needed for this work. Children using their imaginations can secure equipment for any emergency. An ocean greyhound, made by putting two 
chairs together, has satisfactorily taken a group of children across the Pacific. A cart has become a jinrikisha, a stick has become a gun, a mirror has become a piece of ice, and white pieces of paper have become snowflakes. It is preferable that the children should secure their own equipment, however crude, through their own mental reactions rather than that it should be provided ready-made. Dramatization as an educational means should not be confused with the finished product of the professional. The actors of the formal play perform their parts over and over again in order that they may reach mechanical perfection. They finally play their parts through habit reactions to such an extent that fresh mental activity is practically eliminated. The pupil is interested in the play and, according to his interest and the worth-whileness of the production, should be permitted to repeat the performance as an appreciation exercise. Through use of the finished product, the play, the pupil should secure a verification of his belief, while working up the play, that the effort was worth while; the teacher, however, is primarily concerned with the relations sustained, the mental activity involved. the problems met, and the content used in moving toward the desired goal-the dramatic production. The teacher is interested in the achievement as a means of giving the pupils a motive for achieving; the pupil is interester in the achievement as a result which involves values worth striving for.

Children instinctively dramatisc. Whoever has watched a group of children at play knows that the instinct to dramatize is strong. They become self-conscious only when adults are near. If an adult enters into the spirit 
of make-believe with them, however, they soon lose their self-consciousness in the realization that they have a pal who thoroughly enjoys the exercise. The utilization of dramatization in geography, therefore, is merely making use of an instinct that is highly developed among children. Unless the teacher sympathetically recognizes this tendency the children will inhibit and in time practically smother it. Lack of encouragement has caused many pupils to inhibit group expression and to substitute therefor numerous words which in too many instances represent merely a knowledge of language forms.

Dramatization and current events. Current events have been brought vividly before the children through dramatization. ${ }^{1}$

The teacher chose for the first lesson the finding of Scott, the hero of the south pole.

The children were to place themselves on the spot at the time of the rescue and were to express the emotions aroused in the rescue party when they read the part of Scott's diary which told of hardships, disappointments, and love of humanity. To read the words of the diary even once without a vivid personal appreciation of the wonderful meaning behind them would be to lose forever their deepest significance. For that reason the first expression was to be in writing. On the morning of the experiment the words at the end of Scott's diary were put on the board, and there arose a discussion as to the discovery of the south pole, Amundsen's success, and Scott's vain efforts and death. When interest in the subject was at a high pitch the children were told to choose the moment at which the rescue party came, then to decide and

${ }^{1}$ Alberta Walker, "Dramatization and Current Events," Elementary School Tcacher, Vol. XVI, pp. I25-126. 
write what the different men would do and say at such a tragic and intense moment. The following, written by a girl and selected for brevity, was one result.

\section{THE FINDING OF SCOTT'S PARTY}

SCENE: Inside of tent, not far from south pole

Cast : Scott, Wilson, Bowers, Wright, Nelson, Gran (a few others)

\section{(Men uncover heads when entering)}

Nerson (steps inside tent, sees men in sleeping postures, turns pale at sight of smile on Bowers's face). God! he is still smiling; it almost gives me hope.

Wright (comes in, goes toward ScotT, touches his face, shivers slightly). England's bravest men!

GRAN (comes in, followed by others, sees BowERs, coughs to hide his emotion). How splendid to die smiling! And no word to tell us of their brave deeds.

Wrigit (looks thoughtful). Captain Scott must have been the last to pass away, for the others are securely wrapped in their sleeping bags, which he, of course, did, not being in his own sleeping bag. (Mloves ScorT's hand, sees diary) What is this? Read, Nelson, while I search for other word.

(NELson takes diary, turns to first page)

GraN (impatiently). The last, man, read the last !

Nibson (turns pale, reads). "We took risks; we knew we took them. Things have come out against us, and therefore we have no cause for complaint, but bow to the will of Providence, determining to do our best to the last. But if we have been willing to give up our lives to this enterprise, which is for the glory of our country, I appeal to our countrymen to see that those who depend on us are properly cared for. Had we lived I should have had a tale to tell of hardihood, endurance, and courage of my companions which would 
have stirred the heart of every Englishman. These rough notes and our dead bodies must tell the tale, but surely a great, rich country like ours will see that those who are dependent on us are properly provided for.-R. Scott."

Wright. How sad! And Amundsen was there before him.

Gran (emotionally). To seek, to strive, to find, and not to yield.

\section{Curtain}

Each pupil, through his attempt to reproduce the reactions called forth by the situation and through the vigorous imagery aroused, secured a vivid impression of the climax of Scott's journey. The dramatic situation pictured constituted the principal organizing center about which further details of the journey or even of the polar regions might be gathered.

Value of dramatization in geograplyy. Dramatization work is particularly desirable among the smaller children and is therefore to be emphasized in the lower-grade work. In the first round of the world-whole it incluces children to go into the activities of other people in a detailed fashion in order that they may reproduce the impressions gained. It can be used successfully in the relational work of the upper grades. In fact, if we consider the appeal of dramatization to adults and children, both as actors and as spectators, we can understand that the instinct to dramatize is fundamental.

Children may both participate in and be spectators of plays. When a class is ready to stage a play, other classes may be invited to see the performance. The children will directly benefit through observation and will be encouraged to engage in similar dramatic work. 
The dramatic in geography helps to give vividness and realism to scenes beyond direct observation, gives excellent training in oral expression, gives practice in social relations, and, if the more significant situations are dramatized, makes these situations stand out in such a clear, definite fashion as to make them organizing centers for many details. The amount of geographic knowledge secured through dramatization, however, is incidental, except as the dramatic motive is held before the child to induce him to study geographic topics in order that he may have the necessary material for his play, or except as the dramatization adds vividness to the more important topics.

\section{Suggestions for Further Study:}

1. Is dramatization of value primarily in teaching geography or in teaching desirable social relations through the content of geography?

2. What difficulties may arise in the use of dramatization in geography classes?

3. What are the relative advantages of informal and formal dramatization?

4. Do children instinctively dramatize?

Selected References:

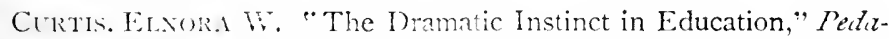
gogial teminary (1908), Fol. Al, pp. 299-3+6.

Hi:rTs. Alire M. "The Dramatic Instinct - Its Use and Misuse,"

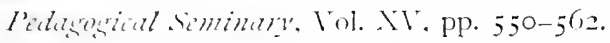

Procket, Ifetex E. "Children's Dramatic Interest and how this may be Utilized in Education," Elimentary School Toukr\%, Vol. Vil. p. 510 .

W.aker. A. "Iramatization and Current Events," Elimentary Sithol Teather (1916). pp. $125-13 \mathrm{t}$. 


\section{CHAPTER XX}

\section{THE PROJECT}

A school project. In the preceding chapters dealing with the teaching of geography various phases of the teaching process have been considered. The teaching process has been dissected in order that the whole may be more intelligently grasped. For working purposes it would be unfortunate to emphasize the different phases in isolation. Attention to a sequence of steps in teaching a lesson type tends to formalize the work. Each teacher should have sufficient practice in formal work, such as the analysis and application of a lesson type, so that she will understand the possibilities of the several organizations of subject matter in relation to the child. Fundamentally, however, the teacher is interested in studying the parts in order that she may understand the whole. Formality seems necessary in order that the teacher may become master of the informal, the natural, and the project method of teaching. The working out of a project may involve any or all of the lesson types discussed, standing out prominently or blended in any proportion. The teacher is interested in placing the child in appropriate contact with a desirable environment.

A desirable school project is a unit of activity that has a well-defined, worth-while objective. If the project is to be of maximum educational value, the goal must appeal 
to the child as worth while, and he must have an attitude that will make him desire to reach the goal. The projects should be graded so that the child will develop rapidly and economically. In so far as method is concerned the success of the project or problem may be measured by the extent to which the pupil economically, whole-heartedly, and purposefully works toward the desired goal.

Motive. The ordinary individual considers a unit of activity in relation to the use to which the product may be put. A bridge spanning the Mississippi River may be completed, an area may be drained, a river may be dammed, the arid land may be irrigated, the ship may be built. In each instance the promoters are not interested in the resulting product simply as a product; they are interested in the use that can be made of the results of their endeavors. The bridge is built in order that the river can be crossed; the land is drained in order that the health of the community will be safeguarded; the river is dammed in order that the energy secured may furnish light and power; the arid land is reclaimed in order that agriculture can be established; and the ship is built to carry commodities and passengers.

The boy constructs a kite, builds a bird house, or makes a tennis court in order that he may use the product. The girl makes a dress, prepares the meal, or washes the clothes with the use of the product in mind. In each case it is the worth-whileness of the goal that furnishes a healthful motive, and in each case suggested the anticipated functioning of the completed product furnishes the needed stimulation. 
A foreigner may attempt to master the English language to facilitate his business and social relations; women may attend instruction schools in citizenship in order that they may learn how to vote; committeemen may meet in a nominating convention in order that they may select a candidate who may win the election; representatives of nations may meet with the view of eliminating war or of settling differences.

The use to which the completed product may be put may be less tangible. The artist may draw a picture, the sculptor may carve a statue, the musician may compose a masterpiece, the author may write a book. The impelling motive may be the meeting of a social need through the product, the desire for social approval, or an attempt to uplift society. The author may be prompted to express some definite idea. This inward impelling, leading to selfexpression, furnishes the highest possible kind of motive for accomplishment.

In a practical way it may be noted that most individuals are prompted to reach a goal, to the extent that they value the anticipated results of their activity. A desirable aim of education is to develop in people an appreciation of their activities in terms of the direct usefulness of the products to society. The indirect result, money and its purchasing power, tends to overshadow the worthwhile purpose that should be found in the work itself. In the school, while the indirect product of an activity, the teacher's grade, is significant, the pupil should be led to find the actuating motive in the work itself. The indirect goals, grades and money, should be so carefully correlated with the direct goal that the worker will feel that if he 
throws his heart into the work fair recognition of accomplishment will be given. If the inherent worth of the activity is appreciated, even though the social recognition may be meager, the pupil will have the pleasure which comes from feeling that service has been rendered or that worth-while accomplishment has been effected.

The child's interest in usable products. The child primarily is interested in products that he can use. The concrete environment is the best laboratory for him. Social values, and particularly social values of a somewhat intangible nature, are acquired only gradually, except as meaningless generalizations. Self-expression as a means of social betterment or as a means of symbolizing abstract ideas is dependent on and-strongly developed-comes later than the activities which result in direct usable achievement. Our public schools should provide abundantly for the refashioning of materials and for other types of intellectual activity in which the possibility of use is so clearly seen that the pupil will work with a will.

Illustration of project work. A geographic problem may also be a project if it is coextensive with the dominating unit of activity. In other instances the project may be much more comprehensive than a problem. As the result of a discussion the pupils may desire to hold a state fair to acquaint the rest of the school, the parents, and the patrons with the resources of the state (for example, Missouri) and their utilization and needed development. The pupils will need to accumulate and arrange samples of products, pictures, maps, diagrams, etc. Under proper direction the pupils will not be satisfied with mere 
accumulation; they will want to consider the underlying physical factors affecting distribution. Numerous problems of considerable complexity may arise. A consideration of the lowlands of southeast Missouri will indicate a remarkable development cluring the last few years, out of which may arise the problem "Account for the wonderful development of southeastern Missouri during the last two decades." City problems may arise; as, "Account for the location and development of St. Louis." Transportation problems may arise; as, "Is the development of the Missouri River as a transportation carrier desirable and practicable?" Rural problems may arise; as, "Is it probable that dairy farming in the Ozarks would be profitable?" Mining problems may arise; as, "Why is Missouri so important in the mining of lead and zinc?"

The project suggested will involve a wealth of questions, exercises, and problems bearing on the goal. The pupils will inform themselves thoroughly concerning the exhibit so that they can discuss intelligently the problems connected therewith. The exhibit or state fair becomes an organizing center for a wealth of details. When the exhibit is held the pupils will be in charge, prepared to make it meaningful through their explanations.

The project exhibit of accomplishment may be the same in appearance as numerous school exhibits in which the pedagogical emphasis has been placed on objective results without reference to the way that the materials were secured. The teacher is interested primarily in the use of the fair as a means of motivating the work by giving the children a definite goal of value from their standpoint. In moving toward the goal the pupils will encounter many 
difficulties the interpretation of which offers the opportunity of securing substantial intellectual and moral development. The educational possibilities of the exhibit are increased through the placing of the pupils in personal charge. The viewpoint shifts from the exhibit as an exhibit to the meaning of the exhibit as a major organizing center to the child.

Projects on the play level. Under the restrictions imposed by schoolroom conditions it has seemed necessary to confine projects primarily to activities on a play and recreational level. Teachers of the lower grades stimulate the pupils to respond to situations which involve, as a means of self-expression, miniature reproductions of the principal buildings, parks, and streets of a city, and to construct in miniature a cattle ranch, the Panama Canal, a dairy farm, a river front, etc. Except on the play and recreational level the tangible products of such activities may serve no useful economic purpose, although the mental development incidentally secured may be invaluable.

Irrelevant problems as parts of projects. Through the lack of a well-defined, worth-while goal many recognized units of activity do not become desirable school projects. The evolution of the problem organization of geographic material as an offspring of the topical method has retarded the movement toward an ideal use of the project method. The old topical outline has been retained in too many instances as a specific, enslaving guide. The teacher has attempted to arouse interest in some problem that will involve every topic of the outline. The pupils suggest different topics that should be considered in the solution 
of the problems; the topics are then rearranged; and presto, change! under the guise of a problem attack the old standard outline confronts the class. The teacher similarly arouses problems concerning other areas, the solutions involving the completed standard outline. The pupils, stumblingly at first, suggest the topics that should be considered. They finally comprehend the "game" of the teacher and come to suggest the topical outline for each problem. Both teacher and pupils, blinded by the desire to include all material that should be studied in one large problem, tend to include much irrelevant material in the solution. The class which starts to work by the problem method may rapidly shift to the old topical outline basis. The class desires to be up-to-date and therefore continues to cap the topical outline with a problem. If the topical outline is of greater concern than the problem, the tendency is to shift from true problem-solving to an endeavor to "work through" the topical outline under the guise of problem-solving. The topical outline does not necessarily hold out a concentrated aim toward the reaching of which each topic is contributing. The pupil's aim may be to complete a study of the topics for a given region. The chances are slight, therefore, that a problem degenerating into a topical outline discussion will be genuinely motivated.

Shortcomings of problems overcome through use of projects. The problem method, as generally used in geography, has retained one of the striking disadvantages of the topical outline; that is, the pupil's inability to use directly the results of problem interpretation. The problem method has rightly been considered a means of 
bringing together in meaningful relation many detached topics. An attempt has been made to place before the child introductory material adapted to his interests and experiences, out of which might arise a problem which could be used as an organizing center. To this extent the problem method is to be heartily approved. The teacher becomes so interested in the problem organization of material, however, that a funclamental defect subtilely creeps in. She tends to lose sight of the need of making the child deeply conscious of the worth-whileness of the goal. Accounting for the backwardness of Mexico may solve a mental query, but the chances are that this type of problem will not make a maximum appeal. The product of such a problem cannot be directly used by the child in satisfying any of his personal or social ambitions. The problem is too general, and its solution is made up of too many scattered elements. In striking contrast, the problem or project which involves a result that can be used in a definite manner in the social group, as the state fair or the construction in miniature of the Panama Canal, stands a better chance of calling forth whole-hearted, sustained effort.

\section{ILLUSTRATIONS OF PROJECTS OF A GEOGRAPHIC NATLRE}

Illustration One. The pupils of a school made an investigation of a vital problem affecting community life, using the following steps: ${ }^{1}$

I. Introduction. The danger of impure drinking water brought viviliy before the pupils.

"Collines, Pryo: McBee, "The Rent School Curriculum," Missouri

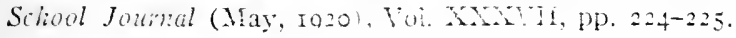


2. Survey made to determine local conditions.

3. Conditions ascertained and conclusions reached.

4. Conclusions presented to community to arouse a community consciousness of the dangers.

How to protect the People of the Community From IMPURE Drinking Water

I. How the people of this community take care of the drinking water.

a. Investigation: The students investigated the source, location, and care of the drinking water of this community, using the following questionnaire: (I) source of the drinking water; $(2)$ location with reference to dwelling and barn etc.; (3) if a well, kind of top; (4) how often cleaned.

b. Conference discussions: In conference with the teacher the students made a study of the facts gathered and discovered that 78 per cent of the people of this community get their drinking water from wells, Io per cent from springs, and I 2 per cent hauled the water from their neighbors; that 80 per cent of the drinking water was located lower than the dwelling and barn; that 95 per cent of the wells had wooden tops; and that only 5 per cent of the homes had cleaned the wells during the past year. In this connection they discussed how impure drinking water causes typhoid fever, and noted that the homes that had the most impure drinking water-for instance those that hauled the water-had had cases of typhoid in the past. In this discussion the question arose whether the people of this community take the proper care of the drinking water. This suggested a study of the reference brobs and bulletins relative to the source of 
drinking water, location, and care. A graphic chart was made illustrating the facts discovered in this investigation.

2. How to get pure drinking water and how to keep it pure. a. Investigation: Here the students investigated the location, source, testing, kind of well tops, methods of cleaning wells, etc., using as a guide the following questionnaire.

\section{Questionnaire}

(I) Location of drinking water with reference to the dwelling, barn, and other outbuildings.

(2) Kind of top for wells, pumps, and buckets.

(3) Drainage and frequency of cleaning the water.

(4) Method of testing polluted drinking water.

b. Conference discussions: In discussing the facts the students concluded that the source of drinking water should be on higher ground than the dwelling, barn, hog pens, other outbuildings, and that it should be free from all drainage; that the best top for wells is concrete; and that the wells should be cleaned at least twice each year. In this connection the group made a concrete top for the school well in accordance with the information they had gathered. The investigation further revealed the fact that the people of this community did not take proper care of the drinking water-that they were very, very careless in this matter. In order to get this matter before the people of the conmunity the group decided to present the information discovered, in illustrated form, at one of the community meetings.

3. Community meeting. The following program was given at one of the night community meetings by this group of students : 
a. Community singing and phonograph music.

$b$. Explanation of the graphic chart showing the source, location, and care of the drinking water of this community.

c. Illustrated talk by one of the students, using a set of lantern slides, on "How to get pure drinking water and how to keep it pure."

d. Demonstration: How to test water for its purity.

$e$. Community singing and phonograph music.

Illustration Two. In Miss Chandor's School in New York City an attempt was made to organize a course of study in which the children would have a vital interest by building it up around the children's questions. An attempt was made to arouse a community spirit in the school by securing the assistance of upper-grade pupils in answering the questions of the pupils of the lower grades. ${ }^{1}$ Numerous questions were raised.

One bright boy of seven asked, "How do we get silk?" He continued, "You know, the kind that hair ribbons and neckties and girls' sashes are made of, and your dress," referring to my taffeta. The other children seemed to think this interesting, so, being a community interest with tremendous possibilities in the way of "leading on," it was selected as the question to be asked first. The young leader asked the girls in chapel the following morning if they would be willing to answer questions put to them by the primary grades. A senior replied to this, saying that the school would consider it a privilege to answer such questions. Then the question on silk was asked. A sixth-rade child volunteered an explanation, but failed to satisfy through lack of preparation.

\footnotetext{
1 Edith A. Linke, "An Experiment in Teaching in Response to Children's Questions," Teachers College Record (January, I920), Vol. XXI, pp. 50-5s.
} 
In the third-grade handwork class we discussed the question and answer, and the third grade decided that the question had not been fully answered. One child decided to look it up in the "Book of Knowledge." She did so, consulting the science teacher for further information. After writing a short paper, which she copied voluntarily three times in order to make it legible, she submitted it to the English teacher for correction and then read it before the school. It was entitled "How we get Silk." In connection with it, she explained a silkworm exhibit procured from the Museum of Natural History by an eighth-grade girl. The teacher of mathematics contributed some raw silk from the yellow cocoon, and afterwards in their own classroom the children examined it, heard about the "combing" process, and with hand lenses studied the exhibit while the science teacher told them many interesting facts. The children in the first grade were overjoyed when they deciphered the labels. They attempted to reel the silk, and later begged for strands to take home to show their parents.

The question was then raised by the primary children. How is raw silk changed into the material that we know as silk? The third-year class volunteered to find out. One day the entire third grade gave before the school a talk on the manufacture of silk. It began with the silkworm and ended with the dyeing process and an exhibit of the finished procuct. During the exposition a hand loom was shown and later minutely explained to the children in their classroom. Of course they wanted to use it. As there was no other available material they used raffia and found themselves making matting. Then they demanded a doll house for the rugs. We decided to have one and to make everything in it for the Children's Hospital. One loom, of course, did not suffice. They begged for more. We procured the simplest type of loom with a heddle, and all of the first-grade children began to make rugs. First they designed them, then compared patterns, and then wove 
them. The second grade wished another loom like the model, as it went faster, so one of their number decided to copy the more complicated type. We compared looms and found the one first used by the Indians.

One day, while I was setting up the warp, the children divided into groups to assist in the process in order that it might be finished before they went home. We accomplished the work in a third of the time it would otherwise have taken. The result is that when working on the loom three or four children run it, one holding the loom firmly, one using the heddle, while the third and fourth weave. This led one little girl to stand the loom on end one day and say that she thought if it were fastened to a box in that position it need not be held. This, of course, was just what was needed to set off a talk on factory machinery in that position.

Illustration Three. In the Wyman School, St. Louis, Missouri, the curriculum of the elementary school was centered about a world's fair. Each class had a definite objective toward which to work. A community spirit in the school was emphasized through the common goal toward which the whole school was moving. The principal, Irofessor John J. Maddox, discussed with the teachers the purpose of the fair. He advised each teacher to make a selection of a unit of work that seemed best for her group. The teacher was to emphasize the educative process, and the exhibit was to grow out of the interests of the children. The teachers were enthusiastic. They discussed the possibility of holding a world's fair, and the classes eagerly welcomed the suggestion. One advantage of the goal toward which the whole school was moving was its flexibility. Each teacher had an opportunity to develop the type of work fitted to her pupils and at the 
same time to do work of importance in helping to realize the common aim. The students at the Harris Teachers College and the fathers, mothers, and patrons of the school were to be invited to attend the fair. The materials to be exhibited at the world's fair were worked out incidentally in connection with the life situations studied. While the pupils looked upon the world's fair as the controlling motive, the teachers were particularly concerned in the questions and problems leading to and coming from the expression work. The manual-training room became a laboratory shop in which the pupils attempted to express their ideas. Numerous articles were made. Once a cursory glance through the shop revealed different pupils at work making a miniature reproduction of the first printing press, the first reaper, an aëroplane, a bird house, a $\log$ cabin, a model of a flatboat, a stockade, and a dining-room set. The walls and floors of the rooms and halls were used in placing the exhibits of the various groups. The work of the lower grades had been built about type studies, the intermediate grades about regional geography, and the upper grades about situations intended to develop a national and international viewpoint.

The kindergarten and first-grade work was centered about the home. Pictures to illustrate the uses of the various rooms of the home and the work of various members of the family were placed on charts. The children had represented their own conceptions through crude drawings and had constructed of boxes a two-story house. By way of contrasting our homes with those of less developed people, a first-grade class had made a study of Indian life, and the children informally dramatized Indian 
life, making use of the various materials they had constructed. A second-grade class studied about the people of Holland, and the children had constructed a Dutch village and had drawn pictures representing scenes in Holland. Another class had constructed of cardboard a miniature reproduction of the school building and had placed in proper position miniature reproductions of the important places that they had directly observed in the immediate vicinity of the school. The places represented included a fire department, a dairy plant, a park, a florist's shop, a special school, and their own homes. A third-grade class had constructed a miniature floor representation of the city of St. Louis, locating the more important landmarks and the Mississippi River. Another class had constructed a miniature representation of the state capital, Jefferson City, on the bluffs of the Missouri River. A fourth-grade class had constructed a miniature farm, properly divided for the various crops. Corn, wheat, and oats were planted, and the various buildings were constructed of cardboard. Another class had made a special study of a factory and had learned in detail the processes involved in making margarine. The exhibits in the intermediate and upper grades, related to regional and world geography, were not so directly related to the local area. Among these exhibits were a miniature representation, with the use of clay and water, of New York Harbor, a model of the Panama Canal, a cattle ranch, and displays of various economic products, as cork, wheat, and silk. Charts and cliagrams were an important part of the uppergrade exhibits. The pupils, who were in charge, eagerly discussed and explained the various exhibits. Emphasis 
was not placed on the exhibit as an exhibit, but on the exhibit in relation to the activities of the children.

Geography the ccntcr for the organization of school work on a project basis. All the illustrations cited are earnest attempts to direct the experiences of children into socially valuable channels, the content being organized in life situations within their comprehension and interests. To an increasing extent the geography work will be taught through problems and projects which appeal to the child on his level of development, which are graded, and which are socially and individually desirable. Through desirable school projects, adequately motivated and involving worth-while goals, educational leaders may hope materially to expedite the development of the child. Because of the emphasis that geography has always placed on present situations, this subject naturally becomes the nucleus for the organization of all school work on a project basis. In the development of the world's fair project various subjects contributed, but the fundamental subject was geography.

Suggestions for Further Study:

1. What is a project as defined by various educators? Which conception do you prefer? Explain.

2. What is the relation of problems and projects?

3. Is it possible to build up a course of study in geography altogether through projects?

4. Do projects tend to emphasize the boundary lines between subjects or to break down the boundary lines?

5. Make a list of projects that you believe can be successfully used in the geography classes.

6. Elaborate in cetail a project for a specific grade. 


\section{Selected References:}

Braxom, M. E. The Project Method in Education, p. 278.

Burbank, Luther. Training of the Human Plant (The Century Company, 1907), p. 99.

Collings, P. M. "Rural School Curriculum," Missouri School Joumal (1920), Vol. XXXVII, pp. I 70-I 74, 222-227.

Coviris, S. A. "Teaching through the Use of I'rojects," Teachers College Record (1920), Vol. XXI, pp. I39-149.

Hotchisiss, Caroline W. "Pageant of the Earth," Journal of Geography (I9I9), Vol. XVIII, pp. I7I-178.

Kilpatrick, Willian H. "The Project Method," Teachers College Record, Vol. XIX, pp. 319-335.

Krackowizer, Alice M. Projects in the P'rimary Grades, p. 22 I. Krackowizer, Alice M. "Social Enterprises of Little Children," Kindergarten and First Grade (1920). Vol. V, pp. I42-I 45.

Linke, Enith A. "An Experiment in Teaching in Response to Children's Questions," Teachcrs College Record (1920), Vol. XXI, pp. 55-67.

McMurry, Cirarles A. Teaching by l'rojects (I920), p. 25\%.

Michel, Stella. "Fourth-Grade I'roject I'roblem in Geography," Missouri School Joumal (1920). Vol. XXXVII. pp. IO-I1.

Storu, Grice. "A Map of the United States," Elementary School Teacher, Vol. XV, pp. 29-40.

Sweexey, Ella L. "Problem-Project Ifethod in the Primary Grade," Kindergarten and First Grade (1920). V'1. 1. pp. 177-180.

Towne, MARY E. "Developing a Class l'ruject," Industrial-Arts Magaine (1920), Vol. IX, pp. $442-4+5$.

Vox Hofe, George D. "The Development of a I'roject," Tiahers College liecord, Vol. XVII, pp. 240-2f f.

Wintenti, Fren C. "General Project Method of Teaching the Industrial Arts," Industrial-Arts Magazine (1920), Vol. IX, pp. $131-13^{6}$. 


\section{PART SIX. TESTS AND SCALES}




\section{CHAPTER XXI}

\section{MEASURING RESULTS}

The viewpoint. The teaching of geography involves (I) the setting up of criteria as a means of selecting subject matter and organizing it into a course of study, (2) the setting up of well-defined aims which it is hoped to realize through the subject matter properly related to the child, (3) the organization of the class and the use of the materials of the subject in such a way that these aims may be realized, (4) testing to ascertain whether the aims have been realized, and ( 5 ) the devising of means to overcome determined failures of instruction.

The teacher of geography may test for (I) facts, (2) interpretation of facts, (3) ability to use geography content, and (4) ideals, attitudes, habits, tastes, and skills. Factual testing can be more readily accomplished, because of the definite response (easily measured) required. Much of the emphasis in teaching has been placed on factual geography. At present interpretative geography, usable geography, and geographic experiences which will assist in giving the pupil a desirable world-wide outlook are being increasingly emphasized. In part because of the recency of emphasis, in part because of the difficulties involved in measuring the product, most of the testing has been confined to factual testing. Teachers may desire to teach more than mere facts, but 
if the tests devised to measure accomplishment are primarily factual, the influence of the measuring exercises will be greater than the possibilities revealed in an analysis of geographic aims. The more significant phases of geography, based on the factual, will not be properly emphasized unless appropriate tests are devised.

Geography fundamentally deals with the location of places and interpretations related thereto. The mere testing of place geography, however, reveals a very limited amount of the modern geographic knowledge demanded of a pupil. As a matter of fact, place geography may be taught solely by means of drills, or it may be taught incidentally in connection with the solution of geographic problems. The place tests, since they do not indicate whether relations were developed or merely taken for granted, manifestly do not measure the most vital part of geography.

Criteria suggested for selection of contcnt. Professor George J. Miller ${ }^{1}$ has suggested the following criteria for determining what subject matter shall be included in grade geography.

\section{NATURAL ENIIRONMENT}

I. Ts this particular element of the environment essential to an understanding of other elements of the environment and responses in the succeeding parts of the course?

2. Is this particular element of vital importance for the child to know in after life, even though it is not provided for in the course of study?

1" Essentials of Modern Geocraphy and Criteria for their Determination," Journal of Geography (January, I915), Vol. XIII, pp. I34-I35. 


\section{LIFE RESPONSE}

I. Is this particular subject matter concerning plant and animal life clearly a response to the natural environment and within the comprehension of the child?

2. Are the human responses, especially human activities, clearly responses to the natural environment and within the comprehension of the child?

3. Are these life responses clearly essential for a child to know in daily life, even though not provided for in the course of study?

Boston's attcmpts to asccrtain results. In setting up tests for the pupils at the close of their grade work it was believed that the pupil should gain, as a resuit of his sivily of geography,

I. An abiding interest in the different peoples of the world, - their industries, their achievements, and their relations to ourselves.

2. A mastery of geographic facts and principles sufficient to enable him to explain

a. The growth of the leading cities of a region.

$b$. The development of important industries.

$c$. The dependence of one part of the world upon another.

3. A breadth of mind which will lead to a sympathetic understanding of races and nations other than his own.

4. A working knowlerge of the subject by a thorough training in the use of maps, texts, and reference books, so that he can work out new problems independently.

The following set of questions was included in a completion test for the grades:

ISchnol Document No. If (1015), Boston Public Schools. Conducted under the supervision of Professor L. O. Packard. 


\section{QUESTIONS ON THE UNITED STATES}

(An outline map of the United States was printed at the head of the questions)

I. Locate on the map the cities named at the right:

2. In the column marked "Products" write opposite the name of each city the name of a product for which the city is noted.

3. Give reasons for the growth of Minneapolis.

\begin{tabular}{|c|c|}
\hline Crties & Pkodects \\
\hline Minneapolis & \\
\hline Pittsburgh & \\
\hline Lowell & $\ldots$ \\
\hline New Orleans & - non \\
\hline Duluth & \\
\hline Galveston & -... \\
\hline Lynn & $\cdots$ \\
\hline
\end{tabular}

4. Below is given a list of articles which we use in our homes. Write below each word the name of the state in which that article is produced in large quantities.

cotton oranges cane sugar rice coal iron

5. Write on the map the name of each state which you have just written in answering question 4 .

6. Why do the states just east of the Rocky Mountains receive less rain than Massachusetts?

7. Explain the way in which the flood plains of the Mississippi River have been formed.

8. Why are these flood plains good for agriculture?

9. Locate New York City on the map. Locate San Francisco on the map.

Io. Give reasons why the commerce of San Francisco is not so important as that of New York City.

Place geography has been happily blended with interpretative geography in the above set of questions.

Place-geography tests. Professor Whitbeck, ${ }^{1}$ in discussing the results to be expected from a school course in

${ }^{1}$ R. H. Whitbeck, "Results to be expected from a School Course in Geography," Journal of Geography (April, I905), Vol. IV, pp. I49-152. 
geography, divides his discussion into ( $\mathrm{I}$ ) home geography, (2) the world as a whole, (3) knowledge of location, (4) facts of physical geography, (5) facts of commercial geography, and (6) general facts. Under knowledge of location Professor Whitbeck indicates in a general way the classes of place names that should be familiar, such as important political units, the more important rivers, islands, mountains, capes, political colonies, and cities of the world.

Minimal place material has been selected (I) through the individual judgment of a teacher or geography specialist, (2) through the collective judgment of a number of teachers or geography specialists, (3) through a comparison of the relative emphasis given to certain materials in textbooks of geography, and (4) through a study of the frequency with which place names occur in newspapers and magazines.

The individual-judgment method was used by Mr. T. E. Thompson ${ }^{1}$ in his exercises in minimal essentials and by Superintendent Witham" in establishing "a minimum standard for measuring geography" in the sixth grade through a list of fifty-five questions to be answered in forty-five minutes.

The textbook method applied by Dr. W. C. Bagley ${ }^{3}$ to the content of history could be used similarly with geography. This method is in effect, however, substantially the same as the combined judgment of experts. A

${ }^{1}$ Minimum Essentials in Geography.

2 Ernest C. Witham, "A Minimum Standard for Measuring Geography." American School Board Journal (January, I915), Vol. I, p. I3.

"The Content of American History," Bulletin No. 16, University of Illinois School of Education. 
minimal list of places on the basis of frequency of mention in current literature was reported by Dr. Bagley. The results of this investigation were inconclusive, but incicated that such a method, if taken alone, would be unsatisfactory as the basis for the selection of minimal essentials.

The collective-judgment method was followed by a group of teachers of Springfield, Illinois, working under the direction of Professor D. C. Ridgley ${ }^{2}$ with respect to the fourth-grade and fifth-grade work. As a result the following number of place names was recommended and adopted for these grades in the Springfield schools: World, 30; North America, 27; United States, I43; South America, 35; Asia, 39; Africa, I9; and Australia, I I.

A gcography scale. In the tool subjects--reading, writing, and arithmetic - scales have been devised which can be used by any individual in letermining his standing. The same scale can be used by children of the several gradies, a higher per cent being required in the upper grades than in the lower. A tentative attempt to make such a scale (the Hahn-Lackey scaie) in measuring ability in geography has been made." Through a comnarative study of six of the modern textbooks in geography about six hundred questions and exercises, emphasizing

1"The Detemination of Minimum Essentials in Elementary Geosraphy and Ifietor." Fourtenth Vearbook of the National Society for the Study of Erluration, Part I, Pp. 13I-1.47.

"2"The Teachene wf Place Geocrayhy," Journal of Geography (Sep-

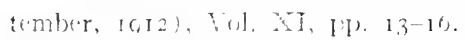

"E. E. Lackry, "Mcasurine the Ability of Children in Geography,"

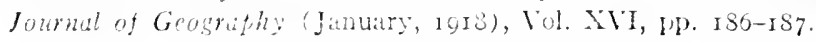


both the memory and the rational phases of geography, were secured. The questions and exercises were given to I 696 students, and on the basis of difificulty were grouped in "steps." There are twenty-five steps, designated by letters of the alphabet.

QUESTIONS AND EXERCISES OF "STEP P" OF THE SCALE

79. Name two large rivers of South America.

So. What two important products are brought to us from Brazil?

S8. How can you get from New York to London, and in what direction would you go?

89. How can steamboats go from New York to San Francisco by the shortest route?

I00. Name the chief occupation of the people of Australia.

I05. Give two reasons why mountainous regions are not good for farming.

28. How can we tell how big a country is by studying a map?

Io. How long does it take the earth to go around the sun?

67 . Give the principal reason why such dense forests grow along the Amazon.

70. Which part of the United States is most important for manufacturing and which for agriculture?

74. Where may snow be found in the hot belt near the equator?

77. Why is there so little rainfall in the Great Basin of the United States?

78. Name one way in which the Panama Canal will be an advantage to the United States in its trade with South America.

8 I. During what months does Argentina have winter?

S2. In what industry or kind of work are most of the people of England engaged?

3I. Why do so few people live in deserts? 
According to the scale an average fourth-grade pupil ought to make $34 \%$ on the questions and exercises of this step or any part of it, a fifth-grade pupil ought to make $50 \%$, a sixthgrade pupil $58 \%$, and a seventh-grade or eighth-grade pupil $73 \%$.

The authors suggest that the steps can be used in the following ways :

I. To measure a pupil's ability in geography for his promotion or classification.

2. To measure the ability of a class as a whole for comparison with the standard given in the scale.

3. To compare the progress of a year's work in geography for comparison with the nornal progress shown by the scale.

4. To measure the balance between the different phases of geography work.

5. To measure the merit of different methods of instruction and of school organization.

Determining minimal essentials as a basis for testing. The aims of geography teaching are to impart the more important facts of conventional or practical value, to secure on the part of the pupil ability to interpret properly the geographic factors that enter into problems of timely moment, and to develop an appreciation of the importance of the United States intrinsically and in its relational aspects to the world as a whole. The realization of these aims requires a general knowledge of ( $\mathrm{x}$ ) the relative location of the large land and water bodies, (2) the location of the more important countries of the world, (3) the location of the more important cities of the world, (4) the physical conditions of the more important countries, 
(5) the occupations of the people and the conditions of transportation, (6) our commercial relations with these countries, and (7) the fundamental relationships between the physical factors and human activities.

It is desirable that the more important phases of geography be recognized to insure that the testing shall adequately emphasize the essentials. In determining a minimal essential list of countries of the world the following standards were employed: ( I ) the area of the country in square miles, (2) population, (3) total value of imports, (4) total value of imports from the United States, (5) total value of exports, and (6) total value of exports to the United States. These criteria not only offer objective data of great significance in the study of a particular country but also afford a means of measuring the relationships of the United States to each country.

The statistical data for each of the above criteria were secured from the Statistical Abstract of the United States (I9I5), in which reports covering the latest year for which statistics were available, for the fifty-two more important countries of the world, were given. The countries were ranked according to their relative importance with respect to each of the six criteria and have been numbered accordingly in Table I, p. 276 .

The fifty-two countries of Table I were then divided into quintiles under each of the six criteria previously discussed, and values were assigned to rank in the various quintiles as follows: (I) rank in the first quintile in each criterion received a score of 5 points; (2) rank in the second quintile, a score of 4 points; (3) rank in the third quintile, a score of 3 points; (4) rank in the fourth 
quintile, a score of 2 points; and (5) rank in the last quintile, a score of I point. The total score thus received by a country would serve as an index of the relative importance of that country among the countries of the world in area, population, and import and export trade, and of its relative importance to the United States in import and export trade.

Table II indicates the total score of each country by this method. These scores range from 30 points in the case of the United States - a perfect score because it is the home country of the child-to 6 points for Liberia. An examination of the scores clearly indicates the greater importance of certain countries and suggests the desirability of establishing a line of demarcation between the important and less important countries. The placement of this line is somewhat arbitrary, and, through experimental evidence or radical changes in statistical data, some readjustment may be desirable. The score of 20 points, the lower limit of the second quintile, seems to offer the most satisfactory place for a tentative limiting line for minimal essentials. This places twenty-one countries in the "minimal-essential list." These countries should receive a more comprehensive treatment than would be given to the remaining thirty-one countries.

In the selection of a minimal list of cities several factors, such as import and export trade, advantages of location, importance of hinterland, and advantages of transportation, were tried as standards, but the lack of sufficient lata for many cities renclered such work unsatisfactory. A very close correlation, however, was found to obtain between these standards, in cases where such data were 
available, and the single standard of population. It was decided, therefore, to use the standard of population as a criterion for determining the list of cities. After considering the list of cities determined by the single standard of population, it was believed that the largest city of each of the twenty-one essential countries of the world (as previously determined) should be included in the list, with the addition of all other cities of more than 200,000 population in the Western Hemisphere, of all other cities of more than 600,000 population in Europe, and of all other cities of more than 800,000 population in the rest of the world. This standard of population was established on the basis of American relations to the different regions of the world.

This basis of selection gives a list (for a complete list of cities see the test that follows) of 29 cities for the United States; ro for the Western Hemisphere, exclusive of the United States; 8 for Europe; and 9 for Asia, Africa, Australia, and the scattered islands. All of these are located in the more important countries, with the exception of Habana, Montevideo, and Santiago.

In selecting a minimal list of products dependence has been placed upon the value of production in the United States, supplemented by the value of products imported into the United States. The aggregate value of a class of products may be large with large quantities in use and a low price. or with small quantities in use and a high price. Neither price nor quantity is an exclusive index of the importance of the products to man. Ranking products in order of aggregate values has the advantage of taking both these factors into consideration. 


\section{TABLE I. FIFTY-TWO COUNTRIES RANKED IN IMPOR- TANCE IN TERMS OF SIX CRITERIA ${ }^{I}$}

\begin{tabular}{|c|c|c|c|c|c|c|c|c|c|c|}
\hline \multicolumn{5}{|c|}{ COINTRY } & AREA & $\begin{array}{c}\text { PortLA- } \\
\text { TION }\end{array}$ & $\begin{array}{l}\text { TOTAL } \\
\text { IMPORTS }\end{array}$ & $\begin{array}{c}\text { IMPORTS } \\
\text { FROM } \\
\text { UNITED } \\
\text { STATES }\end{array}$ & $\begin{array}{c}\text { TOTAL } \\
\text { EXPORTS }\end{array}$ & \multirow{2}{*}{$\begin{array}{c}\text { EXPORTS } \\
\text { TO } \\
\text { UNITED } \\
\text { STATES } \\
\text { (1) }\end{array}$} \\
\hline I. United Stat & & - & . & . & 4 & 4 & 3 & (I) & I & \\
\hline 2. Great Britai & & . & - . & . & 29 & 8 & I & 1 & 3 & 3 \\
\hline 3. Germany & $\cdot$ & . & . . & . & 21 & $\vdots$ & 2 & 2 & 2 & 2 \\
\hline 4. France. & . & . & . . & . & 22 & $\dot{9}$ & 5 & 5 & 5 & 7 \\
\hline 5 . India $\cdot$ & . & . . & . & . & 7 & 2 & 9 & 22 & 6 & $S$ \\
\hline 6. Austria-Hun & nga & iry . & . & . & 20 & 7 & $\$$ & 8 & 9 & 10 \\
\hline 7. Russia . & $\cdot$ & . . & . & - & I & 3 & 7 & 12 & 7 & 27 \\
\hline 8. Canada . & . & . & . & . & 3 & 19 & $1 I$ & 3 & II & 1 \\
\hline 9. Italy. . & . & - & . & . & $3^{2}$ & 10 & 10 & 7 & 10 & 10 \\
\hline 10. Japan. . & . & . & . & . & 27 & 6 & 15 & 10 & 14 & 5 \\
\hline 11. China . & . & . & . & . & 2 & $\mathbf{I}$ & 13 & 15 & 16 & 13 \\
\hline 12. Brazil . & . & . & . & . & 5 & 11 & 21 & 14 & 17 & 6 \\
\hline 13. Argentina & . & . & . & . & 8 & 20 & 16 & 13 & 13 & I I \\
\hline 14. Netherlands & & . & . & . & 49 & 2.4 & 4 & 4 & 4 & 9 \\
\hline 15. Mexico & . & • & - & - & 9 & 14 & 30 & II & 23 & 4 \\
\hline 16. Belgium. & . & - & - & . & 50 & 21 & 6 & 6 & 8 & 16 \\
\hline 17. Australia & - & . & . & . & 6 & 31 & 12 & 9 & 12 & 21 \\
\hline I8. Spain. & . & . & . & - & 24 & 13 & 19 & 16 & 21 & 22 \\
\hline 19. Sweden. & . & . & . & . & 25 & 27 & 37 & 20 & 18 & 25 \\
\hline 20. Egypt . & . & . & . & . & 17 & 15 & 25 & 39 & 25 & 19 \\
\hline 21. Turkey . & . & . & . & . & 12 & 12 & 20 & 34 & 27 & $2 S$ \\
\hline 22. Switzerland & & . & . & . & $4^{8}$ & 35 & 14 & 19 & 15 & 14 \\
\hline 23. Chile. & & & . . & . & 19 & 36 & 28 & 21 & 26 & 12 \\
\hline 2.4. South Afric & an & Uni & ion & . & 14 & 23 & 22 & 23 & 20 & 38 \\
\hline 25. Philippine I & Islat & inds & 5 . & . & $3^{1}$ & I 7 & 33 & 17 & 31 & 15 \\
\hline 26. Yeru. . & . & . . & . & . & II & 26 & 40 & 28 & 32 & IS \\
\hline 27. Cuba. & . & . & . & . & 15 & 29 & 39 & 27 & $3^{5}$ & 17 \\
\hline 2\$. Denmark & . & - & . & - & 47 & 37 & 15 & is & 19 & $3^{6}$ \\
\hline 29. Norway. & . & - & . & . & $2 S$ & $t^{1}$ & 23 & 26 & 28 & 26 \\
\hline 30. Algeria. & . & . & . & . & Is & 25 & 24 & $3 x$ & 29 & $4^{2}$ \\
\hline 31. New Zealan & & . & . & . & 33 & 48 & 27 & 24 & 24 & 29 \\
\hline 32. Persia . & . & . & . & - & 13 & 16) & 31 & 51 & 35 & 40 \\
\hline 33. Portugal. & . & - & . & - & +3 & 25 & 24) & 25 & 33 & 39 \\
\hline 34. Rumania & . & . & . & . & 37 & 22 & 25 & +0 & 22 & 44 \\
\hline 35. Venezuela & . & . & . & . & It) & 39 & 4.3 & 30 & +2 & 24 \\
\hline $3^{3}$. Lruguay & . & . & . & . & 35 & 46 & it & $3^{6}$ & 30 & 23 \\
\hline 37. Bolivia. & . & . & . & . & 10 & $3 x$ & $4^{2}$ & 4 & .36 & 4 tí \\
\hline 3 k. -iam. & . & . & - & . & 23 & ith & 37 & 44 & 34 & $4 t$ \\
\hline 39. Greece. & . & . & . & . & $4^{1}$ & $3^{2}$ & $3^{\prime \prime}$ & +5 & 40 & 35 \\
\hline 40. Norocco & . & . & . & . & $2^{6}$ & 30 & 32 & 4 & 45 & 45 \\
\hline 41. Terbia . & · & . & - & . & 44 & 37 & $+i$ & $\left.4^{t}\right)$ & +1 & +1 \\
\hline 42. Bulgaria. & . & . & . & . & 40 & 33 & .35 & 50 & i4 & +3 \\
\hline 43. Ecuador. & . & . & . & . & 30 & 44 & 47 & 37 & $4+4$ & 32 \\
\hline 44. Maiti. & . & . & . & . & $\vdots 1$ & 40 & 44 & 34 & 43 & 50 \\
\hline 45. Tunis. & . & . & . & . & $3^{\prime \prime}$ & 43 & $33^{3}$ & 43 & 37 & .4 \\
\hline$t^{f} \cdot$ Honduras & . & . & - & . & 34 & 50 & 4) & $i_{2}$ & 50 & 33 \\
\hline 47 Conta Rica & . & . & . & . & $4^{\prime \prime}$ & 51 & $4^{4}$ & 35 & 47 & 30 \\
\hline 4. fivatemila & . & . & . & . & 35 & 42 & 45 & i3 & $4=$ & 31 \\
\hline $4 \%$ lanama. & . & . & . & . & 45 & 52 & $\because{ }^{\prime \prime}$ & 31 & $\vdots 1$ & 37 \\
\hline 50. Lalvador. & . & . & . & . & 52 & 47 & 51 & 42 & $\left.4^{t}\right)$ & 34 \\
\hline 51. Iaraguay & . & . & . & . & if & 311 & $\because$ & $\therefore$ & 40 & 47 \\
\hline 52. Liberia. & . & - & .. & . & $+t^{2}$ & +5 & 52 & in & 52 & 51 \\
\hline
\end{tabular}

1 Compiled from Statistical Abstract of the Lnited States, 1915. 
TABLE II. POINTS SCORED BY FIFTY-TWO COUNTRIES IN SIX CRITERIA OF IMPORTANCE 1

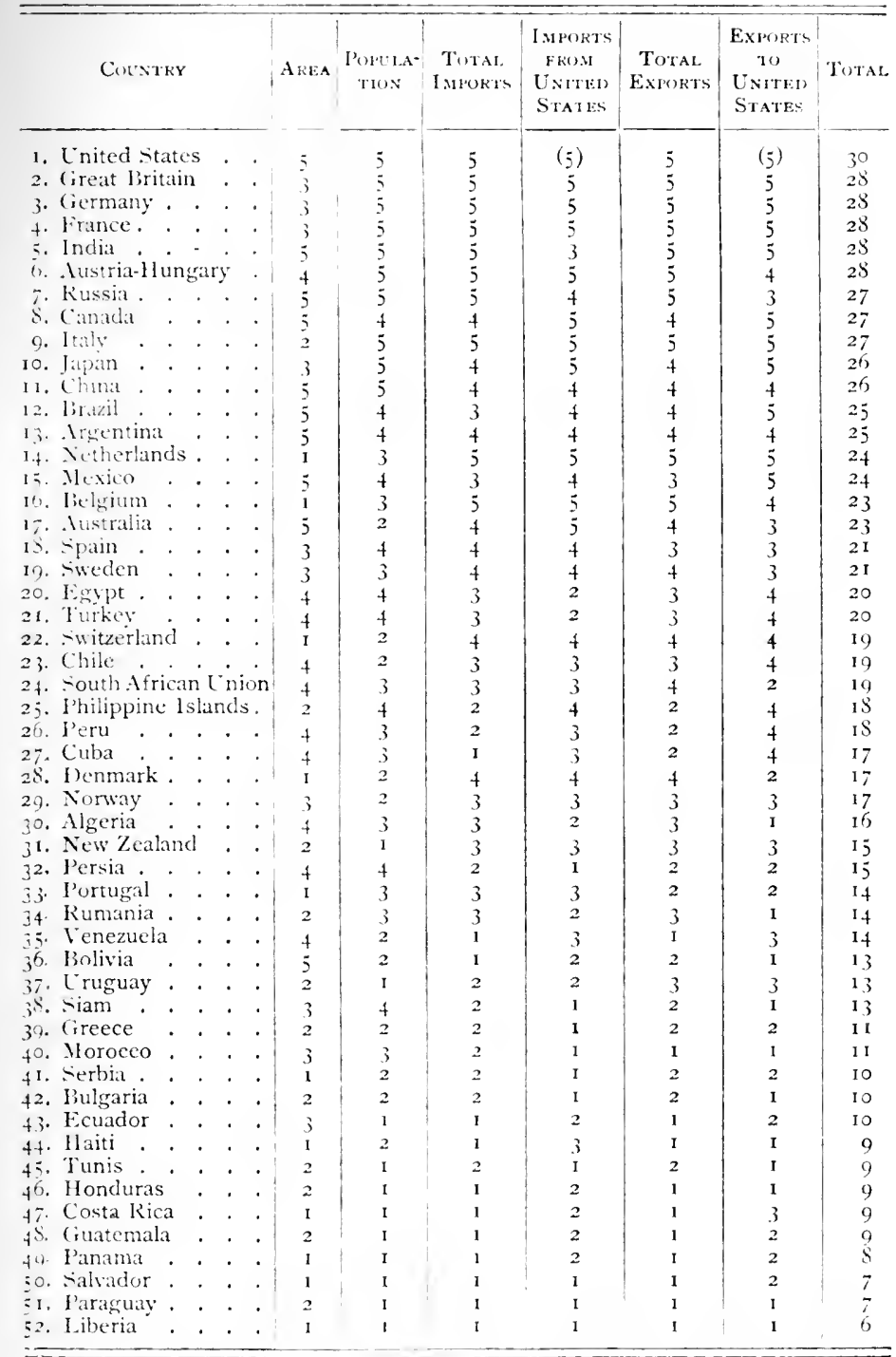

1 Compiled from Statistical Abstract of the United States, 1915. 
Ranking the products on the basis of the aggregate values of each product for all countries is desirable, but, because of unsatisfactory data, impracticable. Fortunately, from a somewhat different point of view statistics almost as satisfactory can be obtained. Recent world events have brought out in an emphatic manner the commercial dependence of every first-class power upon practically every part of the earth. The United States, consequently, either produces practically all important materials or imports them in large quantities from other producing areas. Hence a consideration of the products of the United States and the products imported into the United States offers a comprehensive list of the world's industrial products.

Only the more significant of these products should be included in the minimal-essential list (for this list of products see Part III of the completion test that follows). It has been assumed that all plant, animal, and mineral products with a production value in the United States of $\$ 5,000,000$ or more annually should be considered, and that this list should be supplemented by all products, not otherwise included, imported in quantities valued at $\$ 5,000,000$ annually.

Irrespective of values, however, materials of general distribution (such as hay, clay, sand, and stone) or materials (such as mushrooms) for which information concerning distribution is inadequate have been omitted.

A test based on the minimal essentials. In the following test an attempt has been made to test not only knowledge of place geography but also knowledge of geographic 
relationships. In organizing the relational material it has been assumed that location, area, surface features, soils, climate, distribution of plant and animal forms, and distribution of minerals are the significant physical factors. The pupil's knowledge of geography has not been tested suficiently unless he has shown his appreciation of the ways these factors have influenced man and unless he shows his ability to select important factors that enter into a geographic situation.

COMPLETION TEST FOR THE MEASUREMENT OF MINIMAL GEOGRAPHIC KNOWLEDGE OF ELEMENTARYSCHOOL CHILDREN

\section{PART I}

On an outline map of the world indicate the location of the continents and oceans by writing the names in the proper places.

\section{PART II}

On an outline map of the world write in the correct place the name of each of the following countries: United States, Great Britain, Germany, France, India, Italy, Russia, Canada, Austria-Hungary, Japan, China, Brazil, Argentina, Netherlands, Mexico, Belgium, Australia, Spain, Sweden, Egypt, and Turkey. (The recent readjustments in Europe require a slight modification, Austria and Hungary being two separate countries, and Czechoslovakia. Jugoslavia, and Poland being three new countries that probably should be included.)

Given an outline map of the United States, with the location of the ninimum list of cities indicated by number and the list 
of cities accompanying the map, write opposite each city the appropriate number.

Given an outline map of the world, with the location of the minimum list of cities, except those of the United States, indicated by number and the list of cities accompanying the map, write opposite each city the appropriate number.

\section{PART III}

(Test to be applied to any country)

\section{Country}

I. Give the direction of this country from your home city

2. Give in square miles the approximate area of the United States_. Underline the term that more nearly expresses the area of the above-named country in comparison with the United States: Larger. Smaller. Approximately the same.

3. Give the approximate population of the United States . Underline the term that more nearly expresses the population of the above country in comparison with the United States: Larger. Smaller. Approximately the same.

4. Indicate an important highland of this country

5. Underline the statements that more nearly indicate the prevailing conditions of this highland:

Easy to cross

Extends above tree line

Large cities

Dense population
Permanent snow fields

Much mining

No large cities

Herding industry important Difficult to cross

6. Indicate an important river basin or lowland of this country

7. Underline the statements that more nearly indicate the prevailing conditions concerning this lowland: 
Dense population

River important for navigation

Irrigation practiced

Nuch mining
Agriculture important

Manufacturing important

Sparse population

Herding important

\section{Much swamp and overflow land}

8. Underline the statement that more nearly describes the prevailing temperature of the country: Primarily in hot belt. Primarily in cold belt. Primarily in intermediate belt.

9. Underline the statement that describes the prevailing rainfall: Heavy rainfall (above 50 inches). Moderate rainfall ( 20 to 50 inches). Light rainfall (less than 20 inches).

Io. Underline the name of each plant product that is important in this country:

$\begin{array}{llll}\text { Corn } & \text { Cotton } & \text { Peaches } & \text { Lemons } \\ \text { Wheat } & \text { Tobacco } & \text { Peas } & \text { Fibers } \\ \text { Oats } & \text { Flax } & \text { Silk } & \text { Rubber } \\ \text { Barley } & \text { Rice } & \text { Cocoa } & \text { Bananas } \\ \text { Rye } & \text { Sugar } & \text { Coffee } & \text { Grapes } \\ \text { Buckwheat } & \text { Apples } & \text { Tea } & \text { Nuts } \\ \text { Potatoes } & \text { Beans } & \text { Oranges } & \text { Wood }\end{array}$

Ir. Write the name of one of the products underlined above - Underline its important use or uses:
Food for man
Clothing
Food for animals
Fuel
Shelter
Luxury

12. Underline the name of each animal that is important in this country:

Cattle Hogs Sheep Horses Mules Goats Poultry

I3. Write the name of one of the classes of animals underlined above_Underline its important use or uses :

Meat Milk Clothing Eggs Beast of burden 
14. Underline the name of each mineral product that is important in this country:

$\begin{array}{llll}\text { Coal } & \text { Nickel } & \text { Natural gas } & \text { Aluminum } \\ \text { Iron } & \text { Copper } & \text { Tin } & \text { Zinc } \\ \text { Petroleum } & \text { Gold } & \text { Silver } & \\ \text { Phosphates } & \text { Sulphur } & \text { Lead } & \end{array}$

I5. Write the name of one mineral product underlined above_. Underline its important use or uses:

Fuel

Machinery

Fertilizer

Alloy

Light

Jewelry
Paints

Plumbing supplies

Chemicals

I6. Underline the prevailing manufacturing conditions:

Extensive

Moderate

Slight

I 7. Underline the influential factors in the development of manufacturing:

Good water power

Much coal

Sbundant labor supply

Scarcity of coal
Abundant capital

Little water power

Insufficient labor supply

Scarcity of capital

I 8. Underline statements that properly describe the prerailing conditions of transportation:

Rivers important

Rivers of little importance

lakes very important

Lakes of litule importance
Railroads well developed

Railroads undeveloped

Public roards well improved

Public roads in bad condition

I9. Uncerline each of the cities of this country:

\begin{tabular}{|c|c|c|}
\hline Washington & Jinston & Philadelphia \\
\hline London & Bunfialo & l'ittsburish \\
\hline
\end{tabular}




$\begin{array}{llll}\text { Berlin } & \text { Chicago } & \text { Portland } & \text { Glasgow } \\ \text { Paris } & \text { Cincinnati } & \text { Providence } & \text { Hamburg } \\ \text { Petrograd } & \text { Cleveland } & \text { Rochester } & \text { Liverpool } \\ \text { Vienna } & \text { Columbus } & \text { St. Louis } & \text { Manchester } \\ \text { Tokio } & \text { Denver } & \text { St. Paul } & \text { Moscow } \\ \text { Rio de Janeiro } & \text { Detroit } & \text { San Francisco } & \text { Naples } \\ \text { Buenos Aires } & \text { Indianapolis } & \text { Seattle } & \text { Warsaw } \\ \text { Mexico City } & \text { Jersey City } & \text { New York } & \text { Bombay } \\ \text { Brussels } & \text { Kansas City } & \text { Bahia } & \text { Canton } \\ \text { Sydney } & \text { Los Angeles } & \text { Habana } & \text { Hankow } \\ \text { Madrid } & \text { Louisville } & \text { Montevideo } & \text { Osaka } \\ \text { Stockholm } & \text { Nilwaukee } & \text { Montreal } & \text { Tientsin } \\ \text { Cairo } & \text { Ninneapolis } & \text { Santiago } & \text { Calcutta } \\ \text { Constantinople } & \text { Newark } & \text { Sao Paulo } & \text { Amsterdam } \\ \text { Baltimore } & \text { New Orleans } & & \end{array}$

20. Write the name of one of the cities underlined in the preceding exercise - Underline the statements that describe this city:

Seaport

River port

Lake port

Important railroad center

A political capital
A mountain-pass city

An important manufacturing center

An important commercial center

The various parts of the topical outline-location, area, population, topography, climate, economic products, and important cities-are included in the test. and the relational viewpoint has been stressed. ${ }^{1}$

For a more detailed account of the test see M. E. Branom and II. C. Reavis, "The Determination and Measurement of the Ainimal Estentials of Elementary-School Geocraphy," Seventeenth Yearbouk of the National Society for the Study of Education, pp. 27-39. 


\section{TYPES OF QUESTIONS USEFUL IN TESTING}

I. Informational. Where is New York City? Where is Poland? In what part of the United States are oranges produced in large quantities?

2. Interpretative. Why is there a semiarid region east of the Rocky Mountains? Why is the Amazon basin sparsely populated?

The informational question frequently is used as a basis for the interpretative. The question Where are oranges raised? may be answered, In Florida and California. The next question may be interpretative: Why are oranges raised in Florida and California?

3. Statements to be filled in:

The two chief rivers of Italy are the and the

Mulberry trees are grown in many parts of Italy, especially

The most important nut tree of Italy is the

The largest city of Italy is

4. Statements to be answered "yes" if entirely correct and "no" if in part wrong:

Chicago, located near the southern end of Lake Michigan, is the largest city of the United States. (No)

The United States imports large quantities of raw sugar. (Yes)

5. A meaningful statement to be made if a word or expres. sion is given:

Vesuvius Vienna Punta Arenas Rubber Sahara Desert

6. Varying degrees of definiteness. Tell why New York City has grown so rapidly. The pupil is left to make a brief or elaborate statement as he desires. Name five reasons why New York City has grown so rapidly. The pupil is definitely 
limited. Name all the reasons you can think of why New York City has grown so rapidly. An attempt is made to get the pupil to exhaust his information relative to the question.

7. Questions asked by pupils. Make a list of informational and interpretative questions bearing on Japan.

Conclusion. The formulation of adequate tests in geography is closely related to the establishment of definite aims. Substantial progress has been made in testing knowledge of place geography and factual geography. A beginning has been made in testing knowledge of interpretative geography and of ability to use geographic knowledge; it may be expected that in time ideals also can be tested satisfactorily. The recognition of the significance of geography in giving training for citizenship and for intelligent participation in the world's progress has directed the attention of educators toward the need of reorganizing this subject with the purpose of realizing definite educational results.

Suggestions for Further Study:

1. Why is it desirable to measure results as accurately as possible?

2. Why is it difficult to measure all the desired products of a geographic course quantitatively?

3. Is it probable that tests or scales will be found more desirable in measuring geographic accomplishment ?

4. Select an areal unit for study, as Argentina or Poland, indicate the immediate aims that you have in mind, note the materials of geography that you may use and how you may use them, and set up a test by means of which you can ascertain whether the aims are realized.

5. As suggested by the organization of this book, what should the teacher's knowledge of the "pedagogy of geography" include? 


\section{Selected References:}

BAgler, W. C. "Determination of Minimum Essentials in Geography and History," Fourteenth Yearbook of the National Society for the Study of Education, Pp. I3I-I 47 .

BAGLEr, W. C. "Minimum Essentials in Elementary Geography," Joumal of Geography (I9Ib), Vol. XIV, pp. I20-122.

Barces, Earl. Studies in Education (1902), Vol. II.

BRANoM, M. E., and REAlis, W. C. "The Determination and

Measurement of the Minimal Essentials of Elementary-School Geography," Seventeenth Yearbook of the National Society for the Study of Education. pp. 27-39.

BRowx. R. H. "The Minimum Requirement," Joumal of Giography, Vol. XIII, pp. 48-50.

Buckinghai, B. R. Geography Test, State Department of Public Instruction, Madison. Wisconsin.

CofFun, Lotus D. "Methods used in the Determination of Minimum Essentials," Teachers Collese Recort. Vol. XVIII, pp. 243-252.

Corrtis, S. A. "Measuring the Effects of Supervision in Geography," School and Socicty (1919). Vol. X, pp. 6I-70.

HAHx. H. H. Hahn-Lackey Geography Scale, Wayne State Normal School. Nebraska.

Johisox. D. II. "College-Entrance Examination Answers in Gerugraphy," Journal of Geography (1916). Vol. XV, pp. i 25-127.

KExindl, C. "Standards and Tests of Eificiency in Geography," foumal of Eiduation (1914). Vol. LXXXX. pp. 315-316.

Korr.HT. BEshe I'. "Minimum Essentials in Elementary Geography." Joumal of Geosraphy" (I9I7). Vol. XV. pp. I73-179. LArki. E. E. "Measuring the Ability of Children in (ieography." formal of (roguthy (19I8). Vol. XVI. pp. Is+-188.

MARTI. IAWRENE. "Examinations in Elementary Geography." foumel of (jemptaphy (1916). Vol. XIV. pp. 29\$-299.

Mubik. (. J. " Essentials of Modern (ieography and Criteria for their I)etermination," Jourmal of Geesrafihy (1915). Vol. XIII. pp. $120-135$.

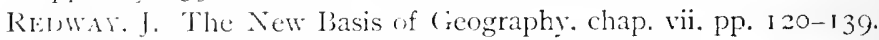
Ruriler. I). (. "Teaching of I'lace Geography," Joumal of Gergrefily (10,2. Vol. XI. pp. 13-16. 
Stakch, D.witl. Geography Tests, Series A, University of Wisconsin, Madison, Wisconsin.

Sithlkhan, Whllin. The Teaching of (icography, cliap. xiii, pp. $27+-29 \mathrm{I}$.

TAkK. R. S. "Results to be expected from a School Course in Geography," Jourmal of Geostaphy (1905). Vol. IV, pp. 145-148;

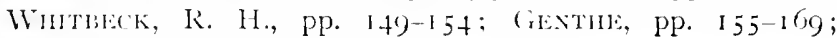
JFFHERSOA, pp. 160-163.

Timmpsos, T. E. Standard Tests in Goography, Monrovia, California.

Whitı:ck. R. H. "Mcasuring Efficiency in the Teaching of Geography," Joumal of Gourrathy (1914), Vol. NIII, pp. 53-55.

Winтв:сk, R. Il. "Where shall we lay the Emphasis in the 'Teaching of Goography?" Joumal of Geography (1910), Vol. XXXI, p. 10 S.

Withan, E. C. Standard Geography Tests, Southington, Connecticut. Yoxi. Sirair. "The Teaching of (Eeography." in Barnes's Studies in Education, Vol. II, pp. 373-3ss.

Boston Tests, Bulletin . V. 5, School Document No. 1.t (1915), Iepartment of Educational Investigation and IIeasurement, Boston.

Report of Boston's Attempt to ascertain Results of Georraplyy Tcaching. School I)ocument No. 14, Joumal of Giography (1917), Vol. XV, pp. 1+1-I+9. 



\section{INDEX}

Activities of man, 4-I7; vocational, $4^{-16}$; agricultural, 5- 8 ; pastoral, $\delta-0$; lumbering, $9-10$; hunting and trapping, Io; fishing, I0-II ; mining, II-I2; manuiacturing, I2-I 3 ; transporting. $13-15$; professional, 15 ; as middleman, 16 ; as investor, $\mathrm{xo}$; recreational, I7; political, is

Actual journeys, 211-2I7

Agricultural activities, $5^{-S}$

Aims, 62-7I; usable knowledge, 62-63; enlightened outlook, 63 ; practical and cultural, 63-64; adjustment, 6.4; method versus content, 65; training and cultural, 66; brotherhood of man, 66; xsthetic enjoyment, 67 ; St. Louis Survey, 68-09; immediate, $60-70$

Andrews, Cyril Bruyn, cited, 234

Appalachians, lumbering in the, 9

Archer, Lewis, and Chapman, cited, 0.3

Argentina developed by topical outline, 203-205

Arrumentative lesson, ro,3-200

Arithmetic, relation of geography to, $45-47$

Assignments, motivated, I56-157

Baber, Znnia, cited, 66-67

Baqlex. W. C. cited, 260-270

Branom-Reavis test, $272-283$

britain a world power, 33

Chamberlain, James F., cited, II I Cinerts and diagrams, I2t

Children, pre-school knuwledge of, $76-78$

Chile, development of. through topical outline, $204-205$
China, civilization of 35

Cities, illustration of type study, $224-225$

Civilization, development of, 22-38

Class as a unit, 133-134

Classes of problems, $\mathrm{IS}_{2-\mathrm{IS}_{4}}$

Collings, Pryor McBee, cited, 253255

Commerce, 3-4

Commercial-geography field trips, 102

Construction work, motivation through, I68-i;0

Content, socializing the, $\mathrm{I}_{45} 5^{-\mathrm{I}} 46$

Cook, Jane Perry, cited, 65-66

Coöperation of pupils, I $46-I_{4} 9$

Correlation, 40-49

Course of study, organization of, $75-89$

Current events, motivation of geography through, 166-167

Dairy plants, trips to, 2II-2I 2

Debatine, 106-199

Demands of socialization, I46-r $5=$

Details, study of, through types, 226

Diagrams and charts, 124

Difiticulties in problem work, IS7I 89

Discoveries through field trips, 2 I 4 -2 I5

Diversity of materials in lower grarles, $S_{1}-S_{2}$

Dodre, R. E., and Kirchwey, C. B., cited, $62-63,07-68$

Dramatization, $23 \mathrm{~S}-245$

Dutch, explorations of the, $32-33$

Earth as a whole, building up a concept of the, $\mathrm{S}_{2}-\mathrm{S}_{3}$

Enclish, relation of geography to, $44-45$ 
Environment, effects of, on people, 22-25

Eskimo type and dramatization, $239-2,40$

Essentials, selecting, 55

Eurasia, development of civilization in, 32-35

Europe, new countries of, 34-35

Excursion work, 95-103

Fairgrieve, James, cited, 36

Fairy tales versus nature stories, 234

Field work, value of, 95-96; reasons for insufficient, 96-102

Fishing activities, I0-1 I

Flour, manufacture of, I $2-I_{3}$

Foreign lands, interest of children in, $79-80$

France a world power, 33

Free activity, 150-r 5 I

Function of teacher in socialized work, 149-150

Geographers, relation of, to the teacher, $5^{6}-5 i$

Geography, practical nature of, 320

Germany, location of, 33-34

Globes and maps, 121-124

Group work, I34-14I

Hahn-Lackey scale, 270-272

Henderson, Bertha, cited, 66

History, relation of geography to, $47-48$

Holtz, F. L., citerd, 63, 224

Home ceosraphy, effects of war (in, 5.3

Human erengraphy, 54

Human typer classification of, 80 Hunting activities, 10

Iberian Peninsula, explorations from the. 3 I

Illustrations, topical outline, 203205 ; project work 240-251

Imasinary journeys, $2 \mathrm{r}_{7}-222$

Indivirlual collections of products. $105-107$

Individual work, I $4^{1-I}+4$
Industries, studying, 2 I6-2 77

Inferences, verifying, through trips, 214

Interests and motives, $170-17$ I

Investment activities, 16

Iron ores, importance of, to St. Louis, I1-12

Japan, illustration of relation of, to various subjects, $40-41$; illustration of topic treated by limited free activity, $15 \mathrm{I}-15^{2}$

Johnson, D. D., cited, 145-146

Journey geography, 2II-223; relation of, to type studies, $82-83$

Lackey, E. E.. cited, 270-272

Lanquage, expression of geography through, I $2.4-125$

Lantern, i $18-1$ i 9

Linke, Edith A., cited. 256-258

Literature, relation of geography to, 49

Local activities, motivation of geography through, i68-1;0

Local environments, importance of, $78-79$

Logical versus pychological development, $87-88$

Lumbering activities, 9-ro

Mcilurry, Charles, eited, 220

Maddox, John J., project work, $258-20 \mathrm{I}$

Manufacturing activitics, 12-13

Maps, 126

Maps and globes. 121-124; use of, during war, 54-55

Margarine plant, vicit to, 21 2-2 I3

Materials for problem-solvine, I so192

Measuring results, $265-287$

Mediterranean civilization, 28-30

Memory work versus problem worli, $17-1-1-8$

Method, evolution of geosraphic, $51-6$ i ; socializine the, $145^{-146}$

Mildleman activities, i6

Milk, preparation of, for market, $211-232$

Hiller, Gcorse J., cited, 266-267 
Mining activities, I I-I 2

Missouri, iron ores of, II-I2 ; a project on, 249-25I

Motivation of geography, 165-1 72

Motive, $247^{-2}+9$

Motives during study periods, I57100

Motion pictures, I I $9-12$ I

Moulton, Estella L., cited, I 20

Mutual assistance of subjects, 40

Natural regions, $84-85$

Nature stories versus fairy tales, 234

Newfoundland Banks, fishing on the, I0-11

New World, spread of civilization in the, $31-32$

New York City to St. Louis, journey from, 2I $7-219$

Nile Valley, civilization in the, $25-$ 26

Observational geocraphy, 93-107

Organization of the class, I33-14t

Oramizine centers, 220-228

Orient, closing of routes to the, 30-3I

Outlines, relation of, to problems, 207

Packard. L. I., cited, $267-268$

Partridee, Emelyn Newcomb, cited, $234^{-235}$

Pascine interests, $15^{8}$

Pastoral activities, S-a

Perlaxpgy of problem-solving, Is4IS:

Phenicians, 28

Physical-geosraphy field trins, IoII 02

Pictures, ito-110; value of, int; collecting, 114-116; classes of, 117

Place ceography, 10-20

Place tests, 208-270, 270-280

Play level. projects on the, $25 \mathrm{I}$

Plays produced by pupils, 238-239

Polind, example of the problem methol. $=-;-60$

Politica! actirities, is
Political regions, 84

Populations, future distribution of, 36-37

Portuguese discovery of a route to the Indies, 3 I

Precipitation, influence of, on the farmer, 5

Pre-geography work, $76-78$

Primary grades, informal work of, $76-78$

Problem, example of, 189-19I

Problem method, I73-192

Products brought to schoolroom, 104-107

Products, distribution of, 3-4

Professional activities, I5

Professional versus educational dramatization, $240-2+1$

Projects, 2+6-26I; relation of, to topical outlines, $251-252$

Psychological versus logical development, $87-88$

Pufflic attitude toward field trips, 08-09

Pupils, attitude of, toward field trips, $97-98$

Questions for testing, $284-285$

Railroads, influence of topography on, $\mathrm{I}_{4}$

Reading, relation of geography to, 43

Reavis-Branom test, $272-283$

Recitation period, relation of, to sturly period, I55-161

Recreational activities, I 7

Regional geography, $83-84$

Rexions, order of study of, $85-86$

Representative geography, I09-130

Reviews, 227

Rideley, D. C., cited, 270

Romans, civilization of the. 28-30

Rudolph, A. Adele, cited, Its-1 70

Russia, the becinnings of, 33

St. Louis to New York City, journey from, 217-219

St. Louis School Survey, 68-69

School projects, 246-2.47

Scoring. 193-196 
Sketch maps, expression through, 2I3-2I4

Smith, J. Russell, cited, 67

Socialization, I45-I $5 \mathrm{I}$

Soils, influence of, on farming, 6-7

South America, example of topic treated by limited free activity, I $52-153$

Spaniards, explorations by, in the New World, 31-32

Spelling, relation of geography to, 43-44

Stereoscopes, II 7-II 8

Story, the, $231-236$

Story-telling by pupils, 233

Study period, relation of, to recitation period, $155-161$

Studying, $160-161$

Subgroups, study of geography through, 134-14I

Subject, geography as a, 39-40

Supervision of geography study, I 58-1 60

Supplementary reading, 127

Sutherland, William J., cited, 64

Symbols, geographic, 109-130; value of, 109-IIO

Teachers, preparation of, for field trips, 103-104

Telling a good story, 232-233

Temperature, influence of, on the farmer, 5-6

Testing, $265-287$

Textbroks, geographic, I 26

Thompson, T. E., cited, 269

Tigris-Euphrates valley's, civilization in the, $26-27$

Tool and content subjects, $4 \mathrm{I}-42$
Topical outline, 20I-209

Topical outlines and projects, $25 \mathrm{I}-$ 256

Topics, study of, in relation, 205206

Topography, relation of, to farming, 7

Transportation activities, I3-I5

Trapping activities, Io

Type studies, 224-230; relations of, to journey geography, $82-83$

United States, cause of the greatness of the, $35-36$

Usable products secured through projects, 249

Valley civilizations, 25-28

Viewpoint, maintaining the geographic, 49

Vocational activities, 4-16

Walker, Alberta, cited, 242-244

Waterways, naviqation of, $13-14$

Wheat, production of, I 2

Whitbeck, R. H., citerl, 64-65

Wilson, H. B., and G. M., cited, I $65-166$

Wilson, J. H., cited, I20-12I

Witham, Ernest C., cited, 269

World geography, 87

World War, interest in geography aroused through the, 3 ; and geography method, 52-55

Writing, relation of, to geography, 44

Wyman School, world's fair project in the, $258-261$ 

. 



\section{INIVERSITY OF CALIFORNIA LIBRARY}

\section{Los Angeles}

This book is DLE on the last date stamped below.

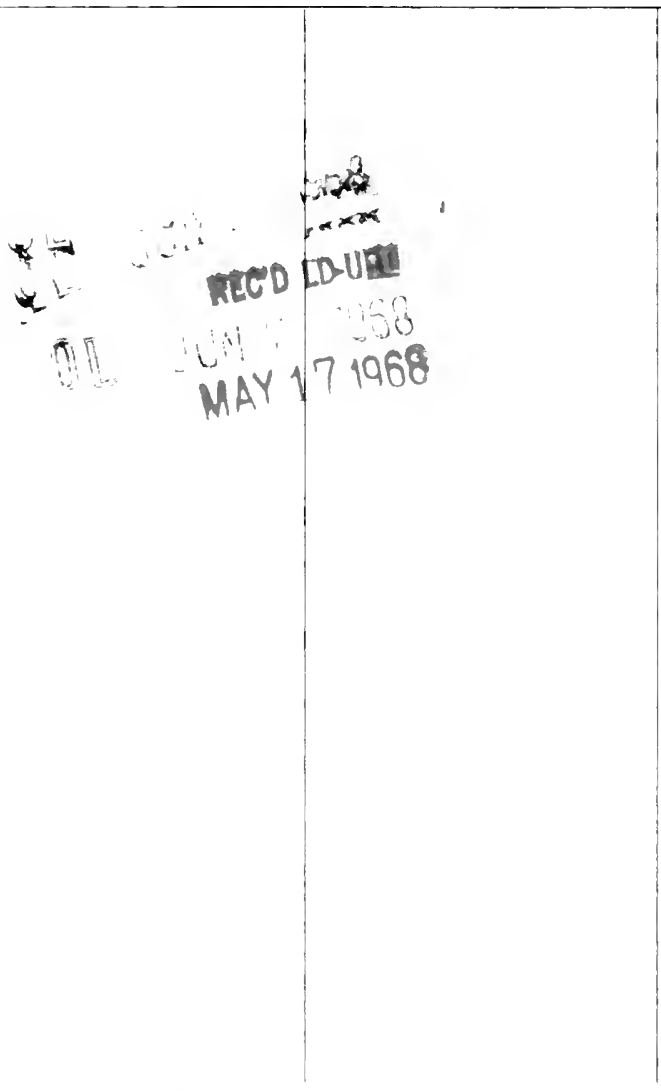


PLEA DO ROT REMOVE THIS BOOK CARD.

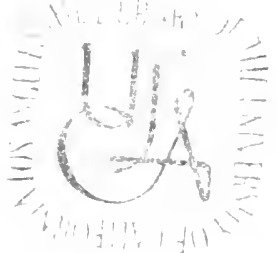


